Andrews University

Digital Commons @ Andrews University

\title{
Programa para Mejorar la Salud Espiritual de la Iglesia Adventista del Séptimo Día de Gainesville-Florida
}

Byron Alexander Rivera Sr.

Andrews University

Follow this and additional works at: https://digitalcommons.andrews.edu/dmin

Part of the Practical Theology Commons

\section{Recommended Citation}

Rivera, Byron Alexander Sr., "Programa para Mejorar la Salud Espiritual de la Iglesia Adventista del Séptimo Día de Gainesville-Florida" (2010). Professional Dissertations DMin. 512.

https://dx.doi.org/10.32597/dmin/512

https://digitalcommons.andrews.edu/dmin/512

This Project Report is brought to you for free and open access by the Graduate Research at Digital Commons @ Andrews University. It has been accepted for inclusion in Professional Dissertations DMin by an authorized administrator of Digital Commons @ Andrews University. For more information, please contact repository@andrews.edu. 
ABSTRACT

A PROGRAM TO IMPROVE THE SPIRITUALITY OF THE

GAINESVILLE SEVENTH DAY ADVENTIST

CHURCH - FLORIDA

by

Byron Alexander Rivera

Adviser: Ricardo Norton 


\section{ABSTRACT OF GRADUATE STUDENT RESEARCH \\ D. Min. Dissertation}

Andrews University

Seventh-day Adventist Theological Seminary

\section{Title: A PROGRAM TO IMPROVE THE SPIRITUALITY OF THE GAINESVILLE SEVENTH-DAY ADVENTIST CHURCH - FLORIDA}

Name of the researcher: Byron Alexander Rivera

Name and degree of faculty adviser: Ricardo Norton, D.Min.

Date completed: May 2010

\section{Problem}

Every church as a social group has the potential to grow and improve its spirituality, its cohesion, its commitment, its fidelity and its participation. The Gainesville Spanish Adventist Church is formed by members that have the ardent desire to improve in all these areas. This investigation aims to improve the spirituality of the congregation.

\section{Methodology}

The investigation began with the selection of 25 members of the Gainesville Spanish Church in Florida who were available to collaborate in the investigation in order to detect the spiritual deficiencies among church members. A questionnaire was used to 
discover the spiritual weaknesses and, based on the results, a program was then elaborated and applied to improve the spirituality of the members.

\section{Results}

The investigation reached the two basic objectives proposed in this thesis: first, to develop a program of spiritual improvement, and second, that, as a consequence of the first, we obtain major participation from the members in all church activities.

The implementation of the program made it possible for the church to internalize and make the most value of improving the life of devotion and prayer, as well as developing the natural desire to participate in missionary work.

Moreover, it was evident that the program produced changes in the church's behavior and, among those, the increase of baptisms. The few people who had negative thoughts and attitudes towards the changes while the program was developing started integrating in the process and ended-up recognizing that they were mistaken, inasmuch as the positive results spoke for themselves.

The evaluation survey reported spiritual improvement of the four areas in which the first survey had reflected deficiency; family worship, participation in missionary activity, lack of participation in the general activities of the church, and finally, neglect of the reading of the Bible. 


\section{SÍNTESIS}

PROGRAMA PARA MEJORAR LA SALUD ESPIRITUAL DE LA IGLESIA ADVENTISTA DEL SÉPTIMO DÍA

DE GAINESVILLE - FLORIDA.

$$
\text { por }
$$

Byron Alexander Rivera

Asesor: Ricardo Norton 


\title{
SÍNTESIS DE TESIS DOCTORAL
}

Tesis

\author{
Andrews University \\ Seminario Teológico Adventista
}

Título: PROGRAMA PARA MEJORAR LA SALUD ESPIRITUAL DE LA IGLESIA ADVENTISTA DEL SÉPTIMO DÍA DE GAINESVILLE - FLORIDA

Nombre del investigador: Byron Alexander Rivera

Nombre y grado del asesor: Ricardo Norton, D.Min.

Fecha de terminación: Mayo de 2010

\section{Problema}

Toda iglesia, como agrupación social, tiene el potencial de crecer y mejorar en espiritualidad, su cohesión, su compromiso, su fidelidad y su participación. La Iglesia Adventista hispana de Gainesville está formada por miembros que tienen el deseo ardiente de superarse en áreas de necesidad. Esta investigación se concentra en mejorar la espiritualidad de la congregación.

\section{Metodología}

La investigación empezó seleccionando 25 miembros de la iglesia de Gainesville, Florida, quienes estuvieron dispuestos a colaborar en la investigación para detectar las deficiencias espirituales que les aquejaba y también, de esta manera, ver su efecto en la 
vida espiritual de la iglesia. Se usó un cuestionario para descubrir las necesidades espirituales, y basados en los resultados, entonces se elaboró y aplicó un programa, para mejorar las áreas espirituales débiles.

\section{Resultados}

La investigación alcanzó los dos objetivos básicos propuestos en esta tesis: primero, desarrollar un programa de mejoramiento espiritual y segundo, lograr una mayor participación de los miembros en las actividades de iglesia.

La implementación del programa hizo posible que la iglesia lograra aprovechar e internalizar el valor de mejorar la vida devocional, los hábitos de oración y la participación entre los miembros de iglesia en la obra misionera. El programa produjo cambios deseables en el comportamiento de la iglesia y en el aumento de bautismos. Las pocas personas escépticas a los cambios se integraron al programa una vez que vieron los beneficios.

La encuesta de evaluación aplicada al mismo grupo reportó mejoramiento espiritual en las cuatro áreas que fueron halladas con deficiencia: culto familiar, participación en la actividad misionera, falta de participación en las actividades generales de la iglesia, y, por último, falta de la lectura de la Biblia.

\section{Conclusiones}

El programa de mejoramiento espiritual para la iglesia de Gainesville, Florida llenó los vacíos espirituales que se diagnosticaron entre los miembros y pudo reenforzar el compromiso cristiano a la "devoción", "oración" y la "obra misionera". De esta 
manera, este programa pudiera ser usado por iglesias con similares problemas espirituales a la de este estudio. 
Andrews University

Seventh-day Adventist Theological Seminary

\title{
A PROGRAM TO IMPROVE THE SPIRITUALITY OF THE GAINESVILLE SEVENTH DAY ADVENTIST CHURCH - FLORIDA
}

\author{
A Dissertation \\ Presented in Partial Fulfillment \\ of the Requirements for the Degree \\ Doctor of Ministry
}

by

Byron Alexander Rivera

May 2010 
Andrews University

Seminario Teológico Adventista

PROGRAMA PARA MEJORAR LA SALUD ESPIRITUAL

DE LA IGLESIA ADVENTISTA DEL SÉPTIMO DÍA

DE GAINESVILLE - FLORIDA

\author{
Tesis \\ Presentada en cumplimiento parcial \\ de los requisitos para el título de \\ Doctor en Ministerio \\ por \\ Byron Alexander Rivera
}

Mayo de 2010 
(c) Copyright by Byron Alexander Rivera, 2010 All Rights Reserved 


\section{PROGRAMA PARA MEJORAR LA SALUD ESPIRITUAL DE LA IGLESIA ADVENTISTA DEL SÉPTIMO DÍA DE GAINESVILLE - FLORIDA}

Tesis

Presentada en cumplimiento parcial de los requisitos para el título de Doctor en Ministerio

por

Byron Alexander Rivera

APROBADO POR EL COMITÉ:

Dicando Cunton Ricardo Norton

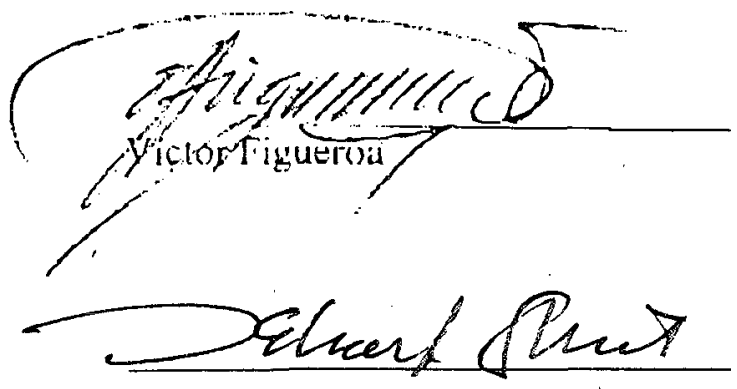

Eduard Schmidt

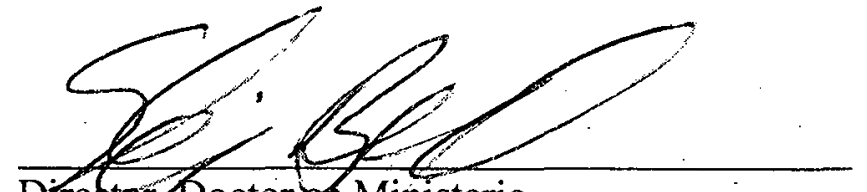
Director Doctor en Ministerio Skip Bell

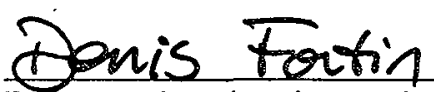

Decano, Seminario Teologico Adventista

Denis Fortin

\section{Decomber 2012}

Fecha de aprobación 


\section{DEDICACIÓN}

A nuestro Dios que es el Gran Médico de las almas.

A mi esposa Ximena por su ayuda, comprensión y sacrificios.

A mis hijos Elías y Byron Jr, quienes fueron fuente de ánimo.

A mi madre, Teresa, quien ha estado pendiente de la culminación de este proyecto. 


\section{ÍNDICE DE CONTENIDO}

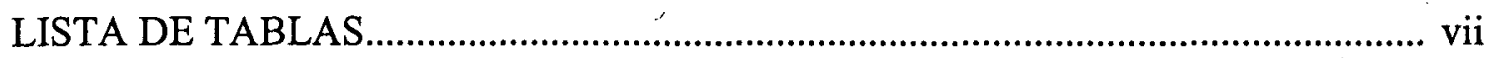

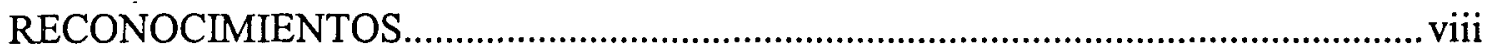

Capítulo

1. INTRODUCCIÓN....................................................... 1

Problema.......................................................... 1

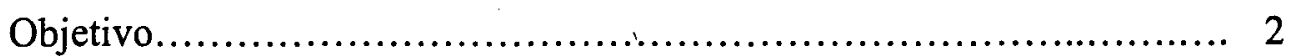

Justificación..................................................... 2

Metodología............................................................ 2

Expectativas....................................................... 3

Organización de la tesis..................................................

2. CARACTERÍSTICAS PARA UNA IGLESIA SALUDABLE................. 5

Una iglesia espiritual............................................. 15

Espiritualidad y oración....................................... 15

Espiritualidad y fe............................................. 18

Espiritualidad y obediencia....................................... 20

El rol del Espíritu Santo en la espiritualidad....................... 23

Una iglesia que practica el discipulado.............................. 28

Significado de discipulado................................... 28

Características del discípulo..................................... 30

El discípulo trabaja con los dones espirituales.................... 36

Cristo y el discipulado.......................................... 39

El discipulado y la misión........................................ 42

El discipulado y el crecimiento numérico............................ 45

Una iglesia que practica la adoración................................... 48

Una iglesia que practica el amor y la amistad......................... 49

3. PROGRAMA PARA ENVIGORIZAR LA SALUD ESPIRITUAL DE LA IGLESIA DE GAINESVILLE............................................ 53

La ciudad de Gainesville................................................ 53

Población....................................................... 55

Economía...................................................... 57 
Educación........................................................... 58

Religión........................................................ 59

La iglesia adventista hispana de Gainesville.............................. 62

Encuesta para medir la espiritualidad de la iglesia de Gainesville.... 67

La espiritualidad de los miembros de la iglesia............................ 68

Descripción del programa............................................. 76

Protocolos y aprobación....................................... 77

Naturaleza del programa....................................... 77

Contenido del programa.......................................... 79

\section{IMPLEMENTACIÓN Y EVALUACIÓN}

DEL PROGRAMA

Inauguración de "Amanecer con Dios"................................ 81

Lugar de reunión.................................................. 83

Horario de reunión.............................................. 84

Materiales y equipo............................................... 84

Formación de células................................................. 85

Elección de líderes.............................................. 85

Capacitación de líderes....................................... 85

Lugar de reunión.................................................. 89

Horario de reunión............................................ 90

Materiales........................................................ 90

Evaluación del programa.......................................... 90

Aplicación de la encuesta...................................... 91

Resultados y tablas de evaluación................................... 91

Resultados de "Amanecer con Dios"................................................. 98

Resultados de la formación de células............................................... 99

5. CONCLUSIONES Y RECOMENDACIONES............................ 101

Conclusiones.................................................... 101

Recomendaciones............................................ 103

\section{APÉNDICE}

A. ENCUESTA SOBRE SALUD ESPIRITUAL .......................... 106

B. "AMANECER CON DIOS" ......................................... 108

C. TEMAS DE 10 DÍAS DE PODER (I \& II) ................................ 110

D. TEMAS PARA LÍDERES........................................... 112

E. RETIRO DE LÍDERES............................................... 130 
F. PROGRAMA DE SERVICIO CELULAR........................... 133

G. HOJA DE CONTROL DE CÉLULAS............................................... 135

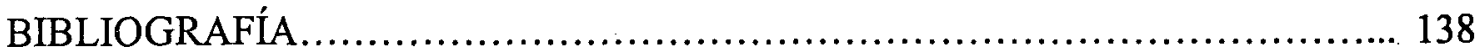

CURRÍCULUM VÍTAE......................................................... 144 


\section{LISTA DE TABLAS}

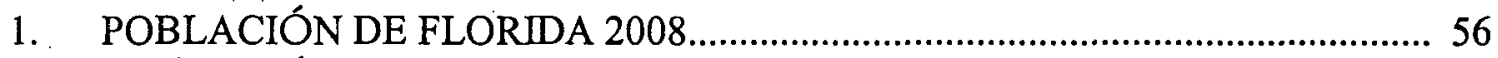

2. POBLACIÓN DE GAINESVILLE 2007 .......................................................... 56

3. PROYECCIÓN DE CRECIMIENTO HISPANO POR EDADES.......................... 57

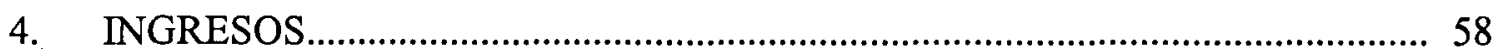

5. MAYORES DENOMINACIONES RELIGIOSAS DE FLORIDA......................, 61

6. BAUTISMOS DE LOS ÚLTIMOS 11 AÑOS..................................................... 66

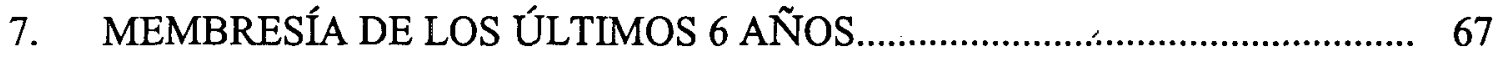

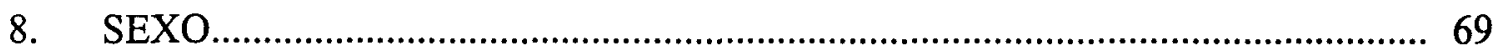

9. EDAD

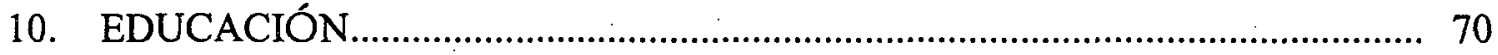

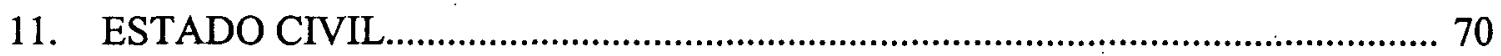

12. CULTO FAMILIAR ……..................................................................... 71

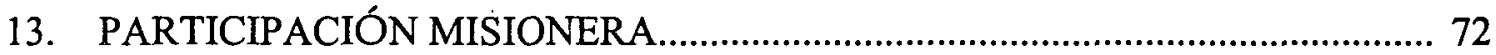

14. PARTICIPACIÓN EN OTRAS ACTIVIDADES DE IGLESIA.......................... 72

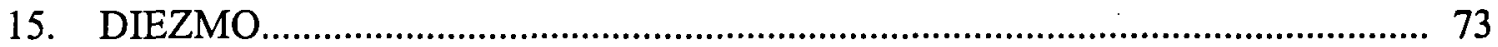

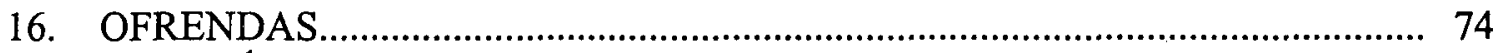

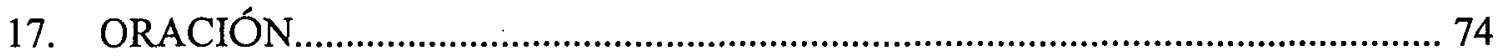

18. LECTURA DE LA BIBLIA ...................................................................... 75

19. CULTO'FAMILIAR

20. PARTICIPACIÓN MISIONERA .............................................................. 93

21. PARTICIPACIÓN EN OTRAS ACTIVIDADES DE IGLESIA............................. 94

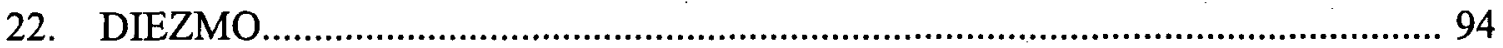

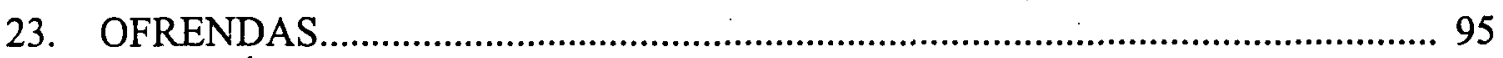

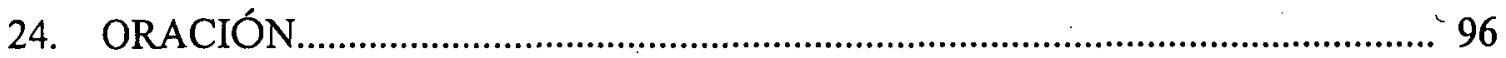

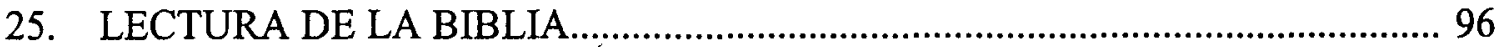

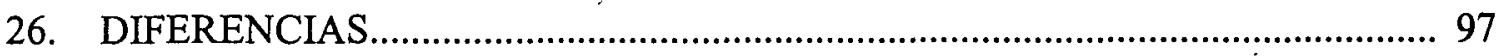




\section{RECONOCIMIENTOS}

En primer lugar, la alabanza, honra y gloria sean dadas a Dios por todas sus bendiciones y misericordias que cada día otorga a sus hijos. A Él sea mi más grande gratitud, pues me ha concedido llegar a este punto de preparación para servirlo mejor en su viña.

Seguido agradezco a mi compañera de batallas, mi amada esposa Ximena, quien, con su amor y sacrificio, me alentó a seguir en los tiempos duros e inciertos de la vida. A mis hijos, Elías y Byron Jr., que, con sus lógros, me han motivado a continuar hacia adelante. A mi madre, Teresa, quien estuvo pendiente de los progresos que iba realizando.

No hubiera sido posible hacer esta tesis sin la guía del Dr. Ricardo Norton, quien, con mucha paciencia, me orientó y ayudó en todos los detalles de fondo y forma durante el proceso de la investigación, a quien va mis agradecimientos. La ayuda del Dr. Victor Figueroa fue muy valiosa, ya que, con sus oportunos consejos y correcciones, el trabajo fue enriqueciéndose, a él también vaya mi gratitud. Las tablas estadísticas de evaluación y su interpretación no tendrían el valor que tienen sin la oportuna ayuda por parte del Dr. Tevni Grajales, quien reciba mi reconocimiento.

Agradezco la hospitalidad y cariño de los esposos Juan Carlos y Janet Rodríguez, al brindarme su hogar en Berrien Springs durante mis continuos viajes de estudio. En la 
misma línea, mi gratitud a las hermanas. Emma y Raquel Tenorio, quienes, cuando fue necesario, también hicieron posible mi hospedaje en la universidad.

Cómo no expresar mi gratitud a las iglesias de mi distrito: Gainesville, la cual colaboró y fue motivo de la investigación; a Marion Oaks y Citrus, cuyos líderes que, a pesar de su trabajo y sacrificio, me animaron a que no desmaye hasta lograr la meta. No puedo dejar de reconocer y agradecer la ayuda financiera que la Asociación de la Florida me brindó para lograr este blanco personal. Una vez más, gracias a Dios y a todas las personas, familiares, amigos y colegas que, si las menciono por nombre, cometa el error de omitir alguno. 


\section{CAPÍTULO 1}

\section{INTRODUCCIÓN}

La buena "salud espiritual" de cada creyente y por ende de la iglesia es vital para que su desarrollo sea armonioso tal como desea y expresa Dios en su Palabra: "Amado, yo deseo que tú seas prosperado en todas las cosas, y que tengas salud, así como prospera tu alma" (3 Jn. 2). El ser humano desea tener buena salud, pero no basta tener el deseo, sino que se necesita cumplir con ciertas condiciones para alcanzar el ideal anhelado.

Este trabajo investigativo, se realizó con el propósito de ayudar a cada creyente de la iglesia adventista hispana de Gainesville, a crecer en espiritualidad, tomando en cuenta los consejos de las Escrituras, y de algunos autores cristianos contemporáneos.

\section{Problema}

Como agrupación social, toda iglesia tiene el potencial de crecer y mejorar en su salud espiritual que está en relación directa con su cohesión, su compromiso, su fidelidad y su participación. Salomón indica que el crecimiento cristiano debe ser continuo: "Mas la senda de los justos es como la luz de la aurora, que van en aumento hasta que el día es perfecto" (Pr. 4:18). La Iglesia Adventista hispana de Gainesville, Florida, está formada por miembros que tienen el deseo ardiente de superarse en todas esas áreas. Descubrir las áreas espirituales débiles de la iglesia es una de las funciones principales de esta investigación. 


\section{Objetivo}

Esta tesis tiene como objetivo, descubrir las áreas espirituales débiles de la congregación y desarrollar un programa para mejorar la salud espiritual de la Iglesia Adventista de Gainesville de la Florida, e incrementar su participación en las actividades de la iglesia.

\section{Justificación}

Una de las razones por qué este estudio es importante es porque así como Dios desea la salud fisica y la prosperidad de cada creyente, de la misma manera desea la salud espiritual de la iglesia. Juan declara: “Amado, yo deseo que tú seas prosperado en todas las cosas, y que tengas salud, así como prospera tu alma" ( $3 \mathrm{Jn} .2)$.

Otro justificativo importante es porque la Biblia enseña que el pecador está enfermo, y que si se arrepiente, Dios puede regenerarle. Lo mismo hace con su iglesia, si se arrepiente y confiesa su condición, Dios está dispuesto a sanarla de su pecado y habilitarle para vivir una vida de armonía con Él y con el prójimo (Is. 1:6, 18; $1 \mathrm{Jn}$. 1:9).

De esta manera, una iglesia que goza de salud espiritual manifiesta los siguientes frutos: comunión con Dios, el uso de los dones del Espíritu, testimonio, y confraternización. (Hch. 2:1, 4, 37, 38, 41-47). Además una iglesia saludable cumple su deber que es la predicación del evangelio (Mt. 24:14; 28:19, 20).

\section{Metodología}

Se examinará el concepto de "salud espiritual" y lo que implica a la luz de las Escrituras y la literatura contemporánea. Luego, se usará una encuesta para medir el índice de espiritualidad de la iglesia de Gainesville, Florida, en áreas como la lectura de 
la Biblia, culto familiar, participación misionera, hábitos en la oración, fidelidad y otras actividades regulares de la iglesia.

Basado en los resultados de la investigación, se creará un programa para mejorar las áreas con deficiencia espiritual, el cual se implementará por un año a partir de Noviembre del 2007. Después de la implementación, el programa será evaluado para medir su efectividad.

\section{Expectativas}

A fin de que la Iglesia Adventista de Gainesville pueda responder a las expectativas de Dios, de sus miembros y de la comunidad, debe mejorar su condición espiritual. Una vez que se haya aplicado el programa de mejoramiento espiritual, la primera expectativa de la Iglesia de Gainesville será observar que su condición espiritual habrá cambiado positivamente y estará trabajando unida y con propósito.

Una iglesia saludable participará activamente en los planes y programas que contribuyen al cumplimiento de la misión. De esta manera, mostrará que está comprometida con su Señor en la ganancia de almas.

Con el programa de mejoramiento espiritual, los creyentes llegarán a demostrar amor genuino entre ellos, a las visitas y a los nuevos miembros de iglesia. Además, se podrá observar en ellos un estilo saludable de vida que incluye la salud física y mental.

\section{Organización de la tesis}

Esta investigación consta de cinco capítulos, los cuales son resumidos en forma breve en los siguientes párrafos. Luego constan los apéndices y termina finalmente con la bibliografia. El capítulo 1 contiene la introducción en la que se explica el propósito, la 
justificación del proyecto, la metodología a seguir y las expectativas que se esperan.

El capítulo 2 presenta cuatro características básicas aplicadas a la "salud espiritual" de la iglesia, obtenidas de la Biblia y la literatura afín, que son: (a) es una iglesia espiritual, (b) es una iglesia que practica el discipulado, (c) es una iglesia que practica la adoración, y (d) es una iglesia que practica el amor.

El capítulo 3 contiene información de la ciudad y de la iglesia adventista de Gainesville. Acerca de la ciudad, se menciona algo de su historia, la población, su economía, educación y religión. En lo que respecta a la iglesia, se aplica una encuesta de diagnóstico para medir su espiritualidad y, finalmente, se describe el programa de salud espiritual para envigorizar la iglesia.

El capítulo 4 describe la implementación del programa de mejoramiento espiritual. Este programa cónsta de dos partes: primero, “Amanecer con Dios” y segundo, la formación de células, los cuales describen el desarrollo de los mismos con información de lugares de reunión, horarios, asistencia y materiales usados, además contiene la evaluación del programa y sus resultados.

Finalmente, el capitulo 5 muestra las conclusiones a las que llega el autor, según los resultados de la aplicación del programa para mejoramiento espiritual, y finaliza con algunas recomendaciones. 


\section{CAPÍTULO 2}

\section{CARACTERÍSTICAS PARA UNA IGLESIA SALUDABLE}

Las iglesias cristianas por estar compuestas de seres humanos, sufren de problemas patológicos de carácter eclesiástico. El éxito de la iglesia, en gran medida, es determinado por su salud espiritual. Una iglesia para crecer necesita buena salud. Este capítulo presenta 4 características más salientes de una iglesia saludable como lo comentan algunos autores como Percy, Cullmann, Warren, Schwarz y otros. Se las resume de la siguiente manera: es espiritual, practica el discipulado, practica la adoración, y fomenta el amor y la amistad.

Antes de estudiar las características mencionadas arriba, se requiere de un análisis de los términos: salud, prosperidad, iglesia y éxito. El estudio empieza con el texto bíblico base del cual surgen dos términos que son "salud" y "prosperidad". A estos se agregan dos términos: "iglesia" y "éxito", los cuales están relacionados directamente con una "iglesia saludable".

El texto base para la investigación es $3 \mathrm{Jn}$. $2^{1}$ "Amado, yo deseo que tú seas prosperado en todas las cosas, y que tengas salud, así como prospera tu alma". En éste versículo el apóstol envia un saludo muy especial a Gayo de quien se expresa de una

\footnotetext{
${ }^{1}$ A menos que en textos individuales, todas las citas bíblicas son tomadas de la versión Reina Valera de 1960. Las abreviaciones también son tomadas de la misma versión.
} 
manera fraterna. Esto se denota en la expresión: "el amado, a quien amo en la verdad" ( 3 Jn. 1). El deseo de Juan es que Gayo tenga salud.

El apóstol Juan inicia su carta diciéndole a Gayo: “y que tengas salud" (3 Jn. 2). Esta era una "forma común de saludo en el mundo antiguo" (Johnson, 1995, 17:166). Juan está expresando el deseo de bienestar físico como era la costumbre, pero el énfasis en la salud espiritual está también presente en el saludo inicial tal como se lee en el mismo verso: "así como prospera tu alma" v. 2 , y en el contexto general de la tercera epístola de Juan. Por ejemplo en los versos 3, 5-6.

Junto con la palabra "salud" está la expresión: "que tú seas prosperado en todas las cosas" (3 Jn. 2). El deseo de Juan para la prosperidad material de Gayo no es de sorprenderse pues también era una costumbre, por la influencia griega, desear a sus lectores en las cartas prosperidad y riqueza (Johnson, 1995, 17:167).

El análisis parte de las palabras arriba mencionadas para entender mejor acerca de la salud espiritual a la que se refiere Juan en su tercera epístola. Luego se aplica estos mismos conceptos a la iglesia adventista de Gainesville, para que también pueda "prosperar en todas las cosas" (3 Jn. 2).

Los términos teológicos que se presentan a continuación tienen el propósito de proveer una infraestructura teológica que el programa de espiritualidad merece. En primer lugar, Juan usa la palabra griega hugiainō que según el Lexicon griego-inglés de Wescott \& Hort (1936, p.196) significa "estar en buena salud" (Lc. 5:31; 7:10; 15:27); hugiainō también se usa para referirse a salud doctrinal (Tit. 1:13;2:2; 1 Ti. 1:10; 2 Ti. 4:3), como a las "sanas palabras" (1 Ti. 6:3; 2 Ti. 1:13). En el diccionario griego-español de Tamez y Foulkes (1978), se traduce como: "estar sano", "correcto o bien 
fundamentado" (referente a enseñanzas o maestros cristianos), "gozar de buena salud" (p. 184).

No existe otro deseo en la mente de Juan que la de expresar sus buenos deseos de salud física, mental y espiritual a manera de oración para su amigo y hermano en Cristo. El propósito de la carta es animar a Gayo para que continúe siendo hospitalario con los misioneros que visitaban la iglesia, pues esto es parte de la salud espiritual y uno de los dones espirituales. Esta actitud cristiana contrasta con la de Diótrefes (3 Jn. 9). Así mismo anima a Gayo para que se mantenga en la verdad (Thomson, 1992, p. 158).

Como se ha visto, la palabra "salud" ó "be in health" en la versión en inglés (KJV) es amplia en su significado. Pero es claro que la salud física acompaña la salud espiritual. Esta misma conexión la podemos observar en las instrucciones dadas por Dios al pueblo de Israel (Ex. 15:26) por medio de Moisés. (Nichol, 1957, 7:695).

El Antiguo Testamento usa el termino hebreo shâlwôm o shâlôm para referirse a la "salud" (2 S. 11:7). Esta palabra hebrea también significa: "a salvo", "bien", "feliz", y 'bienestar' en "salud", "prosperidad", y "paz". El mismo término se usa en otros textos como (Esd. 4:17; Pr. 13:17). El libro Lexical Aids de la versión King James de Baker (1994) describe que shâlôm proviene de la raíz shâlâm que significa "salud"; "seguridad", "tranquilidad", "bienestar" (Gn. 37:14; 1 S. 17:18) como cuando se saluda a alguien (p. 2374).

En la misma línea de pensamiento, en el Interpreter's Dictionary of the Bible, la palabra hebrea shâlêm significa "salud total" (Buttrick, 1990, p. 541). Si se toma en cuenta este concepto al considerar las leyes que Dios le dio a Israel, se observará que cuando Jehová dio a su pueblo las tabla de la Ley de Dios (Dt. 5:1-21; Ex. 12:49; 13:9; 
16:28); también le dio leyes civiles (Lv. 20), de salud (Lv. 11, 12, 13-15), y ceremoniales (Lv. 21-24) pues Dios se preocupa por la salud integral de su pueblo.

Este concepto hebreo de salud total es usado por Juan en su tercera epístola. Del mismo modo es usado por los otros escritores del Nuevo Testamento indistintamente del mensaje que tenían para sus destinatarios (Hch. 1.5:23; 23:26; 27:34; Stg. 1:1).

Por otro lado, luego de estudiar el significado y las diferentes traducciones de la palabra "salud" en griego y en hebreo, se encuentra que también está relacionada con la palabra "sanidad".

En Israel la salud era un regalo divino y junto con la prosperidad material era la confianza de tenerlo por haber sido fiel. Cuando ocurría una enfermedad, el enfermo podía solo mirar a Dios, el Médico de su pueblo, por sanidad y recuperación. El judaísmo post-exílico recurrió a médicos humanos, usurpando la prerrogativa divina en este respecto, Asa fue una de esas excepciones (2 Cr. 16:12) que consultó a los médicos. Los profetas algunas veces aconsejaban con respecto a un tratamiento a esos que estaban enfermos y algunas veces hicieron pronósticos de tiempo en tiempo. Pero porque la enfermedad era un asunto espiritual en última instancia, la sanidad podía ser esperada siguiendo a un reavivamiento o revitalizando la relación entre el individuo y Dios. Así aparte de algunos remedios informales, no hay un guía para tratamiento médico de enfermedades en el Antiguo Testamento, porque esos sistemas terapéuticos simplemente no existían entre los antiguos hebreos. (Buttrick, 1990, p. 546).

En el ministerio de Jesús las palabras "salud" y "sanidad" están íntimamente relacionadas, porque en acto de sanidad, Jesús mostró su interés tanto en la "salud física" de los individuos, como la "salud espiritual". Para la mente hebrea, la enfermedad o la deformidad es el producto del pecado. Por eso, cuando vieron al ciego de nacimiento, los discípulos preguntaron si él "está pagando por sus pecados o los de sus padres" (Jn. 9:2). Pero Jesús explica que no fueron ni "sus pecados ni los de los padres" (Jn. 9:3) los que le tienen ciego y procedió a sanarle (Jn. 9:6, 7). 
Buttrick (1990) destaca que aunque frecuentemente la enfermedad es el resultado del descuido del ser humano en sus hábitos, costumbres, formas de alimentación equivocadas, accidentes u otras razones, algunas enfermedades son producto de la intervención directa del demonio como lo enseña Jesús (Lc. 13:16). Por eso su ministerio fue dirigido a la mente y al cuerpo (p. 547).

En Mt. 8:17, el evangelista Mateo cita el cumplimiento de la profecía de Isaías 53:4 en el ministerio de Jesús. Lo presenta de la mejor manera que cualquier otro comentarista moderno puede describir la obra redentora del Siervo sufriente al decir que llevó nuestras "enfermedades" y "dolencias".

Buttrick (1990) concluye entonces que el sacrificio de Jesús en el Calvario tiene que ver con "muerte" y "enfermedad". La muerte expiatoria de Jesús salva y sana al ser humano por completo en cuerpo y espíritu (p. 547).

En el leguaje moderno, la palabra "salud" tiene diversos significados y todos ellos relacionados con la salud fisica. Por ejemplo, The American Heritage Dictionary of the English Language presenta con respecto al término "health", los siguientes significados: (a) el estado de un organismo con respecto a funcionar, muerte, y una anormalidad dada en cualquier momento; (b) el estado de un organismo funcionando normalmente sin muerte o anormalidad. (c) Funcionamiento óptimo libre de muerte o anormalidad; (d) ampliamente, cualquier estado de funcionamiento óptimo, bienestar o progreso; (e) un deseo de buena salud expresada para alguien en un brindis (Morris, 1973, p. 606).

En breve, cuando Juan le desea a Gayo que tenga "salud", el apóstol tiene el pensamiento de Cristo. La mente hebrea de una salud total que abarca la "sanidad" tanto el cuerpo como el alma está presente en el deseo de Juan. 
En segundo lugar, el deseo de Juan hacia Gayo es que sea "prosperado" (3 Jn. 2), palabra que viene del griego euodoō (Kohlengberger III, 1997, p. 323), deseo noble de prosperidad en general, tanto espiritual como material. En el léxico del Nuevo Testamento griego interlineal de Berry (1976), euodoō es traducido también como "estar bien encaminado" (en el viaje) y "prosperar" (p.43).

En el Dictionary of Old Testament words for english readers de Pick (1977), se hallan otras palabras hebreas afines a euodoō tales como tsolakh que quiere decir "prosperar en todos los pasajes" (caminos). Además, presenta otras variantes hebreas que se traducen como "prosperidad" son las siguientes: touvoh (Dt. 23:6; 1 R. 10:7; Job. 26:11; Ec. 7:14; Lm. 3:17; Zac. 1:17) que en inglés se traduce como "goodness" y según el American Heritage Dictionary quiere decir "bondad, benevolencia, generosidad" (Morris, 1973, p. 567); sholoum (Job. 15:21; Sal. 35:27; 73:3; Jer. 33:9) que significa “paz”; shalvoh (Sal. 30:6; Pr. 1:32; Jer. 22:21; Zac. 7:7) que en inglés tiene dos significados "ease" que quiere decir "libertad del dolor, preocupación o agitación" y "quietness" que se traduce "quietud", "tranquilidad"; y por último hatslokhoh (Sal. 118:25) que quiere decir "prosperidad" (p. 343).

De esta forma se puede apreciar que las palabras hebreas traducidas como "próspero", le dan una riqueza al entendimiento que el mundo del Antiguo Testamento tenía sobre la prosperidad, sobre todo, cuando se señala que Dios está listo para bendecir con "prosperidad". Las palabras "próspero", y "prosperidad" se hallan en los siguientes textos (3 Jn. 2; Ro. 1:10; 1 Co. 16:2) del Nuevo Testamento (Berry, 1976, p. 43).

El Comentario biblico adventista en inglés, comentando acerca del significado de la palabra griega euodoō, en inglés "prosper" y en español "próspero" del pasaje de $3 \mathrm{Jn}$. 
2, lo define como "tener un viaje próspero", "tener éxito", y "prosperar". Agrega el comentario que "El Señor desea que seamos victoriosos en los asuntos temporales y espirituales. Un buen cristiano será un buen negociante, un hombre de trabajo" (Nichol, 1957, p. 7:695).

El Comentario bíblico adventista comenta sobre 2 Cr. 20:20:

En el sistema judaico antiguo, esto se cumplía (seréis prosperados) tanto material como espiritualmente. Dios enviaba sus profetas en primer lugar para que pudieran originar una regeneración espiritual en el corazón de su pueblo. Pero cuanto mayor era la prosperidad espiritual de una nación, más segura era la prolongación de su prosperidad material (Ampuero Matta, 1984, t. 3:267).

En tercer lugar, la palabra "iglesia" requiere de un estudio. Según el American Heritage Dictionary de la lengua Inglesa, la palabra "church" tiene viarias connotaciones: "La compañía de un cuerpo de creyentes unidos en un cuerpo espiritual místico", "un edificio para adoración pública", "una congregación", "adoración pública en una iglesia", "una denominación cristiana específica", "un poder eclesiástico que se distingue de lo secular", "la separación de la iglesia del estado" (Morris, 1973, p. 241).

Siegfried Horn (1995), dice que la palabra "iglesia" que aparece en la carta de Juan (3 Jn. 6), proviene del griego ekklēsía que se origina en el verbo ekkaleō. Este vocablo está formado por dos palabras: ek "fuera" y kaleō "llamar" (p. 572). Los griegos le daban el nombre de ekklēsía a "la asamblea de ciudadanos, convocada por un heraldo para tratar y decidir los asuntos públicos" (Vila y Escuain, 1986, p. 518), o una asamblea en general (Horn, 1995, p. 572). Esta palabra originalmente no fue usada en asuntos religiosos sino seculares.

La palabra ekklēsía en el Nuevo Testamento es una traducción directa del hebreo qâhâl que significa "congregación", "reunión", “asamblea" (Horn, 1995, p. 572). qâhâl 
aparece en el mismo comienzo de las Escrituras, es decir en el Pentateuco con el significado de "congregación" (Ex. 12:3, 6, 19, 47; Lv. 4:13, 14, 15, 21; Nm. 1:2, 16, 18, 53; Dt. 5:22; 23:1; 2). Dependiendo de las versiones de la Biblia, la palabra qâhâl se traduce en algunos casos como "congregación" y en otros como "asamblea" Por ejemplo, Ex. 12:6, que en la versión Reina Valera de 1960 traduce como "congregación" y en la versión en inglés La Nueva Biblia dè Jerusalén traduce como "asamblea" (Wansbrough, 1985, p. 94).

Un caso similar ocurre en Ex. 16:3, en la versión Reina Valera los textos traducidos del Pentateuco directamente como "asamblea" son (Dt. 9:10, 10:4 y 18:16), así lo confirma la Concordancia de las Sagradas Escrituras de la versión Reina Valera de 1960 (Denyer, 1983, p. 62).

En cuanto al vocablo "reunión", éste a veces va acompañando a la palabra “congregación" como en Nm. 16:42: "Y aconteció que cuando se juntó (ó reunió) la congregación contra Moisés ....”. En otras ocasiones (Lv. 8:4) acompaña a la palabra “asamblea" (Wigram, 1997, p. 1094: 6950). A partir de los libros del Pentateuco, estas tres palabras, reunión, congregación y asamblea, se van repitiendo e intercambiándose indistintamente según los traductores bíblicos.

En cuanto al Nuevo Testamento, en los evangelios no aparece el término ekklēsia excepto en Mateo donde se la usa dos veces (Mt. 16:18 y 18:17). En estos pasajes, Jesus se refiere al sentido religioso de la palabra ekklēsía. De la misma manera, el autor del libro de los Hechos de los Apóstoles lee al término un sentido religioso en distintas ocasiones (Hch. 2:47, 5:11, 12:5, etc.). Lo mismo hacen los autores de las epístolas quienes usan ekklēsia como el nombre común para referirse al cuerpo de creyentes. 
En resumen, el significado de ekklēsía según el Nuevo Testamento griego interlineal de (Berry, 1976, p. 32) iglesia es "una asamblea" (Hch. 19:32, 39, 41), una "reunión de mucha gente" (Hch. 11:26), un "cuerpo total de creyentes en la tierra" (1 Co. 12:28; Ef. 1:22), y “los inscritos en los cielos”(He. 12:23). Además, ekklēsía es la “congregación", "reunión", o "asamblea" (Horn, 1995, p. 572) de personas que creen en Jesús como el Mesías y lo aceptan, viven sus enseñanzas y están unidos en una organización creada por Jesús (Mt. 16:18).

Y en cuarto lugar, la palabra "éxito" aparece 4 veces en la concordancia de (Denyer, 1983, p. 325), y los textos que cita son (1 S. 18:30; 1 R. 22:13; Neh. 1:11; Dn. 11:17). En la versión "Nueva Jerusalén" en inglés, en 2 de las 4 citas bíblicas anteriores (1 S. 18:30; Neh. 1:11) se traducen como "success" o "successful" (Wansbrough, 1985, pp. 380, 602), que coinciden con la traducción en español de "éxito". En la versión en inglés de (1 R. 22:13) la palabra "success" o "éxito" no aparece; pero sí es usada en la versión en español. Wansbrough (1985) en inglés lo traduce como "favourably" (p. 466), que es traducido al español como "favorablemente".

Lo mismo ocurre pero en sentido contrario en (1 R. 22:15) donde la versión en inglés usa la palabra "succes" o "éxito", mientras que la versión en español traduce como “prosperado". En el libro de Josué 1:8 de la Nueva Biblia de Jerusalén (inglés), se halla la palabra "prosper" (Wansbrough, 1985, p. 284) y en la Concordancia de Denyer (1997), una de las citas bíblicas para la palabra "prosperar" es Josué 1:8 (p. 713). Se debe observar que la palabra "success" va como compañera de otro vocablo que es "skill", traducido al español como "habilidad", "destreza", "experto"(Morris, 1973, p. 1212). 
La palabra "éxito" no tiene un solo vocablo de origen en hebreo de donde se pueda obtener una traducción directa. Las palabras hebreas que se traducen como "éxito" son las siguientes: (a) $y$ ' $l$ que traducido del hebreo también quiere decir "ganancia", "beneficio", "ser servicial", "ser útil"; (b) ksr se traduce "exitoso", "próspero", "estar deseoso de"; (c) kišrôn quiere decir "éxito y habilidad"; șlh es "ser exitoso", "ser próspero", "ser poderoso"; (d) śkl se usa también como "tener éxito", "entender", "hacerlo con sabiduría", "actuar con discernimiento"; (e) śekellsekel se traduce "discernimiento", "que comprende o entiende" (VanGemeren, 1997, p. 5:189).

Obsérvese que la raíz $k$ šr se refiere al "éxito" primeramente en base al esfuerzo humano". Su uso difiere de su sinónimo hebreo șlh que se traduce como "exitoso". Por lo general el verbo șlḥ se usa poniendo a Dios como sujeto, enfatizando que es Él, el que da "éxito". Por su parte, la raíz hebrea $y$ 'l hace énfasis en que es Dios, no los ídolos, quien provee lo que es ventajoso o beneficioso para la vida del pueblo (VanGemeren, 1997, p. 2:739).

Otro palabra vocablo hebreo traducido como "éxito", es śokhal que quiere decir "llegar a ser sabio" (Pick, 1977, p. 463). Este verbo se usa en Jos. 1:8 donde en la versión La Nueva Jerusalén en inglés se traduce como "succes" o "éxito". (Wansbrough, 1985, p. 284). Por su parte, la versión interlineal inglesa Hebrew-English Old Testament, lo traduce como "successful" o "exitoso" (Kohlengberger III, 1987, p. 2:1).

Como se puede apreciar en toda esta variada gama de vocablos asociados con la palabra "éxito", se puede decir que la salud de la iglesia viene acompañada de "éxito" en sabiduría, en entendimiento y en lo que emprenda. El éxito de la iglesia viene con poder, porque el verdadero "éxito" no viene de otra fuente sino de Dios. 
Luego del análisis de los términos "salud", "prosperidad", "iglesia", y "éxito" se espera que una iglesia saludable tenga estas cualidades. A continuación se presenta el estudio de las 4 características más destacadas de una iglesia saludable. Una iglesia unida a Cristo, goza de beneficios como los que se presentan a continuación.

\section{Una iglesia espiritual}

La espiritualidad es una de las caracteristicas de una iglesia saludable. Hay diversas descripciones de "iglesia espiritual", a continuación se presentan las más significativas, entre ellas: la "oración", la "fe", la "obediencia” y el "Espíritu Santo."

\section{Espiritualidad y oración.}

Según el American heritage dictionary of the English language (1973), la “oración" es "cualquier acto de comunión con Dios, como confesión, adoración, o acción de gracias" (p. 1029). El ejercicio de la "oración" es una parte importante y activa de una iglesia espiritual, esto se confirma a través del Antiguo y Nuevo Testamento (Is. 56:7; 1 R. 8:54; Jon. 2:7; Mt. 21:22; Hch. 1:14; 2:42; 12:5; Col. 4:2; Stg. 5:13-16).

Por otro lado para el Evangelical Dictionary of Christian Education, la“oración", como característica de una "iglesia saludable", debe enseñarse con ejemplo y aprenderse practicándola (Lc. 11:1). Las numerosas referencias en la Biblia a la oración (mencionadas en sesenta y dos de los sesenta y seis libros) testifican de su importancia para el creyente (Anthony, 2001, p. 550).

Con respecto al mecanismo de la "oración", el mismo diccionario afirma, que es "una actividad en la cual el creyente se comunica con Dios (Mt. 6:6-13). Esta comunicación es de dos vías, involucrando tanto al que habla como al que escucha. Estas 
cualidades son esenciales para el desarrollo de una relación saludable entre el creyente y Dios" (p. 550).

Otras connotaciones que se destacan en el Antiguo Testamento referentes a la "oración", es que se refiere a un "acto de intercesión" (Gn. 20:7; Dt. 9:20; 1 Sam. 7:5; 1 R. 13:6; Jr. 29:7), así como también es "un acto de confesión" (Neh. 1:4; Dn. 9:4, 20). De esta forma, se puede notar que la "oración" es un elemento importante en la espiritualidad, ya que encierra aspectos destacados de la comunicación del creyente con Dios (Renn, 2005, p. 749).

O’Mahony (2003) comenta que un par de siglos antes del nacimiento de Jesús, en Israel, se seguía practicando la oración. "Parece que durante los dos siglos que precedieron a la caída de Jerusalén, la 'oración' vino a ser una práctica de todos los días en el templo, no como una cosa reservada para ocasiones especiales y festivales. Muchas de las oraciones e himnos judíos que sobreviven a este periodo justifican esta declaración. Como ejemplo se puede tomar las oraciones en Tobías 3:2-6; 3:11-15 cuya fecha probablemente es alrededor del año 200 a.C." (p. 22).

Con toda certeza, se puede decir que Jesús fue el máximo modelo en la práctica de la oración, respecto a esto, algunos autores contemporáneos, hacen declaraciones al tema. Flynn (1995), por ejemplo, comentando acerca del habito de orar de Jesús, presenta en forma cronológica una lista de veinte y tres citas donde él esta orando. Esta autora dice, que Lucas es el que destaca la humanidad de Jesús, y no es de sorprenderse que quince de las veinte y tres veces que está orando, están en Lucas, y que once de esas ocasiones sólo se narran en este mismo evangelio (p. 6). 
Por otra parte, (Dodd, 1997, pp. 34, 38, 39) declara que Jesús oró porque era verdaderamente humano y como tal necesitaba la asistencia del Padre; además oró para mostrar cómo hacerlo. Jesús oraba de dos formas, una era pública y con los ojos abiertos (Jn. 17:1), la otra era privada, por la mañana y por la noche (Mr. 1:35; Mt. 14:23).

Jesús, en su ministerio, enseñó a sus discípulos algunos aspectos importantes acerca de la "oración" (Lc. 11:1), por ejemplo, les dio pautas de cómo reconocer si una oración es genuina. Les recomendó que cuando oren, no lo hagan para ser vistos, ni usen vanas repeticiones como los hipócritas y los gentiles (Mt. 6:5, 7, 8). Refiriéndose a la “oración privada", el consejo de Cristo fue practicarla a "puerta cerrada" (Mt. 6:6). Y como si esto fuera poco, reconociendo la importancia de la "oración", les dio un modelo (Lc. 11:2-4), el mismo que ha sido seguido desde entonces hasta ahora, pues fue dado para los discípulos y los creyentes de todas las épocas.

Cullmann (1995) comenta que, para Pablo, la "oración" era necesaria e indispensable para tener una iglesia saludable (Ef. 6:18; 1 Ts. 5:17), Cullman añade que, según los siguientes textos (1 Co. 12:3; Ef. 3:20-21), Pablo está diciendo que la "oración necesita de la presencia del Espíritu Santo” ( p. 72).

La iglesia cristiana primitiva estaba "unánime" (Hch. 2:1) y en "oración", cuando fueron bautizados por el Espíritu Santo en el Pentecostés. Esto habilitó a la iglesia a seguir creciendo en fe, conocimiento y testimonio. Hoy, la iglesia es la misma y no debe ser diferente de aquel tiempo.

La vida de los apóstoles fue una vida de oración. Siendo Pablo uno de ellos, su testimonio acerca de su vida de "oración", lo confirman sus cartas (Ro. 15:30; 2 Co. 13:7; 
Col. 1:3). Por su experiencia personal, es que aconseja a las iglesias a practicar la "oración" (1 Ts. 5:17; Col. 4:2; 1 Ti. 2:1).

El éxito de la iglesia apostólica se debió a la "oración" y la obra del Espíritu Santo como respuesta a la misma. Estas oraciones fueron hechas con fe, sinceras, en acción de gracias, perseverancia, de acuerdo a la voluntad de Dios y muy importante en el nombre de Jesús (Wright, 1979, p. 74). De la misma manera hoy en las iglesias, "la oración" es fundamental para llegar a ser una "iglesia espiritual".

\section{Espiritualidad y fe}

La "fe" es otra de las características de una "iglesia espiritual". La práctica de la "fe" o "creer" está presente en la vida de algunos de los personajes bíblicos como Abraham (Gn. 15:6), David (2 S. 22:3), el padre del muchacho endemoniado (Mc. 9:24), Jairo (Lc. 8:50), la mujer cananea (Mt. 15:28), centurión romano (Mt. 8:10) y muchos más, como el mismo pueblo de Israel (Ex. 4:31). La carta a los Hebreos dice que "sin fe es imposible agradar a Dios" (v. 6).

De acuerdo con Mills (1990), en el Mercer Dictionary of the Bible, la Biblia, especialmente el Nuevo Testamento, relaciona la palabra "fe" con otros términos afines tales como "creer, fiel, fidelidad" (p. 289). Según Renn (2005), ampliando el significado de "fe", se encuentran otras palabras que son intercambiables como "creencia", “confianza" y "convicción" (p. 360).

En el libro de Génesis se encuentra la historia de Abraham, quien tuvo "fe" en Dios, que lo llamó a salir fuera de su tierra para que se cumpliera el pacto que Dios quiso hacer con él y su descendencia, que iba a ser padre de "una nación grande" (Gn. 12:2). Además incluyó una bendición (Gn. 12:3) que iba a beneficiar a "todas las familias de la 
tierra" (Vos, 1982, p. 61). La "fe" de Abraham llegó al clímax cuando Dios le pidió que sacrifique a su hijo Isaac (Gn. 22:1-12), y estuvo dispuesto a obedecer, por eso es considerado un héroe de la "fe" (Heb. 11:8-19). Además, el Génesis contiene la historia de los primeros descendientes de Abraham: Isaac, Jacob, sus hijos, especialmente José en Egipto. En todas estas historias está presente la "fe" de sus protagonistas (Gn. 26:3-6, 24; $32: 24-28 ; 39: 7-9)$.

El pueblo de Israel en el desierto mostró falta de "fe" cuando no tuvo agua ni comida y también en otros momentos de crisis (Ex. 15:22-27; 16:1-36; 17:1-7), y es precisamente en esos momentos de crisis, cuando Dios interviene para alimentar la débil "fe" (Ex. 15:25, 27; 16:4, 5; 17:5, 6). Hoy sucede lo mismo, los cristianos tienen falta de fe en situaciones de crisis, y es cabalmente en esos momentos cuando Dios interviene.

La Biblia enseña que la falta de "fe", produce resultados nefastos en los creyentes, por ejemplo, uno es la "murmuración" (Ex. 15:24; 16:2-12), otro es la "idolatría" (Ex. 32:1-35). El doctor Atilio Dupertuis (1995) dice que "a pesar de haber sido redimidos por Dios, y pertenecer al pueblo de Dios, los ex esclavos no estuvieron exentos de pruebas y dificultades...Dios tenía un propósito definido...quería que aprendieran a confiar y a depender de él” (p. 170).

Los Evangelios relatan que el mismo Jesús, en sus enseñanzas hizo notorio que es necesario practicar la "fe" en cada circunstancia de la vida (Mt. 6:30; 8:26; 14:31; 17:20; Mr. 11:22; Lc. 7:50; 22:32).

Las Escrituras claramente enseñan que la salvación es a través de la "fe", Habacuc, dice: "mas el justo por la fe vivirá" (2:4). Además Pablo hace énfasis en sus cartas que por medio de la "fe", la persona es "justificada en Cristo (Ro. 3:28; 5:1; Gá. 
2:16; 3:8, 25, etc.); así la justicia de Cristo llega a ser nuestra por fe en él (Fil. 3:9). El resultado es entonces, que la fe del creyente en Dios, habilita al Señor a hacer cosas milagrosas en su favor (Mt.9:21, 22; Stg. 5:14, 15; etc.) y por medio de él " (Horn, 1995, p. 446).

Según lo estudiado, la "fe", es una característica indispensable para que una iglesia sea espiritual. Esta "fe" empieza a crecer en el corazón del creyente por el conocimiento de Dios a través de su Palabra (Ro. 10:17), y de esta forma se propaga a la familia, la iglesia y la comunidad.

\section{Espiritualidad y obediencia}

Otra característica destacada de una "iglesia espiritual" es la "obediencia" a Dios. Las Escrituras registran en Génesis, que Jehová dio una orden: "Y mandó Jehová Dios al hombre, diciendo: De todo árbol del huerto podrás comer; mas del árbol de la ciencia del bien y del mal no comerás; porque el día que de él comieres, ciertamente morirás" (Gn. 2:16-17). El asunto es muy claro. Es Dios quien dicta las leyes para bendición del hombre y éste debe "obedecer" para tener una relación saludable con Él.

Esta característica se encuentra en toda la Biblia, antes del pecado $(G n .1,2)$ y después del pecado (Gn. 3:1-24). Cuando Dios hace un llamado, sus seguidores deben obedecer, por ejemplo, Dios eligió una familia de Mesopotamia para llevarla a Canaán y que testifiquen de Jehová (Guinan, 1990, p.15), entonces, Abraham escuchó el llamado y obedeció junto con su familia (Gn.12:1, 4).

El mismo pacto de "obediencia" que Dios estableció con Adán $(\mathrm{G} .2: 16,17)$ lo vuelve a hacer con el pueblo israelita cuando llegó al desierto del monte Sinaí, "Ahora, pues, si dieres oído a mi voz, y guardareis mi pacto, vosotros seréis mi especial tesoro 
sobre todos los pueblos; porque mía es toda la tierra" (Ex. 19:5). Ese pacto estaba basado en la "Ley" que se iba a promulgar en el monte (Ex. 20:2-17).

La primera responsabilidad de Israel, fue ser fiel a Yahweh. Esto se nota claramente en el primer mandamiento, (Ex. 20:2,3): "Yo soy Jehová tu Dios, que te saqué de tierra de Egipto, de casa de servidumbre. No tendrás dioses ajenos delante de mi" (Guinan, 1990, p. 63).

Los diez mandamientos (Ex. 20:2-17) fueron dados para que los israelitas los obedezcan por fe en el Creador de los mismos. Dios sabe que el hombre pecaminoso por sí mismo (Jer. 13:23) no puede guardar los mandamientos, pero lo que desea es que los creyentes lo reconozcan como Dios y entonces Él mismo los habilita para obedecer sus leyes por medio del Espíritu Santo. Por lo tanto, sin esta característica, no puede haber una iglesia saludable. Ellos de esa manera serían dirigidos de confiar en sí mismos a creer en Dios, de la confianza en sus propios esfuerzos de fe a creer en la asistencia divina (Gá. 3:23-26). Así la ley los iba a dirigir a Cristo como su único Salvador sin pecado (Nichol, 1978, p. 1:594).

Buttrick (1990) dice que la "obediencia" es necesaria para una relación Dioshombre, porque "la ley viene a ser el instrumento de una relación mutua, en la cual ' $\mathrm{fe}$ ' responde al 'amor'. Esto transforma la 'ley' en una forma de expresar gratitud. La ley como un pacto de relación, es en sí misma una forma de gracia." (p. 1:980).

El pueblo de Israel debía "obedecer" también otro tipo de leyes que se registran en los capítulos 21-24 del Éxodo, que son una serie de ordenanzas, presentadas en forma de casos legales (Blenkinsopp, 1992, p. 198). "Estas leyes intentaban salvaguardar la 
buena salud de la comunidad a través de la práctica de la justicia" (Keck, 1994, p. 869). Esta "obediencia" era el fruto de una buena "salud espiritual".

La desobediencia trae consecuencias dolorosas como son la esclavitud, el dolor, la opresión, el miedo, la muerte, el sufrimiento, etc.; tal es el caso del pueblo de Israel, que sufrió en el tiempo de los Jueces (Jue. 1:1,2, 5). En la época de Gedeón, Israel estaba separado de Dios, sus altares estaban destruidos y olvidados y como resultado, el pueblo estaba siendo hostigado por los madianitas. En forma general, el ser humano se acuerda de Dios en momentos de dolor y sufrimiento, en el caso de Israel no fue diferente. Fue entonces que el pueblo empezó a clamar por ayuda divina, y Dios, en su amor y misericordia, contestó el clamor de los sufrientes. Para esto requirió ciertas condiciones que estaban relacionadas con la "obediencia".

Una de las órdenes claras que Dios dio a los israelitas fue la que destruyeran los altares a los baales y las imágenes de Asera: "Derribaréis sus altares, y quebraréis sus estatuas, y cortaréis sus imágenes de Asera" (Ex. 34:13). De la misma manera, Dios instruyó a Gedeón, la órden de Jehová fue: “...derriba el altar de Baal que tu padre tiene, y corta también la imagen de Asera que esta junto a él" (Jue. 6:25). La reacción de los moradores de Ofra (Jue. 6:28-30) muestra cuán enraizada estaba la idolatría y la desobediencia (Hamlin, 1990, p. 94).

Gedeón representa la iglesia de su tiempo, tenía que volver a la "obediencia" y hacer cambios definidos, como reconstruir el altar de Jehová (Jue. 6:26); para esto se necesitaba arrepentimiento, confesión y fe, que se iba a reflejar en "obediencia". La orden fue obedecida por Gedeón (Jue. 7) y fue entonces que Dios obró concediéndoles libertad. Las demandas de Dios para Israel y Gedeón son las mismas para hoy; Davis (2000) lo 
comenta de la siguiente manera: "Si Yahweh debía ser su Salvador, Baal debía desaparecer" (98). Una "iglesia saludable" requiere "obediencia" a Aquel que es el Libertador.

Jesús es el mejor ejemplo de "obediencia", cumplió toda la ley, haciendo la voluntad del Padre (Jn. 4:34). Fue tentado a no obedecer (Mt. 4:1-11; 26:36-39; Lc. 22:39-42), pero salió victorioso, como lo dice la carta a los Hebreos, "fue tentado en todo según nuestra semejanza, pero sin pecado" (Heb. 4:15). Pablo, hablando de la "obediencia" de Cristo dice: "y estando en la condición de hombre se humilló a sí mismo, haciéndose obediente hasta la muerte, y muerte de cruz" (Fil. 2:8).

Para concluir esta parte, debemos aclarar que la "obediencia" no nos salva de la condenación del pecado, pero se manifiesta como fruto de una continua relación y entrega a Jesús.

El rol del Espíritu Santo en la espiritualidad Una característica indispensable para identificar a una "iglesia espiritual" es la presencia del Espíritu Santo; precisamente el libro de Hechos de los Apóstoles ha sido llamado "El libro de los Hechos del Espíritu Santo". Este libro del Nuevo Testamento, no solo registra los primeros capítulos de la historia de la iglesia, sino también los primeros hechos del Espíritu Santo luego de la ascensión de Jesús al cielo (Simpson, 1996, p. 1).

Es necesario hablar primero acerca de la persona del Espiritu Santo, quien es la tercera persona de la Trinidad y se le conoce con los nombres de "Espíritu de Jehová, Espíritu del Señor, el Espíritu del Padre, el Espíritu de Jesús" (Gn. 6:3; Is. 11:2; 61:1; Mt. 10:20; Hch. 16:18). La Biblia le atribuye una personalidad distintiva como lo hace con el Padre y con el Hijo (Mt. 3:16-17; 28:19; Jn. 14:16-17; 15:26). 
(Vila, 1985, p. 331), presenta algunas de las cosas que el Espíritu hace como persona: piensa, conoce el lenguaje, tiene voluntad (Ro. 8:27, 1 Cor. 2:10-13; 12:11). Además enseña, testifica, convence, conduce, entiende, habla, anuncia (Jn. 14:26; 15:26; $16: 8,13)$.

En el ministerio de Jesús, destaca la necesidad del Espíritu Santo en la vida de sus seguidores, cuando les dice: "Pero yo os digo la verdad: os conviene que yo me vaya; porque si no me fuera, el Consolador no vendría a vosotros; mas si me fuere, os lo enviaré" (Jn. 16:7). El nombre Consolador viene del griego paráklētos que significa también “abogado" (Parker, 1982, p. 62). No cabe duda, que aquí Jesús se refiere al Espíritu Santo como una persona divina, a quien lo iba a enviar desde el cielo.

En la Biblia se encuentra al Espíritu Santo desempeñando algunos roles. En primer lugar, según Jesús, el rol que realiza el Espíritu Santo en la iglesia del primer siglo es mostrar la condición espiritual de la iglesia cuando dijo que "convencerá al mundo de pecado" (Jn. 16:8), tal fue el caso en la predicación de Pedro, los oyentes se convencieron de ser pecadores (Hch. 2:37).

En segundo lugar, tiene el rol de ser “Abogado". Refiriéndose al paráklêtos Turner (1996), en su libro dice:

En griego la palabra es un adjetivo verbal pasivo, "uno llamado al lado de", especialmente a ofrecer consejo, ayuda o asistencia en una corte, o en algún otro escenario potencialmente adverso. Típicamente parākletoi interceden en lugar de alguien, ante una alta autoridad, o apoyan su caso procedimientos judiciales $u$ otros, actuando como intercesor, mediador o testigo de apoyo. Puede así entonces la palabra "abogado" regularmente ser la mejor traducción (p. 77).

Según el Comentario bíblico adventista del séptimo día, el rol de "abogado" en la obra del Espíritu Santo no es completo, ya que en la literatura anterior al cristianismo y en la no cristiana, paráklētos retiene un significado más amplio de "uno que se presenta 
en lugar de otro", de "un mediador", de "un intercesor" o "un ayudador" (5: 1012). Para entender esto, el comentario hace referencia de Mateo 5:4. En este pasaje en particular, el comentario analiza una palabra afin que es parakaléo, que significa: "llamar a lado de", "pedir ayuda", "mandar llamar”, “exhortar”, "alegrar”, “consolar”, "reanimar”, "animar”. De esta manera, el comentario bíblico concluye diciendo que un verdadero amigo es un paráklētos, y su ayuda se denomina paráklēsis. Jesús fue un paráklētos según (1 Jn. 2:1) y Él prometió enviar otro "Consolador" (p. 316).

En tercer lugar, otro rol es que la iglesia lo reconoce como Sucesor y Sustituto de Cristo, lo que, según Turner (1996), se puede entender en tres formas. La primera es que en (Jn. 14:17), los discípulos ya conocían al Parácleto como el "Espíritu de verdad" que ellos habían experimentado a través de la sabiduría revelada en Jesús. Es ese mismo Espíritu que entraría en ellos.

La segunda forma es que el Espíritu que viene no sólo viene a reemplazar la presencia de Jesús, sino viene a mediar entre la presencia del Padre y del Hijo glorificado y los discípulos (Jn. 14:16-26). Por eso Jesús promete que no los dejará huérfanos (Jn. 14:18) y que tanto Él como el Padre vendrán a ellos y harán morada en ellos (14:23). La tercera forma es que no es un mero sustituto de Jesús, pero es el propio emisario de Jesús con su poder ejecutivo; eso significa que es enviado en el nombre de Jesús por el Padre (Jn. 14:26), o el mismo Jesús lo envía (Jn. 15:; 16:7) del Padre (Turner, 1996, p. 81).

En cuarto lugar, otro rol del Espíritu Santo es fortalecer la iglesia para que sea saludable. En Hech. 2:1-4 se relata la historia del recibimiento del Espíritu Santo como un evento indispensable y primordial para la salud espiritual de la iglesia naciente. La 
iglesia fue fortalecida con su presencia, pues habilitó a los discípulos para cumplir la misión dejada por Jesús, dándoles poder (Lc. 4:49; Hch. 2:4). Así mismo, también obró en el corazón de los no creyentes para que se hicieran discípulos a través del bautismo (Hch. 2:38).

Según Simpson (1996), eventos que son capitales en el cristianismo, dos de estos hechos "marcan el comienzo y el fin de la era cristiana, con la partida y el retorno del Señor, y como un gran evento que se levanta entre estos dos, está la venida del Espíritu Santo a administrar esta nueva dispensación, hasta que el Señor Jesús venga otra vez" (p. 17). En la línea de este pensamiento, la segunda venida de Cristo está sujeta al ministerio del Espíritu Santo.

El Espíritu fortalece la iglesia con poder a través del otorgamiento de los dones espirituales como los describen los siguientes pasajes: Ro. 12:6-8; 1 Co. 12:8-10 28-30; Ef. 4:11 y en 1 Ped. 4:10. Siendo que hay diversidad de dones y dada su importancia, se lo tratará por separado más adelante, en el contexto del discipulado; por ahora se toma como ejemplo unos pocos dones que se encuentran en The Holy Spirit in the Bible de Rea (1990) acerca de Ro. 12:3-8 que destaca siete dones espirituales los cuales son profecía, ministerio de servicio, enseñanza, exhortación, generosidad (repartir), dirigir o presidir y hacer misericordia (p. 224).

En quinto lugar, tenemos que otro de los roles del Espíritu Santo es guiar, llamar y llevar a sus hijos al cumplimiento de la misión como en el caso de Pedro que fue enviado por el Espíritu Santo a casa de Cornelio (Hch. 10:19, 20); también como en el caso de Felipe (Hch. 8:26, 29, 39) cuando fue llamado para ir hacia donde el Espíritu le guiaba, darle instrucciones de lo que debía hacer, y luego llevarle a un lugar de trabajo. 
Entonces otra vez el Espíritu Santo viene a nosotros ahora para testimonio y servicio. La dispensación judía no supo nada acerca de esto. Su negocio era mantener la luz entre ellos mismos y ser exclusivos y estar separados de los gentiles. Todo es diferente ahora (Simpson, 1996, p. 20).

En sexto lugar, el rol del Espíritu Santo es enseñar y quizá uno de los más destacados, para desarrollar una iglesia saludable. Rea (1990) declara: "Enseñar no es simplemente una instrucción sistemática ( 2 Ti. 2:2), pero es una manifestación del Espíritu el tener la habilidad de hacer simple el significado de la Palabra de Dios la cual Él la ha inspirado" (p. 223).

Destacando la enseñanza del Espíritu Santo, Turner (1996) comenta, acerca de la tesis doctoral de Eskil Franck en 1985, acerca del "parakleto" en el Evangelio de Juan cuyo título fue Enseñanza revelada ó la enseñanza revelada.

Si uno está yendo a describir al Parakleto por sus funciones, arguye Franck, entonces el está sobre todo en la función de "Maestro" antes que Consolador, Abogado o cualquier otra cosa. La base para afirmar esto se encuentra ampliamente en dos pasajes claves: Juan 14:26 y 16:12-15 (p. 82).

Habiendo estudiado los roles del Espíritu Santo, se hace evidente que su obra es abarcante y con justa razón Jesús dijo a los discípulos que era necesario que él se fuera para que el Consolador venga.

La promesa del Espíritu Santo fue dada por Jesús para todos los creyentes, pero existen ciertas condiciones para recibirlo. Para recibirlo, la primera condición es pedirlo como lo enseñó Jesús: "Pues si vosotros, siendo malos, sabéis dar buenas dadivas a vuestros hijos, ¿cuánto más vuestro Padre celestial dará el Espíritu Santo a los que lo pidan? (Lc. 11:13).

La segunda condición para recibirlo es que debían estar unánimes. Se halla descrita en Hch. 2:1: "Cuando llegó el día del Pentecostés, estaban todos unánimes 
juntos". Simpson (1996) cita la traducción de Rotherham que dice: "Mientras el día de Pentecostés estaba cumpliéndose, todos ellos estaban en un mismo lugar y con un objetivo" (p. 24). La promesa del Espíritu es para todos los creyentes (Hch. 2:38; Jn. 7:39; Ef. 1:13; 3:16-17; Gá. 3:2-5, 13-14; 4:4-6) y es por fe (Vila, 1985, p. 332).

Acerca del Espíritu Santo y la "iglesia espiritual”. Opsahl (1978), dice:“el Espíritu es el creador y sustentador de la existencia de la iglesia. Las expresiones impersonales enfatizan que el don escatológico de Dios es recibido como poder y por gracia a través de la fe la cual habilita la iglesia y a los creyentes individuales a verdaderamente testificar y a empeñarse en el camino de Jerusalén hasta Roma" (p. 37), es decir hasta lo último de la tierra.

\section{Una iglesia que practica el discipulado}

Otro beneficio de una "iglesia saludable" unida a Cristo es que tiene la característica de formar discípulos y practica el discipulado. Una iglesia saludable es una iglesia que obedece el mandato de Jesús en la gran comisión: "Por tanto, id, y haced discípulos a todas las naciones, bautizándolos en el nombre del Padre, y del Hijo, y del Espíritu Santo; enseñándoles que guarden todas las cosas que os he mandado; y he aquí yo estoy con vosotros todos los días, hasta el fin del mundo" (Mt. 28:19, 20).

\section{Significado de discipulado}

El "discipulado" consiste en el desarrollo de los discípulos al aprender, poner por obra lo aprendido y finalmente buscar otros "discípulos" que sigan sus pasos. Para entender mejor el significado de "discipulado", se va a definir primero la palabra “discípulo". 
La palabra "discípulo" aparece en los cuatro Evangelios y en libro de Hechos de los Apóstoles del Nuevo Testamento. Oak (2003) declara que esta palabra es usada aproximadamente doscientas cincuenta veces (p. 125). El diccionario enciclopédico de la Biblia, publicado por el Centro: Informática y Biblia de la Abadía de Maredsous (1993), enseña que la palabra "discípulo" viene del griego mathētēs, término que se aplica a "aquel que recibe enseñanza de un rabi", y del hebreo talmîd (Is. 8:16; 50:4; 54:13), palabra rara en el Antiguo Testamento (p. 443).

Serafin de Ausejo (1981), en su Diccionario de la Biblia, explica que el termino discipulo tiene al menos cuatro connotaciones:

1. En general, el que recibe la enseñanza de un maestro (Mt. 10:24; Lc. 6:40)

2. En sentido más restringido, el que se ádhiere a una doctrina y vive conforme a ella. En este sentido ya los profetas tenían sus discípulos, así como los fariseos (Mt. 22:16; Mr. 2:18) y Juan Bautista (Mt. 9:14; 11:2).

3. En sentido estricto son los seguidores de Jesús, ante todo los doce apóstoles (Mt. $10: 1 ; 11: 1 ; 28: 16$ ), después también un grupo mayor...(Mc. 2:15; Lc. 7:11; Jn. $2: 2 ; 17: 22$ ). Entre estos (Lc. 10:1-17) habla de setenta (según varios códigos y la Vulgata, de setenta y dos), que fueron enviados por Jesús de dos en dos.

4. En Hch. 6:1; 9:19, son discípulos todos los que abrazan la fe de Jesús, de suerte que discípulo viene a ser lo mismo que cristiano (p. 485).

El significado de la palabra discípulo según el Diccionario ilustrado Aristos de la lengua española es "Persona que aprende una doctrina de un maestro o que cursa en una escuela; persona que sigue la opinión de una escuela" (Aristos, 1973. p. 225).

Brow (1981), definiendo el significado de discípulo, dice: "significa un aprendedor, alguien que está aprendiendo a hacer algo, o a ser algo, con la ayuda de un profesor. En este sentido la iglesia está aprendiendo con la ayuda de Jesús, el 'Maestro' (Mc. 10:17; Jn. 11:28; 13:13) y es correcto también decir que está aprendiendo del Espíritu Santo" (p. 20). 
Habiendo visto y entendido las definiciones "discípulo", es más fácil entender el significado de "discipulado". Por ejemplo, el Diccionario ilustrado Aristos de la lengua española acerca de "discipulado" dice: "es ejercicio y calidad de discípulo; es el conjunto de discípulos de una escuela" (p. 224).

Según Oak (2003), "discipulado" es un método de crecimiento en la vida espiritual" (p. 133). Entonces para que exista "discipulado", debe haber un proceso de enseñanza-aprendizaje y de esta manera cumpla las expectativas del maestro, debiendo ser continuo y sin detenimiento. "Discipulado" cristiano entonces, es la acción de conocer al Maestro que enseña, practicar sus enseñanzas y finalmente formar otros como discípulos.

\section{Características del discípulo}

Una caracteristica del discípulo es que "su enfoque es hacia los demás". Percy (2003), opinando sobre "discipulado", dice que esto es una "llave importante para una transformación congregacional. Una congregación puede ser tan buena como fuerte y efectiva, por su habilidad de desarrollar discípulos. Sin un entrenamiento de discipulado intencional es altamente típico que una congregación enfocada en sí misma, pueda ser transformada en una congregación enfocada hacia fuera de sí misma" (p. 70).

El mismo autor presenta tres dimensiones de discipulado que se describen y explican a continuación:

La dimensión personal, que tiene que ver con el entendimiento de uno mismo como hijo de Dios y la relación personal con Dios; crecimiento en entender acerca del Evangelio y sus implicaciones y el proceso de transformación a través del cual el discípulo se parece a Jesús. 
La dimensión corporal, que tiene que ver con el entendimiento de uno mismo como miembro del pueblo de Dios, la iglesia. El llamado a seguir a Jesús es un llamado a unirse a esta comunidad y encontrar un lugar personal de servicio dentro del aspecto básico del discipulado.

El discípulo se distingue también porque tiene una dimensión pública. Como discípulos quieren crecer más y más habilidad de ver el mundo desde la perspectiva de Dios y entender más plenamente la altura, la profundidad, y la anchura del evangelio y sus implicaciones para cada área de nuestras vidas y del mundo entero (Percy, 2003, p. 38-39).

Otra característica es que "el discipulo es elegido" y responde al compromiso del llamado. Jesús en Jn. 8:31-37 subraya la responsabilidad cristiana del discípulo. Fue precisamente él quien eligió a sus discípulos. De esa manera, afirma Spader (1991), hay ciertas cualidades que distingue a esos discípulos. Primera cualidad, la fidelidad, que tiene que ver con la consistencia en seguirlo; segunda cualidad, la disponibilidad, como lo expresara Isaías "Heme aquí, envíame a mi" (Is. 6:8). Es una actitud a abrirse al control y dirección del Espíritu de Dios; tercera cualidad, hambre por aprender, demostrado cuanto le falta por crecer, sin una actitud de "no necesito que nadie me enseñe, ya lo sé todo"; y cuarta cualidad, entusiasmo. Un entusiasmo por el trabajo para el Señor es una señal de crecimiento en la relación personal con él (p. 134-136).

Entre algunos autores contemporáneos se presentan otras características resaltantes del discipulado y que se aplican también al discipulador.

La siguiente caracteristica del discipulado es que "tiene hambre de crecer en su relación con Dios en Jesucristo." Cuando la vida espiritual del "líder discipulador" es 
afirmada, alimentada, y relacionada con la misión de la congregación, grandes cosas suceden" (Foss, 2000, p. 127). Un "maestro" de discípulos, por la naturaleza de su posición, se espera que esté en continuo crecimiento espiritual.

Otra caracteristica del discipulado es "cambio de carácter." Percy (2003) dice que es importante "la transformación del carácter y el comportamiento. Uno de los temas consistentes de Pablo es que los seguidores de Jesús ponen a un lado el yo y se convierten en nuevas criaturas" (p. 36). El carácter de una persona, determinará en parte la manera cómo se va a relacionar con los demás.

El cristiano en su crecimiento espiritual entra en un proceso de cambio donde el Espíritu está haciendo los cambios necesarios, especialmente cuando se está en el camino del discipulado, donde la preparación integral del creyente es vital y una de las primeras evidencias externas es precisamente el cambio de carácter, pues la meta es llegar al modelo que es Cristo.

Malphurs (2004) en este aspecto dice: “El carácter de una persona, sea bueno o malo, afecta directamente cómo él o ella conduce su vida. Gente con un carácter pobre tiende a vivir una vida pobre hasta puede derretirse en la verdad o cortarse en las esquinas al desear cumplir sus blancos" (p. 23).

La penúltima característica del discipulado es que tiene "visión". Barna (1988) en forma simple define lo que es visión: es "un sentido comprensivo de donde uno está, a dónde está yendo, y cómo va a llegar alli" (p. 80). Es decir, tanto el discípulo como el discipulador, necesitan saber exactamente dónde están y a qué lugar esperan llegar.

No puede haber discípulos o líderes sin visión, ya que es parte esencial en su desenvolvimiento. Barna (1988) dice: "La Visión es responsabilidad de un líder y lo 
coloca aparte de sus seguidores. El líder tiene y comunica la visión; los seguidores aceptan y ayudan a llevarla a cabo" (p. 81).

El mejor ejemplo de "líder" es Jesús (Mr. 1:17); compartió su visión de salvar al mundo con sus discípulos y luego ellos siguieron en su ausencia con la misma visión. Pablo confirma que la visión de Jesús se cumple en su propia vida cuando menciona lo siguiente: "Pero cuando agradó a Dios, que me apartó desde el vientre de mi madre, ỳ me llamo por su gracia, revelar a su Hijo en mi, para que yo predicase a los gentiles, no consulté enseguida con carne y sangre, ni subí a Jerusalén a los que eran apóstoles antes que yo; sino que fui a Arabia y volví de nuevo a Damasco" (Gá. 1:15-17).

Describiendo lo que significa "visión", Foss (2000) cita una declaración de Barna que dice: "Visión es un claro y preciso retrato mental por un futuro mejor, impartido por Dios a sus siervos escogidos, basado en el correcto entendimiento de Dios, de sí mismo y de las circunstancias" (p. 131).

La última caracteristica del discipulado es que "prepara nuevos discipulos" para seguir las instrucciones dadas por Cristo de predicar el evangelio en todo el mundo (Mt. 28:19; Hch. 1:8; Ap. 14:6). Las características presentadas pueden intercambiarse entre el discípulo y discipulado.

Elena de White tiene entre sus libros varios consejos respecto al discipulado y entrenamiento de los creyentes; a continuación se presentan algunas citas referentes a la tarea de los ministros como entrenadores o discipuladores. En primer lugar, White (1959) en su libro Servicio Cristiano dice: "Lo que se necesita ahora para la edificación de nuestras iglesias es la obra buena de obreros sabios que disciernan y desarrollen los talentos en la iglesia: talentos que puedan ser educados para uso del Maestro" (p. 74). 
Ella presenta aquí que la obra de los pastores es trabajar en el desarrollo de los dones de los miembros de iglesia.

En segundo lugar, habla acerca de instituir escuelas de capacitación para los miembros de iglesia: "Muchos trabajarían con gusto si se les enseñara a cómo empezar. Necesitan ser instruidos y alentados. Cada iglesia debe ser una escuela práctica para obreros cristianos" (White, 1959, p. 75).

En tercer lugar, White (1959), se refiere a los pastores que hacen la obra que no les corresponde, haciendo el trabajo de la iglesia: "Los predicadores pueden hacer su parte, pero no pueden nunca realizar la obra que la iglesia debe hacer" (p. 87).

En cuarto lugar, ella escribe que "El predicador no debe tener el sentimiento de que debe encargarse por sí mismo de toda la obra de predicación, trabajo u oración; debe educar personas que lo ayuden en ello en toda la iglesia" (White, 1959, p. 88). Esto lo menciona porque hay pastores que ante tanto trabajo piensan que son ellos solos los responsables del mismo, sin educar a la iglesia.

En quinto lugar, la siguiente cita de White (1959), dice: "Los pastores no deben hacer la obra que pertenece a la iglesia, cansándose ellos mismos, e impidiendo que otros desempeñen su deber" (p. 88). Es notorio que ella usa el verbo "impedir", al referirse a pastores que se amontonan de trabajo en lugar de liderar la iglesia hacia el cumplimiento de su deber.

En sexto lugar, el libro Evangelismo, refiriéndose a lo que se debe hacer con los miembros nuevos, ella escribió: "Los que se deciden por la verdad, deben ser organizados en iglesias, y luego el predicador pasará adelante a otros campos...ponga el ministro a los miembros a trabajar, necesitarán que se les enseñe como trabajar con éxito..." (White, 
1976, p. 259, 260). Nótese que ella usa la expresión: "ser organizados", y es precisamente esto lo que el líder debiera hacer primero, organizar el trabajo involucrando a la mayoría de los creyentes.

En séptimo lugar, para un desarrollo saludable de la fe cristiana es necesario que los miembros trabajen pues así lograrán ser fortalecidos. Al respecto ella escribió lo siguiente: "Cuando las almas se convierten, ponedlas al trabajo enseguida. $\mathrm{Y}$ a la medida que trabajen, de acuerdo con su habilidad, se irán haciendo más fuertes. Es haciendo frente a las influencias opositoras como llegan a confirmarse en la fe" (White, 1976, p. 261).

En octavo lugar, cuando una iglesia está pasando por dificultades, erróneamente se piensa que el remedio es sermonear a la iglesia. White (1976), en referencia a esto manifiesta: "La mejor medicina que podéis dar a una iglesia no es predicar o sermonear, sino planear trabajo para sus miembros" (p. 261).

En noveno lugar, cuando el pastor comience en un grupo pequeño de hermanos, la prioridad no es evangelizar en ese momento, sino instruir. En el mismo libro Evangelismo (1976), ella dice: "Cuando trabaje donde ya haya algunos creyentes, el predicador debe primero no tanto tratar de convertir a los no creyentes como preparar a los miembros de la iglesia para que presten una cooperación aceptable" (p. 85).

En décimo lugar, existen algunas iglesias con una expectativa equivocada y es que el pastor ordenado es el único responsable de la obra. "Nuestros pastores ordenados deben hacer lo que puedan, pero no debe esperarse que un hombre haga la obra de todos" (White, 1976, p.87). 
Según lo estudiado, un verdadero discípulo de Cristo debe reunir entre otras, éstas características básicas para un crecimiento personal y cumplir su cometido: (1) su enfoque es hacia los demás, (2) es elegido. 3. Tiene hambre de crecer en su relación con Dios en Jesucristo. 4. Cambio de carácter. 5. Tiene visión y 6. Prepara nuevos discípulos.

El discípulo trabaja con los dones espirituales

Una de las características importantes de una "iglesia saludable" y mencionada por algunos autores tales como Rick Warren, Peter Wagner, Christian Schwarz y otros, es el uso de los dones del Espíritu.

Wagner (1996), en su libro La iglesia saludable, expone que uno de los problemas que afectan la salud de la iglesia es la falta del Espíritu (hipopneumia), y que el primer paso para curar esto es "reconocer el rol del Espíritu Santo y tenerlo en nuestra vida individual, en la vida de nuestras iglesias y estar abiertos a Su ministerio. El segundo paso es ser llenos del Espíritu Santo" (p. 158).

El primer aspecto de una iglesia que practica el discipulado es tener la presencia del Espíritu, sólo entonces serán otorgados los dones para edificación personal y sobre todo para ministrar a otros, convirtiéndose en una iglesia saludable. Schwarz (1999) dice: · "La orientación sobre los dones tiene que ser más que una única reunión, llegando a ser una 'institución fija' de la iglesia. Cada nuevo creyente y cada nuevo colaborador deberían aprovecharse de este ministerio. Durante las sesiones (reuniones de iglesia), se verá que algunos de los creyentes están justo en el lugar donde Dios les ha llamado a estar, mientras que otros no lo están. Es importante que los líderes ayuden a esas personas a encontrar en la iglesia sus dones y así su llamamiento" (p. 65). 
Los dones no son exclusivos, no son todos dados a una sola persona ni a un grupo privilegiado, sino que se complementan.

Dios no ha dado todos los dones a una persona, sino que ha dado a cada creyente algunos de los dones necesarios para edificar el cuerpo de Cristo. Cuanto más use su propio don, más cuenta se dará de lo mucho que necesita el ministerio de los demás para completar sus carencias....A medida que utilice los recursos anteriores podrá descubrir qué dones ha puesto Dios en los miembros de su equipo (Schwarz, 1999, p. $55)$.

La iglesia apostólica entendió bien el ministerio de una iglesia saludable según los dones, por eso Pedro declara: "Cada uno según el don que ha recibido, minístrelo a los otros, como buenos administradores de la multiforme gracia de Dios" (1 P. 4:10).

En el pensamiento de Schwarz (1999), la característica de los dones es importante en el contexto del "desarrollo natural de la iglesia", ya que es vital; él declara: "el concepto de los dones espirituales juega un papel central en todas ellas. Lo que está en juego aquí es nada más y nada menos que la misma esencia del 'cuerpo de Cristo': Cada creyente es un miembro de este cuerpo, y los dones que cada uno haya recibido determinarán el papel que él o ella vaya a desempeñar en ese cuerpo de acuerdo a la voluntad de Dios" (p. 62).

White (1976), en su libro Evangelismo, al refiriéndose a los dones declara: "Los diversos talentos que el Señor ha confiado a sus servidores son esenciales para su obra. Las diferentes partes' de la obra deben unirse, pieza por pieza, para constituir una totalidad. Las partes de un edificio no son todas iguales, $\mathrm{y}$ tampoco son hechas por el mismo proceso" (p. 80).

Más adelante en relación a la edificación de la iglesia comenta: "Para que la obra sea edificada con simetría se requieren diversos dones y diferentes instrumentos, todos ellos bajo la dirección del Señor; él instruirá a los obreros de acuerdo con sus diversas 
aptitudes" (White, 1976, p. 80, 81). Así, ésta simetría necesaria podrá ser alcanzada por el Espíritu Santo a través de los dones.

Según White, los dones espirituales dados por Dios a la iglesia tienen un propósito: "Dios distribuye talentos y dones a los hombres no para que permanezcan ociosos, no para que los empleen en obtener diversiones o complacencia egoísta, sino para que constituyan una bendición para otros al capacitarlos para llevar a cabo un trabajo misionero abnegado y ferviente" (White, 1976, p. 197).

Los dones del Espíritu se mencionan en Rom. 12:6-8; 1Cor. 12:8-10, 28-30; y en Ef. 4:11. Wagner (1990), en el libro Sus dones espirituales pueden ayudar a crecer su iglesia, enumera una lista de 27 dones (p. 9). Según (Hunter,1994, p. 87), la "Biblia dice que cada cristiano ha recibido un don (1 P. 4:10)", y hace una lista sugerente de 24 dones, que en este estudio pueden adaptarse a la Iglesia de Gainesville, Florida.

Según Hunter (1994, p. 88), la lista de dones que son mencionados en el Nuevo Testamento, luce de la siguiente manera:

Romanos 12

1. Profecía

2. Servicio

3. Enseñanza

4. Exhortación

5. Dadivosidad

6. Liderazgo

7. Misericordia

1 Corintios 12 (No están incluidos los que constan en Romanos 12)
8. Sabiduría
9. Ciencia
10. $\mathrm{Fe}$
11. Sanidad
12. Milagros
13. Discernimiento de Espíritus
14. Lenguas
15. Interpretación de Lenguas
16. Apóstoles 
17. Ayuda

18. Administración

Efesios 4 (No se está incluyendo ninguno listado anterior)

19. Evangelista

20. Pastor

Otros dones los cuales son reconocidos por algunos eruditos incluye:

21. Celibato (1 Co. 7:7)

22. Martirio (1 Co. 13:3)

23. Hospitalidad (1P. 4:9)

24. Misionero (Gá. 1:16):

La diferencia entre la lista de dones de Hunter y Wagner es que este último presenta tres dones más que son pobreza voluntaria, intercesión, y exorcismo, de los cuales el de intercesión es otro don que junto con los de Hunter y se pueden aplicar a la iglesia de Gainesville.

\section{Cristo y el discipulado}

La Biblia declara que Jesús escogió a los doce discípulos: "Y cuando era de día, llamó a sus discípulos, y escogió a doce de ellos, a los cuales llamó también apóstoles" (Lc. 6:13). Así, Spader (1991) señala que a este grupo pequeño de seguidores, los entrena ó discipula (Mt. 28:19-20) para el cumplimiento de la misión (p. 36).

Como el ministerio de Cristo creció, vino a ser necesario entrenar y designar a otros a pastorear segmentos del ministerio. Jesús supo que Él no podía adecuadamente satisfacer las necesidades de todos el mismo, así que empezó a entregar algunas responsabilidades a sus discípulos. Eso fue necesario para permitir el continuo crecimiento y desarrollo de sus discípulos, y fue necesario como el paso final de la construcción de un ministerio que continuaría expandiéndose de una manera saludable (Spader; 1991, p. 170).

Jesús ha sido llamado justificadamente "Maestro" de "maestros" ya que los efectos de su enseñanza y discipulado todavía sigue rindiendo resultados. Sus primeros discípulos lo llamaron "Rabi", que significa también "Doctor" o "Maestro" (Jn. 1:38). 
Hubo algo inusual en la vida de Jesús como Maestro, y es que la mayoría de los que llegaban a ser maestros, era sólo luego de haber sido discípulos de otro maestro, en el caso de Jesús nunca fue discípulo de nadie (Baxter, 1987, p. 30). Y sin haber asistido a las escuelas de su época, la gente se sorprendía de su enseñanza (Jn. 7:14-15, Lc. 4:32).

La palabra "discípulo", como se dijo anteriormente, viene del griego mathètēs que significa "estudiante". De esta manera, los discípulos elegidos por Jesús se unieron como grupo de estudiantes, aceptando sus enseñanzas acerca del reino de los cielos (Jn. 6:6071; Mt. 16:16). Fue entonces que ellos llegaron a la conclusión que Jesús es "el Cristo, el Hijo del Dios viviente" (van Bruggen, 1996, p. 187).

Uno de los resultados del discipulado de Jesús, y que contrasta con los otros maestros o rabinos de su tiempo, es la declaración de Juan, que Jesús ganaba más discípulos que Juan Bautista (Jn. 4:1); otro resultado, que observa van Bruggen (1996), es cuando cita otros pasajes de los evangelios para destacar que las masas venían hacia él, (Mt. 4:24, 25; 9:36; Mr. 8:1-3) sea para escucharlo o para ser sanados (p.191).

El método de discipular de Jesús fue muy claro, envolvía dos elementos esenciales: primero, tenía una enseñanza atractiva y de esperanza y segundo, suplía las necesidades de la gente.

Dodd (1970) comenta que la enseñanza de Jesús era diferente a la del judaísmo rabínico de su tiempo (Mt. 18:10-14; 20:1-16), quienes estaban orientados a defender ideologías e interpretaciones de la Ley y los profetas, mientras que Jesús tocaba la vida de la gente con sus enseñanzas a través de parábolas (p. 54). Y al mismo tiempo llenaba sus necesidades físicas y espirituales (Lc. 9:10-17). 
Parte del énfasis de la enseñanza de Cristo era que los discípulos lo conozcan a él, (van Bruggen, 1996, p. 190) dice que mientras la enseñanza de Juan el Bautista era específicamente para "bautismo de arrepentimiento" (Lc. 3:3, 8), la de Jesús era concerniente a sí mismo y su trabajo (Mt. 16:13-17; Lc. 19:9, 10).

Como parte del discipulado mostró una predicación positiva al compartir las “buenas nuevas” (Ef. 2:17, Lc. 4:18, 21), que consistían (Mt. 4:17; 10:7; 13:24, 31, 33, $44,45,47)$ en el anuncio de la cercanía del "reino de los cielos" (Dodd, 1970, p. 55). Fue esto lo que atrajo a los primeros discípulos hacia el Maestro. Entonces fue así que Jesús grupo selecto de doce (Lc. 6:13-16), luego a setenta (Lc. 10:1) con el fin que después de su muerte siguieran su ejemplo. Uno de los líderes más destacados del Nuevo Testamento es Pablo quien siguió el ejemplo de Cristo al formar discípulos como fueron Tito, Timoteo y otros.

El discipulado trabaja efectivamente en grupos pequeños como Cristo lo demostró. Ellen White destaca la importancia de la formación de grupos de trabajo. En el libro Evangelismo, White (1976) dice: "En nuestras iglesias deben organizarse grupos de servicio. En la obra del Señor no ha de haber ociosos. Únanse diferentes personas en el trabajo como pescadores de hombres" (p. 88). En otra parte del mismo libro dice: "La formación de pequeños grupos como base del esfuerzo cristiano, es un plan que sido presentado ante mí por Aquel que no puede equivocarse ... organícense en grupos pequeños, para trabajar no solamente por los miembrós de iglesia, sino por los no creyentes también" (White, 1976, p. 89).

Fue así que Jesús y sus discípulos practicaron el discipulado como un instrumento para propagar el evangelio. Jesús trabajó con un pequeño grupo de hombres 
discipulándolos, y ellos hicieron lo mismo, discipulando a otros. Este trabajo se realizó en grupos pequeños durante la primera parte de la iglesia apostólica. Hoy, el trabajo bajo el método de Cristo debe dar el mismo resultado que en la iglesia cristiana primitiva.

\section{El discipulado y la misión}

Una "iglesia saludable" practica el discipulado, y tiene como prioridad el cumplimiento de la orden dada por Cristo: "Por tanto, id, y haced discípulos a todas las naciones, bautizándolos en el nombre del Padre, y del Hijo y del Espíritu Santo” (Mt. 28:19).

La orden de Jesús tiene que ver con la palabra "misión", que significa "enviar"; así que, una "iglesia saludable" es la que "envía" discípulos para que se cumpla el mandato de Cristo. Elwell (1996), en el Evangelical Dictionary of Biblical Theology, dice que "misión es la divina actividad de enviar intermediarios.... El concepto bíblico es expresado en el uso de verbos que significan 'enviar'.... El verbo hebreo es šāla ḩ" ( $p$. $534,535)$

La palabra "apóstol" viene del verbo griego apostêllo que significa "enviar" (Parker, 1982, p. 12). Jesús mismo se llama "el enviado de Dios" (Jn. 6:38). Cuando Jesús resucitó, prometió enviar su Espíritu a los discípulos (White, 1985, p. 18). Es entonces necesario que para que exista "misión", hayan dos partes, tanto "el que envía" como "los que son enviados".

En la Biblia, Dios es "el que envía", como en los casos de Abraham (Gn. 12:1), Moisés (Ex. 3:10), Isaías (Is. 6:8), Jeremías (Jer. 1:7), Jonás (Jon. 1:2) y otros más. White (1985) recuerda que la iniciativa de este movimiento viene de Dios (p. 18) y esto se aplica tanto en el Antiguo como en el Nuevo Testamento (Mt. 9:1-6; 10:1). Debe notarse 
que para el desarrollo de una iglesia saludable, "los que son enviados" deben recibir “instrucciones específicas” y entonces están listos para cumplir con la misión.

Para entender mejor el significado de la "misión" en el movimiento cristiano, L. White (1985) declara que "separada de la 'misión' la iglesia realmente no existe; ya que donde la 'misión' ocurre entonces la iglesia viva está presente” (p. 20).

Mateo, al final de su Evangelio, registra las "instrucciones" de Cristo para cumplir la misión: "Por tanto, id, y haced discípulos en todas las naciones, bautizándoles en el nombre del Padre, y del Hijo, y del Espíritu Santo; enseñándoles que guarden todas las cosas que yo os he mandado; y he aquí yo estoy con vosotros todos los días, hasta el fin del mundo" (Mt. 28: 19-20).

Esta instrucción amplía Lucas en su Evangelio (Lc. 24:47, 49) y en el libro de Hechos con motivo de la ascensión de Cristo al cielo, donde se especifica claramente el territorio donde se cumplirá la misión y donde se añade la promesa del Espíritu Santo: "Pero recibiréis poder, cuando haya venido sobre vosotros el Espíritu Santo, y me seréis testigos en Jerusalén, en toda Judea y hasta lo último de la tierra" (Hch. 1:8).

Entonces, en primer lugar se confirma que los discípulos son enviados en cumplimiento de la "misión" para hablar de Cristo, de sus enseñanzas y de estar listos para su regreso. En segundo lugar, se destaca el territorio donde se cumplirá la "misión", así los discípulos son enviados primero al pueblo judío, "en Jerusalén, en toda Judea" (Hch. 1:8).

Dentro del aspecto territorial de la misión, y rompiendo con la tradición nacionalista de los judíos, aparece el hecho innegable que esa "misión" debía cumplirse también en el mundo "gentil", llamada así toda persona que no era judía, "en Samaria, y 
hasta lo último de la tierra" (Hch. 1:8); y en Mateo al decir, "a todas las naciones" (Mt. 28:19).

Driver (1994), refiriéndose a la relación entre judíos y gentiles dice:

En el siglo primero de nuestra era, el enfrentamiento entre judíos y gentiles, descrito en Efesios 2:11-12, era un hecho cotidiano. La permanente lucha de Israel por no contaminarse a través del contacto con sus vecinos gentiles llevo al primero a una actitud cerrada, dura y exclusivista ante las otras naciones. Esta situación se tornó particularmente evidente al volver del exilio, época en que la política del aislamiento y separación condujo gradualmente a una postura de intolerancia absoluta (cf. Esdras y Nehemías). Una de las peores ofensas que un judío podía hacer a otro en el primer siglo consistía en calificarlo de "gentil y publicano". Los judíos consideraban que el odio hacia quienes eran, obviamente, los enemigos de Dios estaba justificado: más aun, hasta cierto punto debía ser fomentado (cf. Mt. 5:43). Por otro lado, los gentiles respondían con actitudes agresivas al desprecio que les manifestaban los judíos" (p. 244).

La misión junto con el discipulado hizo del cristianismo un estilo de vida diferente como lo declara White (1985) "Este modelo cristológico le dio a la comunidad cristiana las bases de su identidad y vida" (p. 77).

El libro de "Hechos de los Apóstoles" presenta el resultado de la misión y el discipulado ordenada por Jesús a los discípulos (Mt. 28: 19; Hch. 1:8).

Dibelius (2004) dice, refiriéndose al libro de Hechos, que es "único" por "contar la historia de la primera comunidad cristiana en una forma consecutiva, y esparcir las creencias cristianas al Occidente. Lucas, su autor (Hch. 1:1; 16:10-17; 20:5-14), seleccionó el material que iba a incluir en el libro para presentar cómo se fue cumpliendo el programa misionero de la obra del discipulado. Del capítulo 1 al 5 en Jerusalén, del capítulo 6 al 12 en Judea y Samaria y del capítulo 13 al 28 hasta lo último de la tierra (p. $3,4)$.

El trabajo de discipulado de la "iglesia apostólica" desde la perspectiva de la "misión" se resume en dos actividades que aunque diferentes, estabañ relacionadas: "Y 
todos los días en el templo y por las casas, no cesaban de enseñar y predicar a Jesucristo" (Hch. 5:42).

Estas dos actividades se explican de la siguiente forma: primero, la tarea de la predicación consistía en la proclamación de las buenas nuevas acerca de Jesús e invitar a los oyentes a seguirlo. Siempre la predicación fue dirigida a los no creyentes. Segundo, la enseñanza era dada a aquellos que habían sido bautizados y habían empezado a seguir a Jesús. De esta forma, se entiende que la enseñanza siempre fue dirigida a los cristianos (Baxter, 1987, p. 64).

El discipulado y el crecimiento numérico

Así como un manzano bien cuidado con todos los ingredientes necesarios producen frutos buenos y en abundancia, así una "iglesia saludable" dará frutos buenos y en abundancia, pues los ingredientes necesarios como son el discipulado y la misión han sido puestos en el lugar que les corresponde en el cumplimento de la orden dada por Cristo.

Es importante notar que los números en la Biblia son mencionados con carácter de información para destacar lo que el escritor desea transmitir. Como dice Wagner (1987), "Usar números no es intrínsecamente correcto o incorrecto. Depende del motivo" (p. 43). Considerar el crecimiento numérico es importante para una "iglesia saludable" que desea progresar. A continuación, se presentan dos eventos del Antiguo Testamento donde se encuentra información numérica referente a personas y hechos específicos.

Cuando el pueblo de Israel sale de Egipto, se registra que salieron "seis cientos mil hombres de a pie, sin contar los niños", no se menciona, de acuerdo a la costumbre de 
la época, el número de mujeres que salió, pero añade que "subió con ellos grande multitud de toda clase de gentes" (Ex. 12:37, 38).

En otra oportunidad, el pueblo de Israel estaba sometido a persecución por los madianitas (Jue. 6:1, 2), Dios llama a uno para dirigir la liberación del pueblo de Dios, Gedeón, a quien le da instrucciones para seleccionar un número de soldados que cumplieran con los requerimientos divinos (Jue. 7:2-7), quedando finalmente trescientos hombres. Aquí Dios usa un número de hombres con un propósito definido (Jue. 7:2).

El Nuevo Testamento también registra información con números. El Evangelio de Mateo registra la alimentación a una multitud: "Ý los que comieron fueron como cinco mil hombres sin contar las mujeres y los niños" (Mt. 14:21). En otra oportunidad alimenta a otro número grande de personas: "Eran los que comieron como cuatro mil; y los despidió" (Mt. 8:7).

Si la información numérica es importante en el Antiguo y Nuevo Testamento, entonces el papel del crecimiento numérico es uno entre varios factores para mostrar la salud espiritual de una iglesia. Al comienzo de la iglesia cristiana, la información del número que se bautizaba era muy importante pues era la manera de medir el cumplimiento de la misión.

Existe información de resultados numéricos saludables en el cristianismo creciente del tiempo de los Hechos. Brown (1997) enfatiza el resultado del primer sermón de Pedro en la iglesia de Jerusalén (Hch. 2:41) donde dice: “Así que los que acogieron bien su palabra fueron bautizados; y se añadieron aquel día como tres mil personas" ( $\mathrm{p}$. 286) "alabando a Dios, y teniendo favor con todo el pueblo. Y el Señor añadía cada día a la iglesia los que iban siendo salvos" (Hch. 2:47). 
Como se puede notar, el discipulado en los Hechos fue en aumento, y esto se conoce gracias al informe numérico que la Biblia registra, como confirman los siguientes pasajes: "Pero muchos de los que habían oído la palabra, creyeron, y el número de los varones llego a ser de unos cinco mil" (Hch. 4:4). "Y crecía la palabra del Señor, y el número de los discípulos se multiplicaba en gran manera en Jerusalén; también muchos de los sacerdotes obedecían a la fe" (Hch. 6:7).

Malphurs (1999) destaca el crecimiento en número de los creyentes no solo en Jerusalén, sino en Judea, Samaria y hasta en Asia. A continuación, las citas bíblicas que usa para demostrar su declaración del crecimiento cristiano en el tiempo de los Hechos: "Entonces las iglesias tenían paz por toda Judea, Galilea y Samaria, siendo edificadas y andando en el temor del Señor, y se acrecentaban fortalecidas por la consolación del Espíritu Santo" (Hch. 9:31); El aumento de los creyentes en Antioquia fue muy notorio, lugar donde a los discípulos se les llamó por primera vez cristianos (Hch. 21, 24, 26).

Las últimas citas bíblicas que menciona Malphurs (1999), destacan el crecimiento en lugares lejanos tales como el continente Asiático, tal como había sido el mandato de Jesús, "hasta lo último de la tierra". "Así que las iglesias eran consolidadas en la fe, y aumentaban en número cada día" (Hch. 16:5), y finalmente (Hch. 19:26) "pero veis y oís que este Pablo, no solamente en Éfeso, sino en casi toda Asia, ha persuadido y apartado a muchas gentes, diciendo que no son dioses los que se hacen con las manos" (p. 43, 44).

No se puede dejar de mencionar la actitud de Jesús hacia los números en relación a la ganancia de las almas. Wagner (1987), usando el texto de (Mt. 24:14), comenta que aunque en ese momento su predicación era a un grupo relativamente pequeño de seguidores, El miró más allá de las circunstancias inmediatas y vio el extenderse del 
Reino a todos los pueblos de la tierra (p. 42). En el mismo libro Strategies for church growth, presenta otras citas bíblicas (Mt. 9:38; Jn. 21:11; Mc. 4:8; Lc. 12:6, 7) donde Jesús enseña a través de los números (p. 44, 45).

Se concluye entonces, que el crecimiento numérico es necesario en una iglesia que practica el discipulado en cumplimiento de la misión.

\section{Una iglesia que practica la adoración}

Una "iglesia saludable", unida a Cristo, es una iglesia que practica la adoración. Por eso es necesario entender lo que significa "adoración" y, para eso, se presentan a continuación unas pocas definiciones; esto contribuirá para entender, aunque en manera general, lo significa "adoración".

El Diccionario ilustrado de la lengua española Aristos (1973) lo define "como la acción de adorar"; y la palabra "adorar" significa: "Reverenciar con sumo honor a un ser considerado como divino// Reverenciar y honrar a Dios con el culto religioso que le es debido// Amar con extremo// Orar, hacer oración a Dios" (p. 26).

El Expository dictionary of Bible words de Renn, (2005) define la palabra "adoración" que viene, primero de la palabra hebrea shāhāh que es un verbo que describe las acciones de "inclinarse y adoración en más de sus aproximadamente 170 veces que se repite. Este término hebreo se refiere a 'adoración' a Jehová en diferentes contextos. Es ofrecido por los patriarcas (Gn. 22:5; 24:6); por los israelitas (Ex. 4:31; 33:10; 2 Cr.7:3; Is. 27:13; Jer.7:2); Moisés (Ex. 24:1; 34:8) y Josué (Jos. 5:14). “Adoración es también ordenada por Dios en Dt. 26:10; 1 Cr.16:29; Sal. 99:9".

Segundo, viene del griego, del verbo proskyneō que se encuentra en 65 lugares, un dinámico equivalente de shăḥăh, que significa "adoración" en varios contextos. Entre 
otros está el verbo latreuō, que significa tanto "adoración" como "servir" (pp. 1066, 1067).

En el libro del Génesis aparece Jehová como el Creador y Adán y Eva, sus primeros adoradores (Gn. 1:26-31; 2:2, 3). En los capítulos 1 y 2 del Génesis constan los elementos de la adoración: ¿A quién se va a adorar?, ¿Quiénes van a adorar?, ¿Cómo van a adorar? y ¿Cuándo van a adorar? Estos elementos de la adoración aparecen a través de la historia del pueblo de Israel.

En el Nuevo Testamento aparece el Verbo encarnado (Jn. 1:1), que también recibe adoración como el Jehová del Antiguo Testamento (Mt. 28:17; Jn. 9:38).

Respecto a estilo de adoración, Warren (1995) opina que no existe tal cosa como "estilo" correcto de adoración. Dice: "Jesús solamente puso dos condiciones para la legítima adoración: 'Dios es Espíritu; y los que le adoran, en espíritu y en verdad es necesario que le adoren' (Jn. 4:24)." Enfatiza su idea diciendo que "el estilo de adoración con el cual usted se siente cómodo dice mucho más de su origen cultural que de su teología" (p. 248). Puede decirse que la forma de adoración es personal, dependiendo del lugar y de acuerdo al origen cultural y social de la persona.

Resumiendo, la iglesia es saludable cuando los siguientes elementos de adoración están presentes: "Reverenciar y adorar a Dios", "amar a Dios", "orar a Dios", "inclinarse" (humillarse), "servirle". y "adorar en Espíritu y verdad".

\section{Una iglesia que practica el amor y la amistad}

Finalmente, una iglesia saludable unida a Cristo tiene la característica del amor. El libro: De Egipto a Canaán de Dupertuis (1995) dice: "el 'amor' que es eterno y se manifiesta en dos mandamientos, los cuales tienen diez incisos explicativos (cuatro y 
seis)". A continuación se puede ver el cuadro explicativo del amor manifestado en esos dos mandamientos (p. 225) No puede haber una iglesia saludable si no hay primero "amor" a Dios.

I. Amor a Dios

a. No tener dioses ajenos

b. No hacerse imagen

c. No tomar su nombre en vano

d. Acordarse del sábado
II. Amor al prójimo

e. Honrar a los padres

f. No matar

g. No adulterar

h. No hurtar

i. No decir falso testimonio

j. No codiciar

De esta manera, menciona Dupertuis, (1995) la obediencia a la "ley" (los 10 mandamientos) en su segunda parte, determina las relaciones entre el hombre y sus congéneres (p. 225).

Una iglesia saludable debe mostrar "amistad" y "amor" en lo que predica y hace, especialmente con las personas que llegan por primera vez a la iglesia. La "salud espiritual" de los miembros debe manifestarse por la pasión de las almas dentro y fuera de la iglesia.

Las personas llegan por diferentes motivos a la iglesia, ya sea por una invitación personal, por compromiso, por una actividad comunitaria de la iglesia o por cualquier otra razón. Esa persona antes de salir de la iglesia, habrá tomado la decisión de volver o no, por la "forma" como fue tratada. La siguiente cita de Warren nos aclara esto:

Por supuesto, todas las congregaciones piensan que su iglesia es amorosa. ¡Pero eso es porque la gente que así piensa no son los que están allí! Pregúntele a un miembro típico y le dirá: Nuestra iglesia es muy amigable y amorosa. Lo que generalmente quiere decir: Nos amamos los unos a los otros. Somos amigables y amorosos con las personas que ya se encuentran aqui. Aman a las personas con las cuales se sienten cómodos, pero esa cálida comunión no se traduce automáticamente en amor por los incrédulos y por las visitas (Warren, 1995, p. 217). 
La amistad y la confraternización tienen un lugar preponderante en el desarrollo y crecimiento de una "iglesia saludable". Wagner (1997), en su libro Plantando iglesias para una mayor cosecha, describe esto como "crucial para desarrollar el amor" (p. 114). Él dice:

La confraternización es crucial para desarrollar el amor. La gente debe pasar mucho tiempo junta en situaciones en que puedan estar sosegados y franquearse unos con otros. Hay muchas formas de lograr esto, tal como los grupos células en casa, las clases para adultos de la escuela dominical, las cenas en la iglesia, las cenas en pequeña escala en que se reúnen tres o cuatro matrimonios en una casa para disfrutar de una comida improvisada, los equipos de ministerio, los retiros, y otras actividades. La clave para que resulte es el tiempo. Nada establece la comunión como el tiempo pasando juntos (Wagner, 1997, p. 114).

Este último aspecto es de tanta importancia, para la salud espiritual de una iglesia, que varios autores contemporáneos como Harold Percy, Dann Spader y Gary Mayes, Christian A Schwarz y Christoph Schalk, y otros, hablan de cómo ser más efectivos en esta área importante que muestra no sólo debe haber amor entre los miembros de una congregación, sino amor por los inconversos.

White (1975), en su libro El evangelismo, presenta el ministerio de amor de Cristo: "Cristo atraía hacia si los corazones de sus oyentes por la manifestación de su amor, y entonces poco a poco, a medida que iban siendo capaces de soportarlo, les descubría las grandes verdades del reino" (p. 47).

Esta misma autora recalca que el amor debe empezar en los hogares:

Olvidémonos de nosotros mismos, tratando siempre de alegrar a otros, para aliviar sus cargas por actos de tierna bondad y hechos de amor abnegado. Estas consideraciones corteses, comenzando en el hogar y extendiéndose mucho más allá del círculo familiar, tiene mucho que ver con hacer la vida feliz; y el descuido de ellas constituye una parte no pequeña de la miseria de la vida (White, 1984, p. 274). 
En el mismo libro, White (1984) presenta el resultado del amor de Cristo en un cristiano diciendo: "Un cristiano bondadoso y cortés es el argumento más poderoso que pueda presentarse a favor del Evangelio" (p. 271, 272).

Una iglesia que practica el "amor" y la "amistad" también predicará del amor de Cristo. "Ni una sola alma se salva a menos que aprendamos diariamente de Jesús, su humildad y mansedumbre de corazón....Predique el amor de Cristo, y eso ablandará y subyugará los corazones" (White, 1966, p. 212).

De esta forma, el capítulo a analizado las características de una iglesia saludable, que son "es una iglesia espiritual", "una iglesia que practica el discipulado", "una iglesia que practica la adoración" y finalmente "una iglesia que practica el amor y la amistad"; su importancia radica en que son tan vitales, ya que sin ellas, no habrá crecimiento espiritual saludable ni numérico. 


\section{CAPÍTULO 3}

\section{PROGRAMA PARA ENVIGORIZAR LA SALUD ESPIRITUAL DE LA IGLESIA DE GAINESVILLE}

Este capítulo provee un perfil de la iglesia de Gainesville y el proceso que se siguió para envigorizar la salud espiritual de la Iglesia. Está dividido en tres secciones principales. La primera sección ofrece información histórica, demográfica, económica, educacional y religiosa de la ciudad donde está ubicada la iglesia. La segunda sección se concentra en el origen y el crecimiento de la iglesia desde que fue fundada en el año 1993; además contiene la encuesta que se aplicó para medir la espiritualidad de la iglesia. La tercera sección describe el programa y los procedimientos seguidos previos a la implementación, como los protocolos y aprobación, la naturaleza del programa y contenido del mismo.

\section{La ciudad de Gainesville}

Colonizadores llegaron alrededor de los años 1820 donde hoy se encuentra la ciudad de Gainesville. Los primeros en habitar las tierras de la Florida fueron los españoles, quienes luego abandonaron el área dejando sus huellas como es el "Fuerte de San Marcos" en la bahía de Matanzas; asiento hoy de la ciudad de San Agustín.

Al aumentar la población, para el año 1824 los condados fueron divididos y subdivididos, entre ellos el de "Alachua". Originalmente el pueblo que era el 
representante del condado fue "Newnansville" que estaba situado a unas pocas millas de lo que hoy es Gainesville (Hildreth y Cox, 1981, p. 1).

Gainesville fue fundada el 24 de Enero de 1824 (Rajtar, 2008, p. 1). El nombre fue puesto en honor al General Edmund P. Gaines, quien vino a Florida en la guerra contra los indios Seminoles por la masacre de Dade (Chris Beckmann y Boucias, 1994, p. 17), luego de lo cual se convirtió en la ciudad representante del condado de Alachua. Hildreth (1981) escribe que la primera iglesia que se construyó en la nueva ciudad entre otros edificios fue la Iglesia Presbiteriana, por W. L. y Mike Finger quienes, más tarde (1857), construyeron el edificio de la Corte (p. 8).

Para el año 1859 , la primera parte de la línea del ferrocarril estaba completa, dando a la ciudad un empuje en su desarrollo económico y social. Trajo consigo más negocios, intercambios, desarrollo agrícola y aumentó de número de sus pobladores (Chris Beckmann y Boucias, 1994, p. 20). La guerra civil hizo estragos por los años 1860, casi destruyendo la línea del ferrocarril. Terminada la guerra, vino la época de reconstrucción política, social y económica.

Para fines de la época de reconstrucción (1880), "hubieron cuatro iglesias para blancos: Bautista, Metodista, Episcopal y Presbiteriana. Hubieron también cuatro iglesias de negros: dos Bautistas, una Metodista, y una Episcopal" (Chris Beckmann y Boucias, 1994, p. 30).

A comienzos del siglo veinte, las ciudades de Lake City y Gainesville eran las contendoras para ser la sede de la nueva universidad aprobada por el gobernador Broward de la Florida. La decisión final se tomo el 5 de Julio de 1905, abriendo de esa manera una nueva página en la historia y desarrollo de la ciudad de Gainesville."Una pequeña ciudad 
entre cinco y seis mil habitantes, dieron la bienvenida a un grupo de 136 estudiantes que llegaron para la primera clase universitaria en 1906" (Hildreth y Cox, 1981, p. 104). La ciudad fue expandiéndose tanto en población como en economía, la juventud fue participando en asuntos sociales, políticos, raciales, la mayoría de ellos relacionados con derechos civiles.

En la actualidad Gainesville es una ciudad universitaria, tiene hasta el 2007 un registro de 36,000 estudiantes en la Universidad de Florida. La universidad ha hecho de Gainesville un centro para las artes. Loś deportes en la universidad, en época de Otoño son una obsesión especialmente en football (Sperlin y Sander, 2007, p. 377).

Ha llegado a ser un lugar importante para empezar pequeños negocios; además sus alrededores son un atractivo para la recreación, existen vertientes de agua natural, centros de observación de vida silvestre. Sperlin y Sander (2007) comentan que muchos consideran a esta pequeña ciudad (Gainesville) como un lugar ideal para vivir ya que está en la categoría \#1 como lugar para vivir en el Estado de Florida, como también a nivel de la nación (p. 377).

\section{Población}

Según el Bureau de Censo del 2000, el Estado de Florida era de 15,982,378 habitantes, mientras en el condado de Alachua era de 217,995 habitantes, y en la ciudad de Gainesville 95,447 (Floyd, 2005, p. 4, 5, 14).

De acuerdo con los datos publicados por Demographics USA del 2008 (Ver tabla 1), los nuevos datos de población en el Estado de la Florida hasta el año anteriormente señalado son $18,599,600$ habitantes; de los cuales $75.3 \%$ son blancos, $15.3 \%$ son negros, $2.2 \%$ son asiáticos y $20.7 \%$ son hispanos (Donato, 2008, p. 2-1). 


\section{TABLA 1}

POBLACIÓN DE LA FLORIDA 2008

\begin{tabular}{|c|c|}
\hline Razas & Porcentaje \\
\hline Blancos & $75.3 \%$ \\
\hline Negros & $15.3 \%$ \\
\hline Asiáticos & $2.2 \%$ \\
\hline Hispanos & $20.7 \%$ \\
\hline
\end{tabular}

(Donato, 2008, p. 2-1) (El total puede ser más grande que $100 \%$ por contar los hispanos entre otros grupos.)

En el condado de Alachua, según Demographics USA la población en el 2008 fue de 238,100 habitantes (Donato, 2008, p. 5, 6), y según Floyd (2008), el último dato demográfico proyectado de Gainesville hasta el año 2007, fue de 122,671 habitantes (p. 17).

En el caso de la ciudad de Gainesville, la población está distribuida en porcentajes según las razas como se ve en la tabla siguiente:

TABLA 2

POBLACIÓN DE GAINESVILLE 2007

\begin{tabular}{|c|c|}
\hline Razas & Porcentaje \\
\hline Blancos & $65.1 \%$ \\
\hline Negros & $25.0 \%$ \\
\hline Asiáticos & $5.3 \%$ \\
\hline Hispanos & $7.3 \%$ \\
\hline
\end{tabular}

(Mackenzie, 2008, p. 2) (El total puede ser más grande que $100 \%$ por contar los hispanos entre otros grupos.) 
El porcentaje de la población hispana (7.3\%) en Gainesville en relación con el estado de la Florida, es pequeño, si se compara con (20.7\%) que es el porcentaje total del estado (ver tabla 1), esto se debe a que la mayor parte la población hispana se encuentra del centro hacia sur del estado. Lo que atrae la población hispana a Gainesville es la educación superior y la agricultura.

Otro dato de interés para esta investigación es la proyección de crecimiento aproximado de hispanos hasta el año 2030 según la tabla 3, ya que por este medio se puede hacer proyectos de abrir nuevas iglesias en el futuro.

TABLA 3

PROYECCIÓN DE CRECIMIENTO HISPANO POR EDADES
\begin{tabular}{|c|c|c|}
\hline POBLACIÓN & 2010 & 2030 \\
\hline Menos de 18 años & 4,361 & 7,099 \\
\hline Entre 18 y 64 años & 118,115 & 28,147 \\
\hline Más de 65 años & 1,045 & 4,310 \\
\hline
\end{tabular}

(Floyd, 2008, p. 64).

Economía

Mientras la economía en el Estado de la Florida gira alrededor de la industria del turismo (Morris y Morris, 2007, p. 668), la economía de la ciudad de Gainesville gira mayormente alrededor de la educación, con todo lo que genera la Universidad de la Florida, como vivienda, servicios, transportación, turismo y recreación, agricultura, salud y otros negocios que hacen de esta ciudad un lugar atractivo para vivir.

La tabla 4 muestra que el ingreso per-cápita es casi el mismo comparado con el de 
todo el país, el ingreso por hogar está por debajo del ingreso familiar a nivel de todo el país. Por otro lado, el ingreso porcentual de los que ganan por sobre los $\$ 25,000$, es casi el $10 \%$ mayor sobre el porcentaje de la nación, y esto es positivo en relación a la economía de la ciudad. Y el porcentaje de los que ganan sobre los $\$ 75,000$, hay un $4.8 \%$ más de personas en esta categoría comparado con el porcentaje de todo el país.

\section{TABLA 4}

\section{INGRESOS}

\begin{tabular}{|lc|c|}
\hline \multicolumn{2}{|c|}{ Gainesville } & U.S Promedio \\
\hline Per-Cápita & $\$ 21,336$ & $\$ 23,235$ \\
\hline Por hogar & $\$ 35,575$ & $\$ 46,414$ \\
\hline Por hogar sobre $25 \mathrm{~K}$ & $36.7 \%$ & $26.2 \%$ \\
\hline Por hogar sobre 75k & $20.2 \%$ & $25.4 \%$ \\
\hline
\end{tabular}

(Sperling, 2007, p. 378).

Beers, (2001), comenta que en 1995 la revista Money nominó a Gainesville como el lugar número uno para vivir en los Estados Unidos, ellos dijeron que "esta área pintoresca es uno de los pocos lugares en los Estados Unidos donde uno puede trabajar en la ciudad, vivir en el campo, y tener 30 minutos de viaje entre uno y otro lugar". Y todo esto se debe a un buen trabajo del Gainesville Area Chamber of Comerce (p. 136).

\section{Educación}

La educación pública en el Estado de Florida tiene registro de hace más de siglo y medio, en 1822. Se acordó que "cada 16ava. sección de tierra en cada pueblo, fuera reservada para mantenimiento de escuelas primarias". De todas maneras por 10 años no 
hubieron escuelas en la Florida, excepto de unas pocas escuelas privadas (Morris y Morris, 2007, p. 615).

Morris y Morris (2007), continúa informando que, en 1823, el Congreso decidió que la reservación de "townships" de tierra llamados "tierras de seminarios" sea para dos instituciones de educación superior. Estos seminarios tempranos fueron los "ancestros" de lo que son hoy, la Universidad de Florida en la ciudad de Gainesville y la Universidad del Estado de la Florida (p. 615).

En el estado de Florida, con respecto a la educación hispana, Floyd (2008) registró que el número de estudiantes entre las edades de 5 a 17 en el condado de Alachua era de 33,343 (p. 141). Los graduados de educación secundaria en el periodo del 2006$2007,13,092$ fueron varones y 14,673 mujeres, dando un total de 27,765 ; esto es en todo el estado de Florida. Lo frustrante fue el número de graduados del condado de Alachua, 57 varones y 51 mujeres llegando a un total de 108 graduados (p. 176).

Si se compara el número de estudiantes que culmina la escuela secundaria (108) con el número que ingresa a las escuelas $(33,343)$, se nota una gran diferencia en la culminación de los estudios de enseñanza media. De manera que el número de los que ingresan a la universidad es todavía más reducido, y como resultado los profesionales hispanos en el área son escasos.

\section{Religión}

El cristianismo en la Florida tiene sus inicios en los comienzos del siglo dieciséis con la llegada de los españoles, celebraron la primera misa navideña en el campamento temporario de Hernando de Soto en 1539 en lo que hoy es Tallahassee. En esos tiempos, la monarquía española permitía sólo la religión católica. 
Entre los años 1763 y 1783, Inglaterra tomó posesión de la colonia, época en la cual los ingleses construyeron los primeros lugares de culto protestantes. Con la partida de los ingleses, los españoles volvieron a tomar el dominio del territorio, prohibiendo cualquier otra religión que no sea la católica. El gobernador con el interés de poblar el territorio, decidió ignorar la prohibición, permitiendo que los protestantes que habían quedado, junto con los que venían de los estados del sur de los Estados Unidos, tuvieran sus cultos en forma discreta. No fue hasta 1821, cuando la Florida llegó a ser un territorio de los Estados Unidos, y esto empezó a atraer a los migrantes, la mayoría protestantes. Durante los 1820s, muchas congregaciones, Episcopales, Metodistas, Bautistas y Presbiterianos, fueron establecidas en territorio de Florida (Winsberg, 2006, p. 56, 57).

Aunque el Censo de los Estados Unidos condujo el último censo religioso hace más de 70 años, el "Centro de Investigación, Casa de Misioneros Glenmary" ha llenado esta información religiosa denominacional durante los años 1952, 1971, 1980, 1990 y 2000.

Winsberg (2006) informa que el censo más reciente presenta 149 denominaciones de las 285 encuestadas. Lamentablemente, 14 de las que tienen un estimado de 100,000 y más adherentes no respondieron a esta encuesta y muchas de las que no respondieron fueron denominaciones de población negra (p. 59).

Florida, en comparación con el resto del país, tiene la más alta participación de adherentes religiosos quienes están identificados con las Asambleas de Dios, Iglesias de Dios, Iglesia Episcopal, Iglesia Griega Ortodoxa, Iglesia Santa Pentecostal, Iglesia Presbiteriana en América, Adventistas del Séptimo Día, Bautistas afiliados con la Convención Bautista del Sur y Judíos. Los que menos participación de adherentes tienen 
TABLA 5

MAYORES DENOMINACIONES RELIGIOSAS DE FLORIDA

(Número de adherentes)

\begin{tabular}{|c|c|c|c|c|c|}
\hline Denominaciones & 1990 & $\%$ & 2000 & & $\%$ \\
\hline Asamblea de Dios & 134,297 & 3 & 189,387 & & 3 \\
\hline Católica & $1,598,457$ & 32 & $2,596,148$ & & 41 \\
\hline Iglesias cristianas e Igls. de Cristo & 43,070 & 1 & 58,695 & o & 1 \\
\hline Iglesia de Cristo (Discipulos) & 23,725 & $*$ & 22,545 & & * \\
\hline Mormones & 59,845 & 1 & 75,620 & & 1 \\
\hline Iglesia Nazarena & 39,413 & 1 & 44,208 & & $i$ \\
\hline Iglesias de Cristo & 73,462 & 1 & 72,540 & & 1 \\
\hline Iglesias de Dios (Cleveland, TN) & 70,108 & 1 & 101,188 & & 2 \\
\hline Iglesia Episcopal & 158,595 & 3 & 152,526 & & 2 \\
\hline Igls. Evangélicas Luteranas en América & 92,732 & 2 & 90,594 & & 1 \\
\hline Griega Ortodoxa & ND & ND & 24,796 & & * \\
\hline Estimado Judío (Comité Judío American & 10) 567,000 & 11 & 628,458 & 1 & 10 \\
\hline Iglesia Luterana (Sínodo de Missouri) & 67,787 & 1 & 71,970 & & 1 \\
\hline Musulmán (Islam) & ND & ND & 31,661 & & * \\
\hline Santidad Pentecostal & 11,815 & * & 27,905 & & * \\
\hline Iglesia Presbiteriana (USA) & 165,255 & 3 & 157,751 & & 2 \\
\hline Iglesia Presbiteriana en América & 35,998 & 1 & 43,745 & & 1 \\
\hline Adventistas del Séptimo Día & 57,336 & 1 & 72,619 & & 1 \\
\hline Convención Bautista del Sur & $1,167,850$ & 23 & $1,292,097$ & & 20 \\
\hline Iglesia de Cristo Unida & 43,854 & 1 & 39,326 & & 1 \\
\hline Iglesia Unida Metodista & 462,174 & 9 & 458,623 & & 7 \\
\hline Iglesias Carismáticas independientes & 35,202 & 1 & 34,325 & & 1 \\
\hline Igls. Independientes No-carismáticas & 80,048 & 2 & 57,243 & & 1 \\
\hline Total de Adherentes & $4,992,023$ & 100 & $6,343,994$ & & 100 \\
\hline
\end{tabular}

Note: $\mathrm{ND}=$ No Información o Insuficiencia de datos. * es menos de 1/2\%. (Morton D. Winsberg, 2006, p. 63). 
en comparación con toda la nación son los Mormones, Discípulos de Cristo, Iglesia Evangélica Luterana en América y la Iglesia Luterana (Sínodo de Missouri), Iglesia Unida de Cristo y Musulmanes (Winsberg, 2006, pp. 59, 60).

Las dos denominaciones más grandes de la Florida son: Católica $(2,596,1448$ miembros) y la Convención Bautista del Sur (1,292,097 miembros), seguidos por el grupo Judío (628,458 miembros). Los católicos predominan en las áreas de Gold Coast, Sun Coast, Space Coast, Tampa-St. Petersburg, y North Gulf Coast, mientras los bautistas se hallan en la zona Peninsular interior y todo el Norte de Florida (Morton D. Winsberg, 2006, p. 60).

El mayor número de Adventistas en la Florida, según la misma fuente (p.71), se hallan mayormente en dos áreas, al Sur y en el Centro de la Florida. Según el cuadro anterior ha tenido un crecimiento del uno por ciento en 10 años, (según el mismo autor, ese ha sido el índice de crecimiento desde 1971) lo que significa que no ha llegado al ideal de crecimiento y hay mucho trabajo por hacer.

\section{La iglesia adventista hispana de Gainesville}

La Iglesia Adventista de Gainesville inicia su historia con la llegada de adventistas hispanos a la ciudad, quienes empezaron a asistir a la iglesia americana. Para el año 1988 deciden reunirse en un salón aparte y tener sus cultos en español, programando unirse una vez por mes.

Este grupo inicial estuvo formado por la familia Collado, Anatilde Delgado, su hija Betzy, Berenice e Ismael Rodríguez. En este tiempo fueron atendidos por el Pastor Germán Moreno, que al ser trasladado a otro distrito y otros inconvenientes, el grupo decide volver a reunirse con los americanos. 
En 1990 llegan nuevas familias hispanas a la iglesia, entre ellos Benito Rivera, Laura Rivera y familia, Emérita Ortiz y familia. Nuevamente cobraron ánimo para reunirse aparte, pero siempre dentro de la misma iglesia americana, en esta vez dirigidos por el Pastor Pablo Ayala y su ayudante el Pastor Israel Vásquez. El lugar de reunión fue la capilla de jóvenes, celebrando la Escuela Sabática dirigida por la hermana Laura Rivera.

El grupo de 12 y 15 personas tuvo éxito en sus reuniones, y para el año 1991 tuvieron su primer bautismo (Karla V. Rivera). En el siguiente año llegan Leonardo Rivera, la familia Vélez entre otros, haciendo posible iniciar sus propios cultos de adoración, todavía en la capilla de jóvenes de la iglesia americana. El grupo sintiéndose fuerte decidió en el año 1993 ir un paso más adelante y planificó comprar un terreno para en el futuro construir la primera iglesia hispana de Gainesville. Abrieron una cuenta bancaria con $\$ 5,000.00$ y luego de mucha búsqueda, trabajo y oración lograron comprar un terreno en la Avenida 39 por $\$ 89,000.00$.

Hubo que hacer mucho trabajo de limpieza en el terreno utilizando como "bowser" el camión de Javier Vélez, fue necesario arreglar una casita vieja, remodelando, rompiendo paredes, pintando y muchos otros detalles y ésta ha servido como santuario hasta el momento de escribirse esta tesis. Fue en mayo de 1993, con la dirección del Pastor Pablo Ayala y siendo Director de Grupo Benito Rivera, que empezó en forma oficial las reuniones en este lugar, comenzando así lo que hoy es la Iglesia Adventista Hispana de Gainesville.

El grupo inició sus actividades con alrededor de 40 personas, 12 de las cuales viajaban desde la ciudad de Ocala, entre ellos Julia Giordanni. Los hermanos que hacían 
este viaje de $\tan$ lejos, decidieron formar su propio grupo con el deseo de iniciar una nueva iglesia, esto afectó los planes del grupo de Gainesville, tanto en asistencia como financieramente. Pero Dios sigue bendiciendo el grupo y personas siguen llegando, en 1995 llegan Nesly Ream, familia López, Iris Manfield, Abdel Rodríguez; en 1997 llegan Andy y Sasha Abreu junto con su familia, familia Bonet, y familia Bonilla; en 1998 llegó la familia Contreras, familia Paz, Daniel y Naty Rivera, Carolina y Francisco Pinillos. En febrero de 1999 la junta directiva de la iglesia acordó convertirse en iglesia organizada. Es el Pastor Germán Moreno quien estaba dirigiendo el grupo y tuvo la responsabilidad de hacer este pedido a la Asociación de la Florida. Este intento de organizarse como iglesia no se llevó a cabo desafortunadamente, fallando aún en el segundo intento en el mes de junio del mismo año. El grupo siguió soñando con construir su templo y en abril de 1999, tomaron el acuerdo de refinanciar, el préstamo sea para construcción o remodelar la casa.

En agosto del 2000 se presentaron los planos y proyectos de construcción al grupo, cuyos trámites siguieron hasta abril del 2001; fue cuando se tomó la decisión de conservar la casa que servía de iglésia, y construir el templo al lado. En enero del 2003 llegó el Pastor Eddie Romero con su esposa Nélida, que fueron de ayuda para la iglesia. El Pastor logró concertar una reunión entre los líderes y el Pastor Abel Paulín con el fin de tratar acerca de la organización de la iglesia, la misma que tuvo efecto el 5 de enero del 2005.

Para febrero del 2007, llegan más bendiciones con el Pastor Byron Rivera, su esposa Ximena e hijos Elías y Byron Jr. El Pastor Rivera desarrolló su plan de trabajo teniendo dos objetivos, uno inmediato, que era el crecimiento espiritual de la iglesia, y el 
segundo objetivo a mediano plazo, que consistía en la construcción de un santuario. Para que se logre ésto, los ancianos de iglesia y la junta aceptaron los desafios y decidieron llevarlos a cabo.

Según un informe verbal que Leonardo Rivera le diera al Pastor Byron Rivera, de la iglesia de Gainesville han salido un total de tres iglesias: Marion Oaks (Ocala), Lake City y Jasper. A mediados del año 2008, nació una nueva congregación en la ciudad de Hernando, condado de Citrus, hija de la iglesia de Marion Oaks y resultando nieta de Gainesville.

El anhelo de construir un santuario estuvo latente por varios años y se acercó más cuando la municipalidad del Condado de Alachua, a fines del 2008, aprobó que la iglesia siga con el plan de construcción, lo que resultó en la búsqueda de un constructor y el desarrollo final de los planos del edificio. Mientras se escribe esta disertación, se sometieron los planos finales y otros detalles de construcción a la ciudad para ser aprobados, esperando que para fines de diciembre del 2009, el Condado de Alachua apruebe los permisos respectivos y así empezar con la construcción en los primeros meses del 2010.

Como pastor de la Iglesia de Gainesville, junto con sus líderes, el deseo es impulsar siempre la salud espiritual de la iglesia, haciendo de esto una prioridad, y como resultado se espera un aumento de nuevos miembros de iglesia.

A continuación se presenta la tabla de la historia de bautismos de la Iglesia de Gainesville en los últimos 11 años. Se necesitaron 8 años, de 1999 al 2006 para contabilizar 21 bautismos. Resalta en la tabla, que en sólo 2 años, de 2007 al 2008 se alcanzaron 21 bautismos. Y el año 2009, un record de 23 bautismos. El mayor número de 
bautismos en la historia de la iglesia se han efectuado en los últimos años. (Nota: el dato de éste último año es de carácter informativo, pues está fuera del tiempo de la investigación).

TABLA 6

BAUTISMOS DE LOS ÚLTIMOS 11 AÑOS

\begin{tabular}{|c|c|}
\hline Año & Bautismos \\
\hline 1999 & 2 \\
\hline 2000 & 6 \\
\hline 2001 & 0 \\
\hline 2002 & 0 \\
\hline 2003 & 7 \\
\hline 2004 & 0 \\
\hline 2005 & 6 \\
\hline 2006 & 1 \\
\hline 2007 & 13 \\
\hline 2008 & 18 \\
\hline 2009 & 23 \\
\hline
\end{tabular}

Nota: Datos obtenidos de los archivos de iglesia.

La feligresía ha crecido en los últimos 10 años como consta en la siguiente tabla, donde el número no refleja la asistencia real a la iglesia. El año 2008 fue un año de actualización del registro de miembros de iglesia. 


\section{TABLA 7}

\section{MEMBRESÍA DE LOS ÚLTIMOS 6 AÑOS}

\begin{tabular}{|c|c|}
\hline Año & Membresía \\
\hline 2003 & 69 \\
\hline 2004 & 71 \\
\hline 2005 & 90 \\
\hline 2006 & 100 \\
\hline 2007 & 126 \\
\hline 2008 & 145 \\
\hline
\end{tabular}

Nota: Datos obtenidos de los archivos de iglesia.

Encuesta para medir la espiritualidad de la Iglesia de Gainesville

Para llegar a un conocimiento más real acerca de la salud espiritual, la junta directiva de la Iglesia de Gainesville decidió aplicar una encuesta de diagnóstico sugerida por el Pastor Byron Rivera, la que sería elaborada con ayuda del Doctor Ricardo Norton, $\mathrm{y}$ aplicarla luego con el método de muestreo a un grupo de miembros de iglesia en áreas que abarquen la vida y práctica espiritual.

El lugar que se eligió para tomar la encuesta fue el salón de culto de la iglesia, donde se reunió al grupo que había decidido participar en el proyecto. Con la ayuda del hermano Leonardo Rivera se les hizo provisión de la hoja de encuesta y un lápiz para que la llenaran. La encuesta abarcó dos secciones, la primera recogió información general de los encuestados, y la segunda tenía que ver con la práctica espiritual de la vida de los miembros (ver Apéndice A).

Las preguntas que se formularon fueron en base al criterio general de escritores contemporáneos como Barna (1988), Spader (1991), Wagner (1996), Schwartz y Schalk 
(1996), que hablan acerca del tema de salud espiritual, como son el culto familiar, fidelidad, comunión personal y lectura de la Biblia, y participación en la actividad misionera, entre otros.

La encuesta se programó aplicarla para el mes de agosto del año 2007. El grupo que se escogió para la obtención de datos fue mixto, hombres y mujeres, de diferentes edades. Participaron 12 mujeres y 13 varones, fueron un total de 25 personas.

Los resultados fueron analizados en septiembre del 2007 con los ancianos de la iglesia y luego se presentaron a la junta de iglesia. El mes de octubre se lo dedicó a elaborar un programa para mejorar la salud espiritual de la Iglesia de Gainesville. La aplicación del programa comenzó desde noviembre del 2007, con la participación del comité aprobado por la iglesia: el Director Misionero (Tulio Velásquez) y la participación de los ancianos (Moisés Rodríguez, Rubén Contreras, Nelly Uriarte).

El programa se confeccionó de acuerdo al resultado de la encuesta, y su aplicación avanzó hasta el mes de octubre del año 2008. Fue entonces, que el mes siguiente se aplicó la encuesta de evaluación del programa.

\section{La espiritualidad de los miembros de la iglesia}

El estado de la salud espiritual de los miembros de la Iglesia de Gainesville, se obtuvo a través de la encuesta mencionada arriba con una sección de información general y un cuestionario con preguntas directas, donde los encuestados tenían que autoevaluarse entre los numerales del 1 al 5 , siendo 1 la respuesta como la más débil y 5 como la más fuerte (ver Apéndice A).

Las tablas de la 8 a la 11, contienen la información general del grupo encuestado, y desde la 12 a la 18 exponen el resultado que se obtuvo de las preguntas directas, 
revelando así la espiritualidad de la iglesia de Gainesville.

La tabla 8 señala que son 25 las personas participantes que respondieron al cuestionario, 12 mujeres y 13 varones; con un $48 \%$ de mujeres y $52 \%$ de varones, mostrando un porcentaje bastante equilibrado en cuanto a género

TABLA 8

SEXO

\begin{tabular}{|c|c|c|}
\hline Género & Participantes & Porcentaje \\
\hline Mujeres & 12 & $48 \%$ \\
\hline Hombres & 13 & $52 \%$ \\
\hline Total & 25 & $100 \%$ \\
\hline
\end{tabular}

La tabla 9 contiene las edades de los participantes. Se nota que el más alto porcentaje del grupo de muestra va entre las edades de los 41 y los 50 años de edad, con un $36 \%$, seguidos por jóvenes de entre 20 y 30 años; con $20 \%$.

TABLA 9

EDAD

\begin{tabular}{|c|c|c|}
\hline Edades & Participantes & Porcentaje \\
\hline $20-30$ & 5 & $20 \%$ \\
\hline $31-40$ & 4 & $16 \%$ \\
\hline $41-50$ & 9 & $36 \%$ \\
\hline $51-60$ & 4 & $16 \%$ \\
\hline $61-80$ & 3 & $12 \%$ \\
\hline Total & 25 & $100 \%$ \\
\hline
\end{tabular}


Se puede notar en la tabla 10 que considerando aquellos que han completado educación secundaria y universitaria, el porcentaje total de estos dos grupos da un total de $72 \%$. Es decir hay un alto número de personas que son preparadas intelectualmente, esto quizá se debe a que Gainesville es una ciudad universitaria.

TABLA 10

EDUCACIÓN

\begin{tabular}{|c|c|c|}
\hline Grado de Educación & Participantes & Porcentaje \\
\hline Primaria & 7 & $28 \%$ \\
\hline Secundaria & 14 & $56 \%$ \\
\hline Universitaria & 4 & $16 \%$ \\
\hline Total & 25 & $100 \%$ \\
\hline
\end{tabular}

La tabla 11 muestra que el día de aplicar la encuesta participaron solo personas solteras y casadas, y cabe aclarar que en la congregación hay personas, divorciadas y separadas. Sin embargo el cuadro refleja una verdad, y es que hay un alto porcentaje de personas casadas $(72 \%)$.

TABLA 11

ESTADO CIVIL

\begin{tabular}{|c|c|c|}
\hline Estado & Participantes & Porcentaje \\
\hline Casado & 18 & $72 \%$ \\
\hline Soltero & 7 & $28 \%$ \\
\hline Total & 25 & $100 \%$ \\
\hline
\end{tabular}


Las tablas a continuación corresponden a la segunda sección de la encuesta y presentan la realidad espiritual de los miembros encuestados. En la tabla 12 se puede notar que el Culto Familiar es deficiente; ya que si se observan las primeras tres categorías que son Pobre, Moderado y Bueno y se suman los porcentajes correspondientes, dan un total de $72 \%$. El culto familiar es algo fundamental para la salud espiritual de la familia y es necesario mejorar en esta área.

TABLA 12

CULTO FAMILIAR

\begin{tabular}{|c|c|c|}
\hline Categorías & Participantes & Porcentaje \\
\hline Pobre & 6 & $24 \%$ \\
\hline Moderado & 7 & $28 \%$ \\
\hline Bueno & 5 & $20 \%$ \\
\hline Muy Bueno & 5 & $20 \%$ \\
\hline Excelente & 2 & $8 \%$ \\
\hline Total & 25 & $100 \%$ \\
\hline
\end{tabular}

Las últimas dos categorías de la tabla 13 (Muy Bueno y Excelente), llegan a un total de $40 \%$ de participación misionera, sin embargo la mayoría de miembros de iglesia está en las primeras tres categorías dando un total de $60 \%$ que participan muy poco en la actividad misionera de la iglesia. Ésta, también, es un área que se necesita ser fortalecida. 
TABLA 13

PARTICIPACIÓN MISIONERA

\begin{tabular}{|c|c|c|}
\hline Categorías & Participantes & Porcentaje \\
\hline Pobre & 8 & $32 \%$ \\
\hline Moderado & 5 & $20 \%$ \\
\hline Bueno & 2 & $8 \%$ \\
\hline Muy Bueno & 4 & $16 \%$ \\
\hline Excelente & 6 & $24 \%$ \\
\hline Total & 25 & $100 \%$ \\
\hline
\end{tabular}

La tabla 14 señala que las dos últimas categorías Muy Bueno (12\%) y Excelente (28\%) combinadas, llegan a un $40 \%$, mientras el otro $60 \%$ que cubren las otras categorías refleja que los miembros participan muy pobremente en las actividades generales de la iglesia; en esta situación se hallan casi dos tercios de iglesia.

TABLA 14

PARTICIPACIÓN EN OTRAS ACTIVIDADES DE IGLESIA

\begin{tabular}{|c|c|c|}
\hline Categorías & Participantes & Porcentaje \\
\hline Pobre & 7 & $28 \%$ \\
\hline Moderado & 1 & $4 \%$ \\
\hline Bueno & 7 & $28 \%$ \\
\hline Muy Bueno & 3 & $12 \%$ \\
\hline Excelente & 7 & $28 \%$ \\
\hline Total & 25 & $100 \%$ \\
\hline
\end{tabular}


La fidelidad en los diezmos de los miembros participantes, según la tabla 15 , es bastante aceptable, ya que tomando en cuenta la última categoría, que es la ideal (Excelente), llegan al 48\%, si a ésta se le suma el porcentaje de la que le sigue en fidelidad (Muy Bueno), da un total combinado del $72 \%$. Lo que significa que la fidelidad respecto a los diezmos es buena en términos generales. Sin embargo hay un margen de infidelidad que llega al $28 \%$ sumando las tres primeras categorías.

TABLA 15

DIEZMO

\begin{tabular}{|c|c|c|}
\hline Categorías & Participantes & Porcentaje \\
\hline Pobre & 3 & $12 \%$ \\
\hline Moderado & 1 & $4 \%$ \\
\hline Bueno & 3 & $12 \%$ \\
\hline Muy Bueno & 6 & $24 \%$ \\
\hline Excelente & 12 & $48 \%$ \\
\hline Total & 25 & $100 \%$ \\
\hline
\end{tabular}

La tabla 16 señala que solo la última categoría (Excelente) presenta el $60 \%$ de fidelidad en relación a las ofrendas, mientras el otro $40 \%$ no es fiel en sus ofrendas de gratitud y dadivosidad. La fidelidad en cuanto a las ofrendas reflejan que casi dos tercios de los miembros son agradecidos, lo cual es aceptable por los fieles, pero queda todavía un $40 \%$ que deben mejorar su dadivosidad. 
TABLA 16

\begin{tabular}{|c|c|c|}
\hline Categorias & Participantes & Porcentaje \\
\hline Pobre & 2 & $8 \%$ \\
\hline Moderado & 4 & $16 \%$ \\
\hline Bueno & 1 & $4 \%$ \\
\hline Muy Bueno & 3 & $12 \%$ \\
\hline Excelente & 15 & $60 \%$ \\
\hline Total & 25 & $100 \%$ \\
\hline
\end{tabular}

La tabla 17 presenta el resultado de la encuesta en la práctica de la oración, y muestra que la mitad de los miembros de iglesia es Excelente (52\%). Sin embargo al sumar los porcentajes de las otras características hay un $48 \%$ de los miembros, a quienes les hace falta crecer en el área de la Oraciọ́n y devoción personal.

TABLA 17

\begin{tabular}{|c|c|c|}
\hline Categorias & Participantes & Porcentaje \\
\hline Pobre & 1 & $4 \%$ \\
\hline Moderado & 2 & $8 \%$ \\
\hline Bueno & 7 & $28 \%$ \\
\hline Muy Bueno & 2 & $8 \%$ \\
\hline Excelente & 13 & $52 \%$ \\
\hline Total & 25 & $100 \%$ \\
\hline
\end{tabular}


Finalmente, el resultado de la tabla 18 refleja que el sumado de las primeras tres categorías (60\%), son miembros que necesitan mejorar en el área de la Lectura de la Biblia, siendo este un resultado negativo, ya que destaca que cerca de dos tercios de la feligresía sufren de este problema. Esta área es determinante y fundamental para mantener una buena salud espiritual tanto personal como congregacional.

TABLA 18

LECTURA DE LA BIBLIA

\begin{tabular}{|c|c|c|}
\hline Categorías & Participantes & Porcentaje \\
\hline Pobre & 6 & $24 \%$ \\
\hline Moderado & 5 & $20 \%$ \\
\hline Bueno & 4 & $16 \%$ \\
\hline Muy Bueno & 3 & $12 \%$ \\
\hline Excelente & 7 & $28 \%$ \\
\hline Total & 25 & $100 \%$ \\
\hline
\end{tabular}

El resultado de la encuesta finalmente arroja 4 áreas definidas con necesidad de crecimiento que son culto familiar, participación en la actividad misionera, falta de participación en las actividades generales de la iglesia y por último falta de la lectura de la Biblia. La siguiente sección trata acerca de un Programa para envigorizar la salud espiritual de la Iglesia de Gainesville, cuyo contenido irá llenando las deficiencias halladas en la encuesta. 


\section{Descripción del programa}

Esta sección describe los protocolos, la naturaleza y contenido relacionados al programa de mejoramiento espiritual. La primera parte presenta los protocolos seguidos para la creación del programa; la segunda presenta la naturaleza del programa y la tercera provee una descripción del formato y contenido para este programa

La primera parte de Protocolos y aprobación tiene como fin informar acerca de quienes fueron las personas que conformaron el comité que estuvo involucrado en las decisiones para elaborar el programa de mejoramiento espiritual, también cuáles fueron las personas participantes en el programa y finalmente, fechas, lugares y horas y cuánto tiempo de duración tuvo el programa.

La segunda parte de esta sección, La Naturaleza del Programa, tiene como objetivo exponer lo que el comité y la junta de iglesia decidieron usar para el mejoramiento espiritual de la feligresía, en este caso, la creación de un programa que constó de dos partes: “Amanecer con Dios” y formación de células.

La última parte corresponde a Contenido del programa que presenta el programa desarrollado de la manera cómo fue implementado. "Amanecer con Dios" consta de 3 partes: la primera contiene 10 días de poder, la segunda, cadena familiar de oración, y la tercera, plan de oración anual. Por otra parte describe cómo se formaron las células, el trabajo realizado en ellas. Además describe cómo se hizo el reclutamiento de líderes y su capacitación como parte de la formación de las células, temas que se dieron, lugar y hora de reuniones y quienes asistieron. 


\section{Protocolos y aprobación}

Los resultados de la encuesta revelaron que la iglesia estaba débil en 4 áreas espirituales: tales como culto familiar, participación en la actividad misionera, falta de participación en las actividades generales de la iglesia, y por último falta de la lectura de la Biblia. El informe fue presentado a la junta de la iglesia y se tomó el acuerdo de elaborar un programa de mejoramiento espiritual.

La directiva de la iglesia acordó que el comité a trabajar en la elaboración y aplicación del programa sea formado por el Director Misionero (Tulio Velásquez) y la participación de los ancianos (Moisés Rodríguez, Rubén Contreras, Nelly Uriarte), dirigidos por el pastor de la iglesia.

El mes de octubre fue dedicado a elaborar un programa para mejorar la salud espiritual de la Iglesia de Gainesville. Se planificó la aplicación del programa para que tenga la duración de un año, comenzando en el mes de noviembre del 2007 hasta Octubre del 2008.

\section{Naturaleza del programa}

En base a las decisiones tomadas por la junta directiva de la iglesia, el comité nombrado, la literatura analizada en esta investigación acerca de las características de una iglesia saludable y el análisis de la encuesta realizada, se optó por desarrollar un programa de mejoramiento espiritual. Este programa está formado por 2 partes: "amanecer con Dios" y "formación de células", que incluyeron aspectos relacionados con devoción y oración y obra misionera.

Devoción y oración. Las actividades de oración y consagración fueron realizadas en las instalaciones de la iglesia y en los hogares de los miembros, así, las personas que 
no podían asistir a la iglesia tuvieron la oportunidad de participar en la oración con miembros del vecindario. Esta parte del programa se llamó: “Amanecer con Dios”.

"Amanecer con Dios" ayudó a mejorar las deficiencias encontradas en cuanto al culto familiar, lectura de la Biblia y práctica de la oración. Consistió en " 10 días de poder" que se repitió en mayo del 2008, con temas y versículos bíblicos para cada día (ver Apéndice C); también consistió en una "cadena de oración familiar" con duración de un mes; y finalmente una "cadena de oración diaria".

Formación de células. La formación de células empezó con el reclutamiento de líderes y su capacitación como tales. El reclutamiento se inició con un llamado personal a un grupo de miembros por el pastor de la iglesia, quienes reunían tres características básicas: eran espirituales, participaban de la obra misionera y eran responsables. Luego, en un sermón de sábado, se hizo un llamado a todos los que tuvieran interés en prepararse como líderes.

Los temas de capacitación que se presentaron fueron tomados del capítulo 2 de esta tesis y fueron los siguientes: características del discípulo (líder), el discípulo y los dones espirituales, Cristo y el discípulo, el discípulo y la obra misionera, cómo organizar y dirigir una célula (ver Apéndice D).

Una vez que los líderes fueron reclutados y capacitados, se inició la formación de grupos pequeños. La organización de las células se llevó a cabo con el apoyo del comité nombrado para trabajar en el programa de mejoramiento espiritual de la iglesia. La lista de miembros de iglesia sirvió para formar 11 células por sectores geográficos, tomando en cuenta los lugares donde viven los miembros de la iglesia. A cada célula le fue 
asignada un líder como director de la célula a quien se les dio el título de "pastor de célula".

\section{Contenido del programa}

El contenido del programa fue elaborado tomando en cuenta los factores que mas necesitaban mejoramiento, los mismos que fueron revelados en el análisis de datos de la encuesta, éstos fueron culto familiar, participación en la actividad misionera, falta de participación en las actividades de la iglesia y por último falta de lectura de la Biblia.

Las dos partes sobre los cuales estuvo basado el programa de mejoramiento espiritual, fueron "Amanecer con Dios" y Formación de células. Estos puntos contienen las áreas espirituales con necesidad de mejorar ya mencionadas en el párrafo anterior.

El procedimiento que se siguió para la elaboración del programa empezó con el comité que la junta había designado, el que luego de analizar lo que era mejor para la iglesia, decidió presentar el plan sugerido en el párrafo anterior.

El programa "amanecer con Dios" consiste en lo siguiente: Primero, en "10 días de poder I" (ver Apéndices B y C), 10 días por las madrugadas (noviembre); En mayo se repitió "10 días de poder (fase II); segundo, "cadena de oración familiar" por un mes", consistió en que cada familia debía escoger un día al mes para orar por peticiones familiares y por una lista de peticiones hechas en la iglesia; tercero, "cadena de oración todo el año", consistió en orar todos los días a las $10 \mathrm{pm}$.

La oración y la comunión con Dios (a través del estudio de la Biblia) es una característica que debe acompañar a todo cristiano y sobre todo a los líderes, primero por ser cristianos y luego por su gran responsabilidad tanto con la familia como en la vida de la iglesia y la comunidad. 
El objetivó de este programa fue que la feligresía se motive a leer más la Biblia y practicar más la oración, de este modo su vida cristiana pueda ser victoriosa y así, otros que no conocen de Dios puedan ver las bendiciones de esta práctica y puedan unirse a la iglesia.

La "formación de células" empezó con el reclutamiento de líderes en noviembre del 2007, se tuvieron reuniones de orientación general previas a la capacitación oficial qùe tuvo lugar desde noviembre. La descripción del reclutamiento y la capacitación se presentará en la sección de implementación del programa. El inicio de las células, se llevó a cabo con ayuda de los líderes voluntarios que recibieron capacitación. Estuvieron conformadas por miembros que decidieron aceptar el desafio a ser espiritualmente más saludables (marzo 2008). Los detalles como son los lugares de reunión, días y horas se hallan en el siguiente capítulo. 


\section{CAPÍTULO 4}

\section{IMPLEMENTACIÓN Y EVALUACIÓN DEL PROGRAMA}

Este capítulo tiene como objetivo describir el proceso de la implementación, desarrollo y evaluación del programa. Empieza con la descripción e inauguración de "Amanecer con Dios", siguiendo luego la "formación de células", mostrando cada aspecto del programa en forma más detallada. Se determinan los horarios, lugar de reunión, líderes que participan, materiales y recursos usados en el proceso.

Una vez que la junta de iglesia aprobó llevar a cabo el programa de mejoramiento espiritual, decidió hacer la promoción respectiva en todas las reuniones de iglesia para que participe la mayor parte de la congregación; para esto, tanto el pastor como el comité nombrado por la junta delegaron la tarea a los ancianos para que sean los responsables de dicha promoción en cada reunión de iglesia.

\section{Inauguración de "Amanecer con Dios".}

La actividad “Amanecer con Dios” (ver Apéndice B), se inauguró en su primera fase, "10 días de poder I", en el mes de noviembre del 2007, fue el inicio de un proyecto mucho más amplio, pues siguió una cadena familiar de oración por un mes, y luego de 6

\footnotetext{
${ }^{2}$ Nota: Este término fue usado por su función multiplicadora en el cuerpo humano. Este efecto multiplicador constituye una metáfora muy apropiada en la multiplicación de células misioneras en el cuerpo de la iglesia de Gainesville.
} 
meses, se volvió a celebrar los “10 días de poder" en mayo del 2008. Finalmente, se llevó a cabo un plan de oración diario, dirigido por el ministerio de damas y la directora de oración.

Este programa llevó a los miembros a practicar más la devoción personal, familiar y congregacional. Incluyó alabanza, estudio y oración. Por este medio la iglesia se fortaleció grandemente tratando de llegar a una salud espiritual integral, como se registra en (3 Jn. 2). Previo a la semana de los 10 días, el comité nombró comisiones que se encargaron de la música, de proveer de los materiales didácticos necesarios, y de refrigerio para cada mañana.

El pastor elaboró un programa sugerente a seguir durante los diez días (ver Apéndice B). Este programa estuvo elaborado para tener una duración de 1 hora. Para empezar hubieron alabanzas por 10 minutos, luego oraciones personales por 10 minutos; esto para motivar a los miembros a dedicar más tiempo a la oración personal; luego se dio tiempo para la lectura de la Palabra y meditación del tema sugerente para ese día, esto tomó 10 minutos. De acuerdo al tema y a la porción bíblica, se dedicó tiempo para compartir testimonios en grupos de tres, esto en 10 minutos, luego estos grupos dedicaron tiempo para orar, esto fue en 5 minutos.

La parte final del programa incluyó de 5 minutos alabanzas y nuevamente se dio a los miembros tiempo para la oración personal por 10 minutos, afirmando de esta manera la importancia de la oración personal. La comisión de desayuno tuvo para cada día un desayuno sencillo y nutritivo para las personas que tuvieran tiempo para tomarlo.

Durante la semana de "10 días de poder" se escribieron oraciones de gratitud y peticiones en un rollo de papel que se iba estirando a medida que las oraciones iban 
siendo escritas. Todos los días se oró por esas peticiones. Al finalizar los 10 días, se dio la oportunidad de testificar y agradecer por las oraciones contestadas. Se finalizó con una oración de gratitud y se quemó el rollo con las oraciones escritas.

La primera fase de "10 días de poder" estuvo dirigida en su totalidad por el pastor de iglesia, mientras la segunda fase fue dirigida por los ancianos de iglesia, quienes realizaron una excelente tarea. Como parte del programa, la iglesia nombró una directora de oración para fortalecer esta práctica cristiana. La persona nombrada fue la hermana Ramonita Alburquerque, quien comenzó a participar en todos los eventos que la iglesia realizó.

En conjunto con el Departamento de Damas, el ministerio de oración estableció una hora específica de oración (10:00 pm) para todo el año, donde las damas y toda persona que desee unirse de la iglesia está involucrada en una oración diaria, pidiendo por peticiones especiales. Las damas tienen un registro fiel de peticiones, como también de oraciones contestadas.

En marzo del 2008, se publicó un calendario grande para que cada familia o individuo escoja un día del mes para participar en la cadena de oración por peticiones previamente hechas en los miércoles de oración, sean éstas personales, familiares, congregacionales o de intercesión.

Lugar de reunión

El programa "Amanecer con Dios" se realizó mayormente en la iglesia y en los hogares; el santuario se usó especialmente para los "10 días de poder", ya que era el lugar más cómodo para la actividad. El edificio de la "iglesia" es actualmente una casa 
transformada en santuario. La "cadena de oración familiar" y la "cadena de oración diaria", se realizaron en los hogares.

El ministerio de damas trabajó estrechamente con el ministerio de oración, se reunieron en la iglesia, sea en el santuario o una de las aulas dependiendo de las actividades que la iglesia tenga en ese sábado. El mes de la cadena de oración (marzo, 2008), se recomendó que las oraciones se hagan en los hogares de los miembros primariamente o donde les sea más conveniente hacerlo, ya que la actividad no estaba enmarcada en hora ni lugar específicos.

Horario de reunión

Durante los "10 días de poder", la hora de reunión empezaba a las 5:30 de la madrugada, y terminaba a las 6:30 am. Dependiendo de las personas y sus ocupaciones, algunos se quedaban para participar del desayuno.

El mes de la "cadena de oración familiar", la hora de oración quedó a criterio de cada familia o miembro de iglesia; y la "cadena de oración diaria", el ministerio de oración y el ministerio de damas establecieron su cadena de oración fija a las 10:00 pm de todos los días.

\section{Materiales y equipo}

En “Amanecer con Dios”, el sonido fue operado por los diáconos encargados de la iglesia, se usó la Biblia para las meditaciones, además se utilizaron marcadores de color y papel para escribir las peticiones y gratitud. Para las alabanzas, se usó el equipo de sonido, el video proyector y la computadora de la iglesia. 


\section{Formación de células}

Algunos autores contemporáneos, como Larry Stockstill, C. Peter Wagner, Kent Hunter, Aubrey Malphurs, Harold Percy, Christian A. Schwarz y otros, concuerdan que una de las características de una iglesia saludable es que están divididas en grupos o células, por lo tanto, el pastor de la iglesia recomendó este método como parte del programa de mejoramiento espiritual de la iglesia de Gainesville. Cabe señalar que el Departamento Hispano de la Asociación de la Florida también lo estaba promoviendo entre los pastores hispanos.

\section{Elección de líderes}

El equipo encargado del programa se reunió en el mes de Octubre y decidió seguir el método de elección dirécta de líderes para la implementación de la formación de células. De éste reclutamiento se hizo cargo el pastor de la iglesia por pedido del comité. Las características que se buscaron fueron que sean espirituales, que les guste la obra misionera y sean responsables.

Algunos de estos hermanos por testimonio ya estaban participando de las actividades de iglesia, demostrando ser fervientes en el estudio de la Biblia y la oración, dando buen testimonio a los de adentro de la iglesia como de los de afuera. Tenían el deseo de desarrollar sus dones para ser efectivos en el servicio. Mostraban amor por las almas que llegaban a la iglesia como visitas, igual que con las de afuera.

\section{Capacitación de líderes}

La capacitación se llevó a cabo desde el mes de noviembre (2007), con todos los líderes reclutados, quienes primero fueron instruidos con los temas extraídos del capítulo 
2 de esta tesis, como ya se mencionó en la sección de la "naturaleza del programa" (ver Apéndice D). Se determinó un período de tiempo para estos temas con una duración total de 4 meses: noviembre (2007) a febrero (2008). Al grupo de los reclutados se unieron otros miembros de iglesia que se interesaron en recibir la capacitación ofrecida, teniendo ,un promedio de 24 participantes.

Cada reclutado recibió en cada sesión de estudio copias del material estudiado, el mismo que se lo analizó en detalle. El material en referencia se menciona en el primer párrafo de esta sección. Además se hizo provisión de algunas porciones de literatura que los ayudó en su preparación personal como "Spiritual Body Building" de Kim Johnson, "La iglesia celular" de Larry Stockstill, "Una iglesia con propósito" de Rick Warren, "Persuasión cristiana" de Ricardo Norton y bibliografia para que tengan material de estudio.

En un sermón especial el primer sábado de marzo (2008) hice un llamado a la iglesia para participar de la formación de células. Los que respondieron al llamado para este desafío fueron 90 miembros ( $80 \%$ de la feligresía), entre los cuales estuvieron los que más tarde serían los "anfitriones", ofreciendo sus casas para celebrar las reuniones.

El comité del programa de enriquecimiento espiritual organizó 11 células bajo la dirección de 11 líderes escogidos con sus respectivos anfitriones. A continuación, se presenta la lista de líderes, anfitriones y el nombre que cada grupo le dio a su célula.

El esquema a seguir en cada reunión fue como se presenta en el Apéndice F. Se entregó este modelo de programa con el fin de que los líderes tengan una guía a seguir en las reuniones, pero no sin dejarles en libertad que hicieran ajustes y cambios según lo creyeran conveniente. El esquema constó de cuatro partes: 1. tiempo de alabanzas, 2. 
tiempo de testimonios y oración, 3. tiempo de meditar en la Biblia, 4.tiempo de confraternizar.

\begin{tabular}{|c|c|c|}
\hline Líder & Anfitrión & Célula \\
\hline Tulio Vásquez & Estella \& Omar Paz & Embajadores del Rey \\
\hline Darío Rivera & Zoila Padilla & Esperanza \\
\hline Felipe Vásquez & Ramón Díaz & Monte Sión \\
\hline Moisés Rodríguez & Moisés Rodríguez & Maranata \\
\hline Josué Hernández & Humilde Durán & Renuévame \\
\hline William Castillo & William Castillo & Arqueros de Cristo \\
\hline Nelly Uriarte & Lili Rosales & Tribu de Judá \\
\hline Raúl Rivera & Elizabeth Rivera & Roca de la eternidad \\
\hline Saraín Roblero & José Gutiérrez & Advenimiento \\
\hline Rubén Contreras & Andy \& Sasha Abreu & Mensajeros de la verdad \\
\hline Leonardo Rivera & Blanca Hernández & Pregoneros de Sión \\
\hline
\end{tabular}

Los grupos celulares fueron no más grandes de 12 personas, de acuerdo a su ubicación geográfica. Los líderes estaban listos para comenzar su trabajo pastoral poniendo en práctica todo lo aprendido. Se les entregó una forma (ver Apéndice G) la misma què cubrió dos objetivos: el primero de que el pastor de la iglesia y el comité tuvieran un registro y control de cada célula para dar seguimiento y orientación; y el segundo, que los líderes llevaran un control de los asistentes y pudieran dar la atención pastoral necesaria.

El mes de marzo fue de organización y planificación interna de las células, luego siguieron reuniéndose por 2 meses (abril y mayo), estudiando algunos de los temas dados 
a los líderes en su entrenamiento. Esto trajo unidad a la célula, unió criterios, se resolvieron problemas y los unió finalmente la ganancia de almas.

Las primeras reuniones fueron de ajuste y acercamiento entre los miembros de la célula. Los que asistieron primariamente en los primeros meses fueron miembros de iglesia, pues se esperaba que primero existiera una adaptación de grupo, para brindar luego a las visitas un ambiente de amor y compañerismo. Se instruyó a los líderes de célula que, si al iniciar las células vienen visitas, se debería aceptarlas con mucho amor y teniendo cuidado de lo que se dice y hace en la célula, pues lo que se desea es que se enamoren de la célula por lo que ésta ofrece: amistad, amor, cuidado, y esperanza en la Palabra de Dios.

Cada célula nombró una directiva formada con directores de alabanza, oración, testimonios, obra misionera, niños, actividades sociales y tesorero. De esta manera, se involucró a la mayoría de los miembros de célula a no ser miembros pasivos sino activos en el grupo; esto se hizo considerando los dones de los miembros.

Cuando la célula estuvo compenetrada y los miembros espiritualmente listos, entonces se hicieron oficialmente invitaciones a personas no creyentes para que vengan a beneficiarse de estas reuniones familiares y de compañerismo. Se estudió entre otras series la "Fe de Jesús" y "Nuevos Horizontes". Definitivamente, esto produjo conversiones y los miembros de célula comenzaron a experimentar el gozo de ser ganadores de almas.

En el mes de agosto (2008), las células comenzaron a dirigir los cultos de los miércoles de oración, haciendo posible que casi todos los miembros de las células puedan participar, sea dando la bienvenida, dirigiendo una oración, dando un especial, teniendo 
el tema de meditación. Esto fue un éxito, ya que hermanos que nunca habían participado comenzaron a convertirse en miembros activos.

Lo interesante fue que los nuevos miembros que iban bautizándose, comenzaron su experiencia en la iglesia participando activamente tanto en las células como en las actividades regulares de la iglesia. Con respecto a los miércoles de oración, el promedio de asistencia a la iglesia había sido de un promedio de 35 personas, pero en esta etapa la asistencia ascendió a más de 80 miembros.

La asistencia a las células fue de 110 personas en promedio, haciendo que esta actividad se convierta en una necesidad en la vida de la iglesia de Gainesville; pues no sólo fue un centro de crecimiento espiritual sino un centro de entrenamiento para participar en todas las actividades.

Además se hizo un calendario para que las células fueran responsables, una vez por mes, de realizar una reunión social, proveyendo un refrigerio. Esta última actividad tuvo un poco de dificultades por cuanto la Sociedad de Jóvenes a veces tenía actividades que se extendían más tiempo de lo que debían.

\section{Lugar de reunión}

Las reuniones de capacitación a los primeros líderes que fueron escogidos, fueron en el santuario de la iglesia, y ocasionalmente las áulas de los niños, según lo ameritaba la ocasión. Las reuniones de entrenamiento a los miembros que aceptaron el llamado de mejorar su vida espiritual y participar del programa de la formación de células, recibieron instrucción también en la iglesia. Las reuniones de las células se llevaron a cabo en los hogares de los hermanos que ofrecieron sus hogares. 


\section{Horario de reunión}

Los días propicios para las clases de capacitación fueron los sábados y los días de culto, siendo que de esta manera se garantizaba la asistencia del mayor número de participantes. Las horas de reunión eran las tardes de los sábados (4 pm) y algunos miércoles antes del culto de oración (6:30 pm).

Las células tuvieron la libertad de escoger un día de la semana para celebrar sus reuniones, la hora de reunión osciló entre las 7 pm y las 8 pm., con excepción de los días sábados y miércoles; de esta manera los miembros de cada célula se sentían cómodos y comprometidos con ellos mismos pues fueron ellos los que decidieron el día de reunión. De esta forma, el pastor de la iglesia tuvo la oportunidad de visitar las células, dar su apoyo y orientar cuando era necesario.

\section{Materiales}

Para que los grupos pequeños funcionaran adecuadamente en los hogares, se les proveyó materiales didácticos como libros y folletos de estudio y lapiceros, además se usaron Biblias, DVD con cantos, DVD players, televisores, series como la "Fe de Jesús" entre otros. Los materiales usados en la iglesia para la capacitación de los líderes fueron DVD con cantos, pantalla, hojas con cantos, himnario, Biblia, copias de los temas presentados (ver Apéndice D).

\section{Evaluación del programa}

Se realizó la evaluación del programa con el fin de medir el efecto del mismo en la espiritualidad de los participantes (ver Apéndice A). Esta sección describe el proceso 
que se siguió para la evaluación del programa de mejoramiento espiritual aplicado en la iglesia de Gainesville, cuándo se aplico dicha evaluación y cuáles fueron los resultados.

\section{Aplicación de la encuesta}

La evaluación fue aplicada inmediatamente después de la implementación de los grupos celulares. Las personas que participaron en la evaluación fueron las mismas que llenaron la primera encuesta. Para preservar el anonimato, las encuestas fueron presentadas con la instrucción de que no escribieran sus nombres, tal como se realizó la primera vez.

Se invitó a los participantes a una reunión especial para esta evaluación en el mismo salón de culto de la iglesia. Esta encuesta tuvo el mismo contenido que la primera, es decir, información general de los encuestados y segundo, información de su vida espiritual. En esta oportunidad, el hermano Benito Rivera ayudó en la aplicación de la encuesta. A continuación se presentan las tablas con los resultados.

Resultados y tablas de evaluación

Los resultados evaluativos se expusieron antes de cada tabla para que el lector tenga una mejor apreciación de lo que el cuadro dice. En las tablas que se presentan a continuación, se añadieron los datos de la primera encuesta para tener una idea más clara del resultado del programa implementado en la iglesia de Gainesville. De esta manera se pudo hacer un análisis comparativo del "antes" y "después" del programa.

Al aplicar el programa, la intención era que los resultados que fueron negativos en la primera encuesta pudieran revertirse. Así, en la encuesta de evaluación, los porcentaje 
de las tres primeras categorías deben bajar idealmente. En cambio en las dos últimas categorias, lo ideal es que el porcentaje suba.

En la tabla 19, referente al Culto Familiar, se encontró una mejora en cuatro de las cinco categorías. En la primera categoría (Pobre), disminuyó un 4\% en forma positiva en cuanto al Culto Familiar. La segunda categoría (Moderado), bajó un 20\% positivamente. La tercera categoría también bajo un $4 \%$ pero negativamente, sin embargo, se nota que ese mismo $4 \%$ se aumenta en forma positiva en la siguiente categoria (Muy Bueno). Finalmente se notó una mejora significativa en la última categoria (Excelente), con aumento del $24 \%$ en relación a la encuesta original.

TABLA 19

CULTO FAMILIAR Los números representan porcentajes

\begin{tabular}{|c|c|c|c|}
\hline Categorias & Antes & Después & Diferencia \\
\hline Pobre & 24 & 20 & 4 \\
\hline Moderado & 28 & 8 & 20 \\
\hline Bueno & 20 & 16 & 4 \\
\hline Muy Bueno & 20 & 24 & -4 \\
\hline Excelente & 8 & 32 & -24 \\
\hline Total & 100 & 100 & \\
\hline
\end{tabular}

La tabla 20 muestra que la Participación Misionera en las categorías segunda (Moderado) y última (Excelente), cambiaron a un 4\% negativo, mientras las categorías primera (Pobre) y tercera (Bueno), aumentaron un $16 \%$ en forma positiva, quedando la 
cuarta en el mismo estado del resultado en la primera encuesta. Se nota que los cambios ocurridos negativamente en la primera y quinta categoría se trasladaron positivamente a la categoría del medio (Bueno). En forma general se nota un cambio positivo.

TABLA 20

PARTICIPACIÓN MISIONERA

Los números representan porcentajes

\begin{tabular}{|c|c|c|c|}
\hline Categorías & Antes & Después & Diferencia \\
\hline Pobre & 32 & 16 & 16 \\
\hline Moderado & 20 & 24 & -4 \\
\hline Bueno & 8 & 24 & -16 \\
\hline Muy Bueno & 16 & 16 & 0 \\
\hline Excelente & 24 & 20 & +4 \\
\hline Total & 100 & 100 & \\
\hline
\end{tabular}

En relación a la tabla 21, Participación en otras actividades de iglesia, la primera categoría (Pobre) presenta una mejora, ya que bajó de una participación pobre del $28 \%$ al $16 \%$, resultando en un cambio positivo del $12 \%$, la segunda categoría (Moderado) se mantiene igual, la tercera categoría (Bueno) mejoró en un 4\%, la cuarta categoría (Muy Buena) subió de un $12 \%$ de participación a $28 \%$, con una mejora del $16 \%$, y por último la categoría de Excelente se mantuvo en la misma participación. Como se puede notar, hubo un cambio notable en los miem tabla 21 , tabla 21, bros en relación a esta área.

Respecto de los Diezmos, el producto de la evaluación mostró que hubo cambios en dos categorías. La primera categoría (Pobre), que tenía un $12 \%$ de participación pobre", disminuyó en el resultado a $8 \%$, habiendo una diferencia positiva de 4\%; la otra 
TABLA 21

PARTICIPACIÓN EN OTRAS ACTIVIDADES DE IGLESIA Los números representan porcentajes

\begin{tabular}{|c|c|c|c|}
\hline Categorías & Antes & Después & Diferencia \\
\hline Pobre & 28 & 16 & 12 \\
\hline Moderado & 4 & 4 & 0 \\
\hline Bueno & 28 & 24 & 4 \\
\hline Muy Bueno & 12 & 28 & -16 \\
\hline Excelente & 28 & 28 & 0 \\
\hline Total & 100 & 100 & \\
\hline
\end{tabular}

“categoría (Bueno) que presentó cambio pasó de $12 \%$ a $16 \%$, subiendo un $4 \%$ de fidelidad positiva. Las otras categorias se mantuvieron iguales, mostrando de esta forma que la fidelidad en los diezmos mejoraron. Hay que destacar que la fidelidad entre las dos últimas categorías suma $72 \%$ de fidelidad y esto es muy significativo para la salud espiritual de la iglesia.

TABLA 22

DIEZMO

Los números representan porcentajes

\begin{tabular}{|c|c|c|c|}
\hline Categorías & Antes & Después & Diferencia \\
\hline Pobre & 12 & 8 & 4 \\
\hline Moderado & 4 & 4 & 0 \\
\hline Bueno & 12 & 16 & -4 \\
\hline Muy Bueno & 24 & 24 & 0 \\
\hline Excelente & 48 & 48 & 0 \\
\hline Total & 100 & 100 & \\
\hline
\end{tabular}


La tabla a continuación demuestra que hubo cambios positivos en cuanto a las Ofrendas. Las cuatro categorías primeras reflejaron un aumento de la fidelidad. La primera categoría mejoró un $4 \%$; la segunda, un $8 \%$; la tercera, un $12 \%$; y la cuarta, un 8\%; disminuyendo la ultima un $8 \%$. El aumento de las "ofrendas" fue sustancial como fruto de la mejora espiritual de la iglesia, aunque siempre quedan desafios por alcanzar.

TABLA 23

OFRENDAS

Los números representan porcentajes

\begin{tabular}{|c|c|c|c|}
\hline Categorías & Antes & Después & Diferencia \\
\hline Pobre & 8 & 4 & 4 \\
\hline Moderado & 16 & 8 & 8 \\
\hline Bueno & 4 & 16 & -12 \\
\hline Muy Bueno & 12 & 20 & -8 \\
\hline Excelente & 60 & 52 & +8 \\
\hline Total & 100 & 100 & \\
\hline
\end{tabular}

La salud espiritual requiere la práctica de la Oración, y lo que la siguiente tabla presenta es que la iglesia mejoró en esta área importante. Las primeras cuatro categorías señalaron que los miembros avanzaron en este aspecto. Así, la primera categoría mejoró en un $4 \%$, la segunda en un $8 \%$, la tercera en un $16 \%$, la cuarta en un $32 \%$ y la quinta categoría disminuyendo un 4\%. Definitivamente el resultado fue positivo.

Finalmente, la tabla 25 presenta las mejoras que hubo en la Lectura de la Biblia, y destaca el cambio positivo en todas las categorías. Así, en la primera categoría (Pobre), de $24 \%$ que no leían la Biblia, bajo a $0 \%$, teniendo un aumento positivo del $24 \%$; la 
TABLA 24

ORACIÓN

Los números representan porcentajes

\begin{tabular}{|c|c|c|c|}
\hline Categorías & Antes & Después & Diferencia \\
\hline Pobre & 4 & 0 & 4 \\
\hline Moderado & 8 & 0 & 8 \\
\hline Bueno & 28 & 12 & 16 \\
\hline Muy Bueno & 8 & 40 & -32 \\
\hline Excelente & 52 & 48 & +4 \\
\hline Total & 100 & 100 & \\
\hline
\end{tabular}

categoría de Moderado bajo del $20 \%$ al $12 \%$, obteniendo un cambio positivo del $8 \%$; la tercera categoría (Bueno) subió del $16 \%$ al $32 \%$, con un cambio de mejoramiento del $16 \%$; la cuarta categoría (Muy Bueno), tuvo una mejoría del 12\%; y por último, la categoría Excelente obtuvo un aumento del $4 \%$.

TABLA 25

LECTURA DE LA BIBLIA

Los números representan porcentajes

\begin{tabular}{|c|c|c|c|}
\hline Categorías & Antes & Después & Diferencia \\
\hline Pobre & 24 & 0 & 24 \\
\hline Moderado & 20 & 12 & 8 \\
\hline Bueno & 16 & 32 & -16 \\
\hline Muy Bueno & 12 & 24 & -12 \\
\hline Excelente & 28 & 32 & -4 \\
\hline Total & 100 & 100 & \\
\hline
\end{tabular}


La tabla 26, que se presenta a continuación, es un resumen de las diferencias entre la encuesta de diagnóstico y la evaluación realizada, luego que se aplicó el programa de mejoramiento espiritual.

En esta tabla, se puede apreciar objetivamente la efectividad del programa implementado. Las dos primeras categorías (Pobre y Moderada) y las dos últimas (Muy Buena y Excelente) muestran resultados positivos. Esto se observa en las diferencias que se anotaron. En estas dos categorías se puede notar que sólo en el área de "participación misionera" hay un negativo (-4). Las dos últimas categorías también muestran su resultado positivo, aunque hay tres áreas que arrojaron un resultado no tan bueno $(+4$ en $\mathrm{PM},+8$ en $\mathrm{OF},+4$, en $\mathrm{O}$ ). Aunque tienen signo positivo, en la interpretación de la tabla se significa lo opuesto), sin embargo debe señalarse que en Culto familiar hay un resultado muy positivo.

TABLA 26

DIFERENCIAS

Los números representan porcentajes

\begin{tabular}{|c|c|c|c|c|c|c|c|}
\hline Categorías & CF & PM & POAI & D & OF & O & LB \\
\hline Pobre & 4 & 16 & 12 & 4 & 4 & 4 & 24 \\
\hline Moderado & 20 & -4 & 0 & 0 & 8 & 8 & 8 \\
\hline Bueno & 4 & -16 & 4 & -4 & -12 & 16 & -16 \\
\hline Muy Bueno & -4 & 0 & -16 & 0 & -8 & -32 & -12 \\
\hline Excelente & -24 & +4 & 0 & 0 & +8 & +4 & -4 \\
\hline
\end{tabular}

$\mathrm{CF}=$ Culto Familiar; $\mathrm{PM}=$ Participación Misionera; POAI=Participación en otras áreas de la iglesia; $\mathrm{D}=$ Diezmo; $\mathrm{OF}=\mathrm{O}$ frenda; $\mathrm{O}=$ Oración; $\mathrm{LB}=$ Lectura de la Biblia.

Las áreas en las que había que mejorar según la encuesta de diagnóstico fueron:

Culto familiar, Participación misionera, Falta de participación en las actividades de la 
iglesia y Falta de la lectura de la Biblia, y según los resultados arrojados por la evaluación, se ha obtenido cambios positivos en cada una de las cuatro áreas y aún, mejoró las dos restantes de la encuesta de diagnóstico.

Considerando lo que en el capítulo anterior se expuso en Naturaleza del programa, y de acuerdo al resultado de la encuesta, se decidió elaborar un programa que iba a mejorar las deficiencias encontradas; para esto se determinó que el programa de mejoramiento espiritual iba a constar de 2 partes: "amanecer con Dios" y formación de células, que incluyeron aspectos relacionados con devoción y oración y obra misionera. A continuación, se presentan algunos resultados referentes al programa.

\section{Resultados de "Amanecer con Dios"}

Esta primera parte del programa de mejoramiento espiritual fue de mucha bendición para la iglesia ya que se vieron muy buenos resultados. La primera parte de " 10 días de poder" tuvo una acogida muy buena, ya que asistieron un promedio de 70 miembros (La membrecía de la iglesia era de 110 miembros) cada madrugada incluyendo los jóvenes que se unieron a esta actividad devocional. Esto contribuyó para que los miembros hicieran decisiones de mejorar su vida de devoción personal y familiar, tanto en la lectura de la Biblia como en el hábito de la oración

Otra actividad dentro de "Amanecer con Dios" fue la "cadena de oración familiar" por un mes; fue un éxito ya que 105 personas participaron en la actividad, siendo ellos mismos los que escogieron los días de su participación en la "cadena de oración" ayudando y promoviendo de esta manera al culto familiar y la oración.

Finalmente la "cadena de oración diaria", organizada por el ministerio de la mujer bajo la consejería de la esposa del pastor, Ximena Rivera, y la dirección de la hermana 
Líli Rosales junto con el ministerio de oración de la iglesia con la hermana Ramonita Alburquerque, tuvó una respuesta muy buena ya que el $80 \%$ de las mujeres participaron de esta cadena. Llegó à ser una herramienta poderosa en todas las áreas de trabajo y necesidades de la iglesia. Esta "cadena de oración, hasta el momento de escribirse esta tesis (2009), sigue trabajando y alimentando la fe de las hermanas y de la iglesia.

Resultados de la formación de células

El desarrollo de las células proveyó beneficios notables en la participación y vida de la iglesia, pues no sólo motivó y movilizó a los líderes de iglesia junto con los miembros, sino que les dio una nueva dimensión para desarrollar su crecimiento espiritual y vivir siempre activos, logrando también que los nuevos conversos lleguen a ser discípulos activos.

Participación de miembros. El primer resultado notable fue la casi total participación de los miembros en las células (ver "Capacitación de líderes" de este capítulo); el segundo resultado fue que los que no se involucraban en las actividades generales de la iglesia se volvieron más activos; el tercero fue que los nuevos miembros en corto tiempo estaban destacándose como líderes en las actividades de la iglesia; el cuarto resultado visible fue el aumento del número de visitas que asistían a las células primero, y luego, a la iglesia; el quinto resultado fue que las células se organizaron para dirigir los cultos de oración de los días miércoles; el sexto resultado es que la iglesia comenzó a desarrollar el ministerio del discipulado a través del establecimiento de un Instituto Bíblico que estaría funcionando durante todo el año en la misma iglesia. Un séptimo resultado es que las células permitieron que se consolide la unidad y el 
compañerismo de la iglesia. Y finalmente las células son las que dirigen y están a cargo de los minutos misioneros los sábados por la mañana.

Incremento de bautismos. Este fue un resultado natural de la formación de las células, ya que el promedio de bautismos desde el 2007 hasta noviembre del 2009, subió de un promedio de 2.6 bautismos al año (1999-2006) a 10.5 por año. El siguiente resultado fue que la asistencia promedio a la iglesia al empezar el año 2007 fue de 95 personas, y al terminar octubre del 2008 subió a una asistencia de 150, y en noviembre del 2009, la asistencia es de más de 180 personas. Además, siendo que el edificio (es una casa) es pequeño, la junta de iglesia decidió que desde junio del 2008 se efectúen 2 servicios. En último lugar, debido a todo el movimiento de la iglesia y su crecimiento en número, provocó que se adelante el proceso de la construcción del templo. 


\section{CAPÍTULO 5}

\section{CONCLUSIONES Y RECOMENDACIONES}

Esta tesis ha tenido como propósito principal elevar el nivel de espiritualidad entre los miembros de la iglesia y motivarlos a vivir una vida cristiana saludable y práctica a través de un programa de mejoramiento espiritual. Un promedio de veinte y cuatro fueron los participantes que fueron reclutados y capacitados por un año en el que recibieron instrucción teórica y práctica relacionada a la formación espiritual.

En general, los resultados fueron excelentes. La mayoría de los participantes dijeron que les había sido de grande beneficio tanto en crecimiento personal, familiar, como miembros de iglesia. Muchos decidieron continuar con su preparación y solicitaron que se abra un instituto bíblićo de capacitación.

Varias áreas del programa pueden mejorarse en el futuro, ya que este programa abre oportunidades de hacer una obra de crecimiento más amplia y detallada en cada una de las categorías que contiene la encuesta.

\section{Conclusiones}

El éxito del "programa de mejoramiento espiritual" de la iglesia de Gainesville, estuvo en reconocer su condición y buscar la manera de crecer en espiritualidad. El programa sugerido tuvo los elementos necesarios para fortalecer las áreas débiles.

El programa sirvió a la formación y consolidación de nuevos líderes; a su vez 
ellos ayudaron en el desarrollo del mismo en cada una de sus actividades y fases a cumplir. Por ejemplo en "amanecer con Dios" en la parte de "10 días de poder" (fase II), fueron ellos quienes lo dirigieron en su totalidad. Otro ejemplo, ellos participaron y trabajaron con entusiasmo en la formación de las células.

Este programa fue una bendición, ya que la membrecía experimentó el cumplimiento del verdadero cometido cristiano, que es la ganancia de almas, primero fue necesario entender el tema de la "salud espiritual" de la iglesia para llegar al conocimiento de su estado espiritual. De igual manera cada iglesia si desea ser saludable espiritualmente, debe conocer primero la o las enfermedades espirituales que le aquejan, y necesita entrar en una acción real, buscando un "remedio" como en este caso fue, un "programa de mejoramiento espiritual".

Las iglesias que crecen son iglesias saludables porque han implementado algún elemento de cambio en la vida y practica cristiana de los miembros. Toda iglesia que desea ser saludable debe implementar un plan o programa de mejoramiento espiritual, en que la iglesia pueda desarrollar los dones espirituales y vivir bajo la base del discipulado haciendo de esto su forma de vida constante. Una iglesia que practica el discipulado, es una iglesia que profundiza sus raíces espirituales y crece en fe, testimonio y obediencia.

La iglesia que pasa por la experiencia de un proceso de sanidad espiritual empieza a tener resultados positivos, entre ellos el crecimiento numérico natural de la membrecía, ya que el deseo de testificar se multiplica por parte de los miembros y contagia ese espíritu a aquellos adormecidos espirituales.

Un "programa de mejoramiento espiritual" efectivo hace que la familia se fortalezca y enriquezca. Ésta ha sido la experiencia de la iglesia de Gainesville, 
provocando una asistencia constante a los servicios y actividades de la iglesia; además, promueve la unidad y el trabajo combinado, evitando así la apostasía.

El programa que se aplique debe despertar en los miembros el deseo de seguir aprendiendo de Dios y de cómo ser más efectivos en la obra misionera. Así se va generando amor genuino por las almas que perecen, quienes entonces son invitadas a participar de las reuniones celulares, donde al asistir reciben ayuda, apoyo, consuelo, consejo, y hallan amigos permanentes; la iglesia de Gainesville llegó a tener esta experiencia.

La formación de "células" o "grupos pequeños" son la clave o el vehículo para llevar adelante una congregación saludable y activa que coloca su atención en los miembros y la ganancia de nuevas almas. Los programas espirituales cristianos que son efectivos no son originales del hombre; todos están basados en las Escrituras y en última instancia, toda medicina espiritual extraída de la Biblia es prescrita por el Médico Divino.

\section{Recomendaciones}

Ya que toda iglesia debe preocuparse por su salud espiritual y siendo que su compromiso no es con el hombre sino con Dios, está en el deber de hacerse un "análisis espiritual". A continuación propongo algunas recomendaciones.

1. Ya que el "programa de mejoramiento espiritual" que se aplicó en Gainesville dejó una puerta amplia para profundizar cada una de las áreas encuestadas, se indague más profundamente acerca de la fidelidad en el culto familiar, participación misionera, diezmo y las demás áreas.

2. Siendo que cada área es un campo amplio, se recomienda afirmar lo que ya se ha alcanzado, y para esto pueden hacerse "festivales" de oración, de lectura de la Biblia 
(puede ser por libros, secciones o temas), de diezmos, de dadivosidad, etc.

3. Así como los seres humanos necesitan saber su condición de salud, y por lo tanto acuden a los médicos, de la misma manera, la iglesia es un cuerpo de creyentes que está compuesta de seres humanos, los que constantemente sufren cambios en su espiritualidad; de manera que será necesario hacer evaluaciones espirituales periódicas (puede ser cada dos años), no necesariamente con la misma herramienta usada en esta investigación, sino con otras que recomienden algunos autores.

4. Que el pastor consiga las herramientas necesarias con tiempo para alimentar la iglesia y se mantenga ésta en buena salud.

5. Que cuando se obtengan los resultados de una evaluación, "la medicina" pueda estar disponible para ser aplicada. Tanto el pastor como los líderes deben hacer planes para obtener los recursos necesarios para sus congregaciones.

6. Que ninguna iglesia inicie un programa sin antes haber realizado el diagnóstico apropiado y dado el entrenamiento a los líderes que van a ayudar en la aplicación del programa de mejoramiento espiritual.

7. Que el pastor o líder puedan usar temas apropiados en la preparación de líderes. Los temas que se presentan en al Apéndice $\mathrm{D}$ de esta tesis, pueden usarse y adaptarse de acuerdo con las necesidades particulares de cada iglesia; esto será antes de implementar ningún programa espiritual.

8. Que los pastores con sus líderes presenten a sus juntas directivas la necesidad de tener una evaluación, tantas veces como sea posible hasta que sea en ellos un hábito el autoevaluarse aún cuando las congregaciones estén sin pastor.

9. Que los líderes discipulados sean los que preparen a otros discípulos usando 
seminarios, cursos y otras herramientas, de manera que el ciclo sea continuo. Para esto el pastor de la iglesia les provea las herramientas necesarias para que estos líderes sean efectivòs en su trabajo.

10. Que cada iglesia aparte un presupuesto especial y que en el calendario anual de la iglesia consten fechas especiales que tengan que ver con crecimiento espiritual, entrenamiento y capacitación de líderes.

11. Que esta tesis pueda servir de inspiración parà investigar otros tópicos como puede ser ¿Cómo la salud emocional de una iglesia puede afectar su efectividad?; el proceso del nacimiento de una iglesia a través de una célula; un programa de cómo. romper modelos tradicionales para un crecimiento efectivo. 
APÉNDICE A

ENCUESTA 


\section{ENCUESTA SOBRE SALUD ESPIRITUAL}

Para miembros de la Iglesia Adventista de Gainesville

El propósito de esta encuesta es descubrir el índice de espiritualidad de los miembros de iglesia. La información recibida es confidencial y ayudará al investigador a descubrir los factores que ayudarán a fortalecer la vida espiritual de los miembros. Los participantes necesitan ser mayores de 18 años y están libres de abstenerse de participar en el estudio en cualquier momento. Por favor no anotar su nombre.

INFORMACIÓN GENERAL

Edad

Años de bautizado

Sexo

País de origen Nivel de educación Estado civil

\section{CUESTIONARIO}

Conteste las siguientes preguntas asignando un número del 1 al 5 , para determinar con la nominación más baja si es "Débil" y con la nominación más alta si es "Fuerte".

Débil Fuerte

1. Evalúe, la frecuencia con que realiza el culto familiar

2. Evalúe su participación misionera en la iglesia

3. Evalúe su participación en otras actividades de la iglesia

4. Evalúe su fidelidad en los diezmos

5. Evalúe su fidelidad con las ofrendas

6. Evalúe sus hábitos en la oración

7. Evalúe la frecuencia con la que lee la Biblia
$1-2-3-4-5$

$1-2-3-4-5$

$1-2-3-4-5$

$1-2-3-4-5$

$1-2-3-4-5$

$1-2-3-4-5$

$1-2-3-4-5$ 
APÉNDICE B

AMANECER CON DIOS 


\section{"AMANECER CON DIOS"}

"10 días de poder"

Los objetivos que se quieren lograr con éste programa son: Primero, que los

miembros tengan una mejor relación personal con Cristo a través de la oración. Segundo, que puedan desarrollar el hábito de la lectura de la Biblia, personal y también familiar.

Tercero, que tengan una mejor y más activa participación en las actividades de la iglesia.

Cuarto, que puedan ver que su participación y testimonio hace posible ganar almas para Cristo.

\section{Programa}

1. Alabanzas

$10^{\prime}$

2. Oración personal

$10^{\prime}$

3. Lectura Bíblica y meditación personal (Estudio del tema)

$10^{\prime}$

4. Testimonios en grupos (no más de 3 personas)

$10^{\prime}$

5. Oración en grupo

6. Alabanzas

$5^{\prime}$

7. Oración personal

8. Desayuno (opcional) 


\section{APÉNDICE C}

TEMAS DE: 10 DÍAS DE PODER (I \& II) 


\section{Temas de: "10 días de poder" I}

1. Dios y su Palabra (2 Ti. 3:15; Lc. 11:28)

2. Dios y su amor (Ef. 2:4-6; Jer. 31:3)

3. Dios y su poder (Sal. 89:8; 33:6, 9)

4. Dios y yo (2 P. 3:18; Gá. 4:6, 7)

5. Dios y mi familia (Dt. 6:6, 7; Gn. 12:8; Jos. 24:15)

6. Dios el Sanador (Jer. 33:6; Jn. 5:6-9)

7. Dios el Consolador (Jn. 11:25, 26; Is. 51:11-15)

8. Dios el Restaurador (Ez. 11:19, 20; Jn. 8:3-11)

9. Dios de victoria (1 Co. 15:17; Ro. 8:37)

10. Dios de esperanza (Ro. 15:13; Jl.3:16)

\section{Temas de: "10 días de poder" II}

1. Dios el Padre (1 Jn. 3:1; Lc. 12:32)

2. Dios el Hijo (Is. 44:6; Ap. 22:13; 1:8)

3. Dios el Espíritu Santo (Jn. 14:16; Ro. 8:26)

4. Dios y su carácter (1 Jn. 4:8; Sal. 103:8)

5. Dios y sus mandamientos (Mt. 22:37-40; Is. 48:18)

6. Dios y su perdón (1 Jn. 1:9; Ef. 4:32)

7. Dios nuestro amigo (Is. 41:8, 9; Jn. 15:14)

8. Dios y la fe (Stg. 1:6; Lc. 7:2-9)

9. Dios y el sábado (Éx. 16:4, 22, 23, 27-29; Lc. 6:7-10)

10. Dios y el cielo (Ap. 21:23, 24; 1:1-5) 
APÉNDICE D

TEMAS PARA LIDERES

SEMINARIO: UNA IGLESIA QUE PRACTICA EL DISCIPULADO 


\section{TEMA 1. CARACTERÍSTICAS DEL LÍDER (DISCÍPULO)}

\section{INTRODUCCIÓN.-}

Para ser un piloto de avión, se necesita que el piloto, primero tenga una preparación personal; debe reunir ciertos requisitos, destrezas especiales para poder pilotear un avión, como también, es necesario que conozca el aparato que va a volar, pues de eso depende el éxito de su carrera como piloto. De la misma manera, es necesario que la persona que va a actuar como líder de célula (ó de cualquier otra área), se prepare y adquiera el conocimiento necesario para cumplir con su cometido.

\section{Su enfoque es hacia los demás}

Una característica del discípulo es que su enfoque es hacia los demás. Percy (2003), opinando sobre "discipulado" dice que esto es una llave importante para una transformación congregacional. Una congregación puede ser tan buena como fuerte y efectiva, por su habilidad de desarrollar discípulos. Sin un entrenamiento de discipulado intencional es altamente típico que una congregación enfocada en sí misma, pueda ser transformada en una congregación enfocada hacia fuera de sí misma" (p. 70).

El mismo autor presenta tres dimensiones de discipulado que se describen y explican a continuación:

Primero, la dimensión personal, que tiene que ver con el entendimiento de uno mismo como hijo de Dios y la relación personal con Dios; crecimiento en entender acerca del Evangelio y sus implicaciones y el proceso de transformación a través del cual el discípulo se parece a Jesús.

Segundo, la dimensión corporal, que tiene que ver con el entendimiento de uno mismo como miembro del pueblo de Dios, la iglesia. El llamado a seguir a Jesús es un 
llamado a unirse a esta comunidad y encontrar un lugar personal de servicio dentro del aspecto básico del discipulado.

Tercero, el discipulado tiene una dimensión pública. Como discípulos quieren crecer más y más en habilidad de ver el mundo desde la perspectiva de Dios y entender más plenamente la altura, la profundidad, y la anchura del evangelio y sus implicaciones para cada área de nuestras vidas y del mundo entero (Percy, 2003, p. 38-39).

\section{Es elegido}

Otra característica es que el discípulo es elegido. Jesús eligió a sus discípulos. De esa manera afirma Spader (1991), hay ciertas cualidades que distingue a esos discípulos. Primera, fidelidad, que tiene que ver con la consistencia en seguirlo; segunda la disponibilidad, como lo expresara Isaías "Heme aquí, envíame a mi" (Is. 6:8). Es una actitud a abrirse al control y dirección del Espíritu de Dios; tercera, hambre por aprender, demostrando cuanto le falta por crecer, sin una actitud de "no necesito que nadie me enseñe, ya lo sé todo"; y cuarta, entusiasmo. Un entusiasmo por el trabajo para el Señor es una señal de crecimiento en la relación personal con él (p. 134-136).

Entre algunos autores contemporáneos se presentan otras características resaltantes de discipulado y que se aplican también al discípulo.

\section{IIl. Tiene hambre de crecer en su relación con Dios.}

La primera característica que el discipulado debiera tener es como dice Foss: "tiene hambre de crecer en su relación con Dios en Jesucristo." Cuando su vida espiritual en forma personal es afirmada, alimentada, y relacionada con la misión de la congregación, grandes cosas suceden" (Foss, 2000, p. 127). El crecimiento espiritual es básico en el éxito de la vida de un líder, puesto que su vida es puesta de manifiesto 
delante de sus seguidores o liderados, por lo tanto, en este aspecto es donde debe ser un verdadero ejemplo.

\section{Cambio de carácter}

Ésta característica del discipulado es que tenga "cambio de carácter" Percy, (2003) dice que es importante "la transformación del carácter y el comportamiento. Uno de los consistentes temas de Pablo es que los seguidores de Jesús ponen a un lado el yo y son nuevas criaturas" (p. 36).

El cristiano en su crecimiento espiritual entra en un proceso de cambio, donde el Espíritu está haciendo los cambios necesarios, especialmente cuando se está en el camino del discipulado, donde la preparación integral del creyente es vital y una de las primeras evidencias externas es precisamente el cambio de carácter, pues la meta es llegar al modelo que es Cristo.

Malphurus (2004) en este aspecto dice: "El carácter de una persona, sea bueno o malo, afecta directamente como él o ella conduce su vida. Gente con un carácter pobre tiende a vivir una vida pobre hasta puede derretirse en la verdad o cortarse en las esquinas al desear cumplir sus blancos" (p. 23).

\section{Tiene visión}

Una característica importante del discipulado es que tiene "visión". Barna (1988) en forma simple define lo que es visión: Es "un sentido comprensivo de donde uno está, a dónde está yendo, y cómo va a llegar alli’" (p. 80).

No puede haber discípulos o lideres sin visión, ya que es parte esencial en su desenvolvimiento. Barna (1988) dice: "La Visión es responsabilidad de un líder y coloca 
al líder aparte de sus seguidores. El líder tiene y comunica la visión; los seguidores aceptan y ayudan a llevarla a cabo" (p. 81).

El mejor ejemplo es Jesús (Mr. 1:17), compartió su visión de salvar al mundo con sus discípulos y luego ellos siguieron en su ausencia con la misma visión. Pablo confirma el cumplimiento de la visión de Jesús en su vida "Pero cuando agradó a Dios, que me apartó desde el vientre de mi madre, y me llamo por su gracia, revelar a su Hijo en mi, para que yo predicase a los gentiles, no consulté enseguida con carne y sangre, ni subí a Jerusalén a los que eran apóstoles antes que yo; sino que fui a Arabia y volví de nuevo a Damasco" (Gá. 1:15-17).

Foss (2000), cita una declaración de Barna que dice: "Visión es un claro y preciso retrato mental por un futuro mejor, impartido por Dios a sus siervos escogidos, basado en el correcto entendimiento de Dios, de sí mismo y de las circunstancias” (p. 131).

\section{Prepara nuevos discípulos}

Una característica infaltable del discipulado que es que prepara nuevos discípulos para seguir la instrucción dada por Cristo, la de predicar el evangelio en todo el mundo (Mt. 28:19; Hch. 1:8; Ap. 14:6).

La iglesia saludable tendrá una constante preparación de nuevos discípulos, los que habrán de seguir con la obra de la predicación, y a su vez tendrán también la responsabilidad de prepararse y seguir con el ciclo del discipulado.

\section{CONCLUSIÓN}

Cuando el piloto tiene experiencia, le es más fácil aprender a manejar otros modelos de avión con mayor facilidad, así, un verdadero discípulo de Cristo debe reunir 
estas características de preparación básicas para un crecimiento personal y cumplir su cometido. 


\section{TEMA 2. EL LÍDER (DISCÍPULO) Y LOS DONES ESPIRITUALES}

\section{INTRODUCCIÓN.-}

Una de las características importantes de una "iglesia saludable" y mencionada por algunos autores tales como Rick Warren, Peter Wagner, Christian Schwarz y otros, es el uso de los dones del Espíritu.

\section{La necesidad del Espíritu Santo}

Wagner (1996), en su libro "La iglesia saludable", expone que uno de los problemas que afectan la salud de la iglesia es la falta del Espíritu (en Inglés: hipopneumia), y que el primer paso para curar esto es "reconocer el rol del Espíritu Santo y tenerlo en nuestra vida individual y en la vida de nuestras iglesias y estar abiertos a Su ministerio. El segundo paso es ser llenos del Espíritu Santo" (p. 158).

Por lo tanto el primer aspecto de una iglesia que practica el discipulado es tener la presencia del Espíritu, y por lo tanto serán otorgados los dones para edificación personal y sobre todo para ministrar a otros, siendo así una iglesia saludable.

\section{La importancia de los dones espirituales}

Schwarz (1999), dice: "La orientación sobre los dones tiene que ser más que una única reunión, llegando a ser una 'institución fija' de la iglesia. Cada nuevo creyente y cada nuevo colaborador deberían aprovecharse de este ministerio. Durante las sesiones, (ó "reuniones". El paréntesis es nuestro) verá que algunos de los creyentes están justo en el lugar donde Dios les ha llamado a estar, mientras que otros no lo están. Es importante que los líderes ayuden a esas personas a encontrar en la iglesia que corresponda sus dones y de esta manera su llamamiento" (p. 65). 
Los dones no son todos dados a una sola persona, sino que se complementan.

Dios no ha dado todos los dones a una persona, sino que ha dado a cada creyente algunos de los dones necesarios para edificar el cuerpo de Cristo. Cuanto más use su propio don, más cuenta se dará de lo mucho que necesita el ministerio de los demás para completar sus carencias....A medidā que utilice los recursos anteriores podrá descubrir qué dones ha puesto Dios en los miembros de su equipo (Schwarz, 1999, p. $55)$.

En el tiempo de la iglesia apostólica se entendió bien el ministerio de una iglesia saludable según los dones, por eso Pedro declara: "Cada uno según el don que ha recibido, minístrelo a los otros, como buenos administradores de la multiforme gracia de Dios" (1 P. 4:10).

En el pensamiento de Schwarz (1993) la caracteristica de los dones en el contexto del "Desarrollo natural de la iglesia", es vital; y declara: "el concepto de los dones espirituales juega un papel central en todas ellas. Lo que está en juego aquí es nada más y nada menos que la misma esencia del 'cuerpo de Cristo': Cada creyente es un miembro de este cuerpo, y los dones que cada uno haya recibido determinarán el papel que él o ella vaya a desempeñar en ese cuerpo de acuerdo a la voluntad de Dios" (p. 62).

\section{Clasificación de los dones}

Los dones del Espíritu se mencionan en Romanos 12:6-8; 1 Corintios 12:8-10, 2830; y en Efesios 4:11. Wagner (1990) en el libro Sus dones espirituales pueden ayudar a crecer su iglesia, enumera una lista de 27 dones (p. 9).

Según Hunter (1994), en la "Biblia (1 Pe. 4:10) dice que cada cristiano ha recibido un don", (p. 87) y hace una lista sugerente de 24 dones, que en este estudio se aplica a la Iglesia de Gainesville-Florida.

Contando solamente esos dones que son mencionados en el Nuevo Testamento, la lista luce de la siguiente manera: 
Romanos 12

1. Profecía

2. Servicio

3. Enseñanza

4. Exhortación

5. Dadivosidad

6. Liderazgo

7. Misericordia

1 Corintios 12 (No están incluidos los que están en Ro. 12)

8. Sabiduría

9. Ciencia

10. Fe

11. Sanidad

12. Milagros

13. Discernimiento de Espíritus

14. Lenguas

15. Interpretación de Lenguas

16. Apóstoles

17. Ayuda

18. Administración

Efesios 4 (No se está incluyendo ninguno listado anteriormente)

19. Evangelista

20. Pastor

Otros dones los cuales son reconocidos por algunos eruditos incluye:

21. Celibato (1 Co. 7:7)

22. Martirio (1 Co. 13:3)

23. Hospitalidad (1 P. 4:9)

24. Misionero (Gá. 1:16)

(Hunter, 1994, p. 88).

La diferencia entre la lista de dones de Hunter y Wagner es que este éste último presenta tres dones más, que son: Pobreza voluntaria, intercesión, y exorcismo, de los cuales el de intercesión es otro don que junto con los de Hunter y se aplica a la iglesia de Gainesville. 


\section{TEMA 3. CRISTO Y EL LÍDER (DISCÍPULO)}

\section{INTRODUCCIÓN.-}

El mejor ejemplo para seguir en cuanto a la elección de los discípulos, es

indudablemente Jesucristo, por lo tanto analizaremos sus métodos y enseñanzas respecto del reclutamiento de líderes.

\section{Elección de los discípulos (líderes)}

Es Jesús mismo quien escoge a doce discípulos "Y cuando era de día, llamó a sus discípulos, y escogió a doce de ellos, a los cuales llamó también apóstoles" (Lc. 6:13). Así, a este grupo pequeño de seguidores (Spader, 1991, p. 36) los entrena (ó discipula) para el cumplimiento de la misión de Mt. 28:19-20.

Como el ministerio de Cristo creció, vino a ser necesario entrenar y designar a otros a pastorear segmentos del ministerio. Jesús supo que El no podía adecuadamente satisfacer las necesidades de todos el mismo, así que empezó a entregar algunas responsabilidades a sus discípulos. Eso fue necesario para permitir el continuo crecimiento y desarrollo de sus discípulos, y fue necesario como el paso final de la construcción de un ministerio que continuaría expandiéndose de una manera saludable (Spader, 1991, p. 170).

\section{Jesús como Maestro (Discipulador)}

Jesús ha sido llamado justificadamente "Maestro" de "maestros" ya que los efectos de su enseñanza y discipulado todavía sigue rindiendo resultados. Sus primeros discípulos lo llamaron "Rabí", que significa también "Doctor" o "Maestro" (Jn. 1:38).

Hubo algo inusual en la vida de Jesús como Maestro, es que la mayoría de los que llegaban a ser maestros, era solo luego de haber sido discípulos de otro maestro, en el caso de Jesús nunca fue discípulo de nadie (Baxter, 1987, p. 30). Y sin haber asistido a las escuelas de su época, la gente se sorprendía de su enseñanza (Jn. 7:14-15, Lc. 4:32). 
La palabra "discípulo" como se dijo anteriormente, viene del griego mathētēs que significa "estudiante". Estos discípulos se unieron como grupo de estudiantes del Rabí Jesús, aceptando sus enseñanzas acerca del reino de los cielos. (Jn. 6:60-71; Mt. 16:16). Así, ellos llegan a la determinación que él es "el Cristo, el Hijo del Dios viviente" (van Bruggen, 1996, p. 187).

El resultado inmediato del discipulado de Jesús, se destaca de entre los otros maestros o rabinos de su tiempo, la Biblia tiene declaraciones como la del Evangelio de Juan que sin mayor detalle menciona que Jesús ganaba más discípulos que Juan (Jn. 4:1), van Bruggen (1996) cita otros pasajes de los evangelios que declaran que las masas que venían a escucharlo (Mt. 4:24, 25; 9:36; Mr. 8:1-3) o para ser sanados (p.191).

\section{Jesús y el método de discipulado}

Definitivamente el método de discipular de Jesús envolvía dos elementos esenciales, que son: Primero, una enseñanza atractiva y de esperanza y segundo, suplir las necesidades de la gente.

La enseñanza de Jesús es diferente a la del judaísmo rabínico de su tiempo, quienes estaban orientados a defender ideologías e interpretaciones de la Ley y los profetas, (Dodd, 1970, p. 54) mientras Jesús toca là vida de la gente con sus enseñanzas a través de parábolas (Mt. 18:10-14, 20:1-16) y al mismo tiempo llenando sus necesidades fisicas y espirituales (Lc. 9:10-17).

Así Jesús empieza el ministerio de discipulado, escogiendo de entre todos los discípulos primero un grupo selecto de doce (Lc. 6:13-16), luego a setenta (Lc. 10:1) para que luego de su muerte siguieran su ejemplo. 


\section{Objetivo de la enseñanza de Cristo}

Jesús al discipular, enfatiza la importancia del conocimiento de Su persona. (Bruggen, 1996, p. 190) dice que mientras la enseñanza de Juan el Bautista era específicamente para "bautismo de arrepentimiento" (Lc. 3:3, 8), la de Jesús era concerniente a sí mismo y su trabajo (Mt. 16:13-17; Lc. 19:9, 10).

(Dodd, 1970, p. 55), dice que al discipular mostró una predicación positiva pues contenía "buenas nuevas" (Ef. 2:17, Lc. 4:18,21), y esas "buenas nuevas" consistía en que anunciaba la cercanía del "reino de los cielos" (Mt. 4:17, 10:7, 13:24, 31, 33, 44, $45,47)$.

\section{Conclusión}

En resumen, la primera iglesia de Cristo se formó con un grupo pequeño de doce discípulos, los que van aumentando en número a medida que se expanden las "buenas nuevas del reino de los cielos". Pablo con su predicación a los gentiles, también siguió el ejemplo de Cristo al formar discípulos como Tito, Timoteo y otros. 
TEMA 4. EL LIDER (DISCÍPULO) Y LA OBRA MISIONERA

\section{INTRODUCCIÓN}

Una "iglesia saludable" practica el discipulado, y tiene como prioridad el cumplimiento de la misión. Los líderes de iglesia, deben enfocar su trabajo en el cumplimiento de la obra de la proclamación del evangelio a todo lugar. Los discípulos fueron entrenados por Cristo para que la obra de la salvación se llevase a cabo en el mundo entero, y para el cumplimiento de ésto preparó a los doce.

\section{Significado de "misión"}

La palabra "misión", significa "enviar"; por lo tanto una "iglesia saludable" es la que "envía" discípulos para que se cumpla el mandato de Cristo. Ellwel, (1996), en el Evangelical Dictionary of Biblical Theology dice que "Misión es la divina actividad de enviar intermediarios...El concepto bíblico es expresado en el uso de verbos que significan "enviar"...El verbo hebreo es šālah (p. 534, 535). La palabra "apóstol" viene del verbo griego "apostêllo" "enviar" (Parker, 1982, p. 12). Jesús mismo es llamado "el enviado de Dios”. Cuando Jesús resucitó, prometió enviar su Espiritu a los discípulos (White, 1985, p. 18). Por lo tanto para que exista "misión", es necesario que existan dos partes, tanto "el que envía" como "los que son enviados".

\section{Ejemplos bíblicos de "enviados"}

En la Biblia Dios es "el que envía", como en los casos de Abraham (Gn. 12:1), Moisés (Ex. 3:10), Isaías (Is. 6:8), Jeremías (Jer. 1:7), Jonás (Jon. 1:2), y otros más. White (1985) recuerda que la iniciativa de este movimiento viene de Dios (p. 18) y esto se aplica tanto en el Antiguo como en el Nuevo Testamento (Mt. 9:1-6; 10:1). Debe 
notarse que para el desarrollo de una iglesia saludable, "los que son enviados" deben recibir "instrucciones específicas" y entonces están listos para cumplir con la misión.

Para entender mejor el significado de la "misión" en el movimiento cristiano, Leland, J. White (1985) declara que “separada de la 'misión' la iglesia realmente no existe; ya que donde la 'misión' ocurre entonces la iglesia viva está presente" (p. 20). Mateo al final de su evangelio registra las "instrucciones" de Cristo para cumplir la misión: "Por tanto, id, y haced discípulos en todas las naciones, bautizándoles en el nombre del Padre, y del Hijo, y del Espíritu Santo; enseñándoles que guarden todas las cosas que yo os he mandàdo; y he aquí yo estoy con vosotros todos los días; hasta el fin del mundo" (Mt. 28: 19-20).

Esta instrucción amplía Lucas en su evangelio (Lc. 24:47, 49) y en el libro de Hechos con motivo de la ascensión de Cristo al cielo, donde se especifica claramente el territorio donde se cumplirá la misión y donde se añade la promesa del Espíritu Santo: "pero recibiréis poder, cuando haya venido sobre vosotros el Espíritu Santo, y me seréis testigos en Jerusalén, en toda Judea y hasta lo último de la tierra" (Hch. 1:8).

Por lo expresado anteriormente, se confirma que los discípulos son enviados en cumplimiento de la "misión" para hablar de Cristo, de sus enseñanzas, de estar listos para su regreso, es decir un modelo de vida diferente basada en la vida de Jesús.

\section{TERRITORIO PARA LA MISIÓN}

Jesús señala el territorio donde su cumplirá la "misión" (Hch. 1:8). Los discípulos entendieron y aceptaron la orden de Cristo, que primero habían sido enviados al pueblo judío, "en Jerusalén, en toda Judea". Y luego al resto del mundo. 
Dentro del aspecto territorial de la misión, y rompiendo con la tradición nacionalista de los judíos aparece el hecho innegable que esa "misión" debía cumplirse también en el mundo "gentil", llamada así toda persona que no era judia; "en Samaria, y hasta lo último de la tierra" (v.8); y en Mateo al decir "a todas las naciones" (28:19).

Driver (1994) refiriéndose a la relación entre judíos y gentiles dice:

En el siglo primero de nuestra era, el enfrentamiento entre judios y gentiles, descrito en Efesios 2:11-12, era un hecho cotidiano. La permanente lucha de Israel por no contaminarse a través del contacto con sus vecinos gentiles llevo al primero a una actitud cerrada, dura y exclusivista ante las otras naciones. Esta situación se torno particularmente evidente al volver del exilio, época en que la política del aislamiento y separación condujo gradualmente a una postura de intolerancia absoluta (cf. Esdras y Nehemías). Una de las peores ofensas que un judío podía hacer a otro en el primer siglo consistía en calificarlo de "gentil y publicano". Los judíos consideraban que el odio hacia quienes eran, obviamente, los enemigos de Dios estaba justificado: más aun, hasta cierto punto debía ser fomentado (cf. Mt. 5:43). Por otro lado, los gentiles respondían con actitudes agresivas al desprecio que les manifestaban los judíos" ( $p$. 244).

La misión junto con el discipulado hizo del cristianismo un estilo de vida diferente como lo declara White (1985) "Este modelo cristológico le dio a la comunidad cristiana las bases de su identidad y vida" (p. 77). El libro de "Hechos de los Apóstoles" presenta el resultado de la misión y el discipulado ordenado por Jesús a sus discípulos (Mt. 28: 19; Hch. 1:8).

Dibelius (2004), dice refiriéndose al libro de Hechos, que es "único" por "contar la historia de la primera comunidad cristiana en una forma consecutiva, y esparcir las creencias cristianas al Occidente. Lucas su autor (Hch. 1:1, 16:10-17, 20:5-14), selecciona el material que iba a incluir en el libro para presentar cómo se fue cumpliendo el programa misionero de la obra del discipulado. Del capítulo 1 al 5 en Jerusalén, del capítulo 6 al 12 en Judea y Samaria, y del capítulo 13 al 28 hasta lo último de la tierra (p. $3,4)$. 


\section{CONCLUSIÓN}

El trabajo de discipulado de la "iglesia apostólica" desde la perspectiva de la "misión" se resume en dos actividades que aunque diferentes, estaban relacionadas "Y todos los días en el templo y por las casas, no cesaban de enseñar y predicar a Jesucristo" (Hch. 5:42).

Primero, la tarea de la predicación consistía en la proclamación de las buenas nuevas acerca de Jesús e invitar a los oyentes a seguirlo. Siempre la predicación fue dirigida a los no creyentes. Segundo, la enseñanza era dada a aquellos que habían sido bautizados y habían empezado a seguir a Jesús. Así, la enseñanza siempre fue dirigida a los cristianos (Baxter, 1987, p. 64), y obviamente está relacionado con un programa de discipulado 


\section{TEMA 5. CÓMO ORGANIZAR Y DIRIGIR UNA CÉLULA}

\section{INTRODUCCIÓN}

De la misma manera como una madre se prepara para atender su primer hijo y hacer que crezca saludable, así, todo líder debe tener un conocimiento previo de cómo organizar y dirigir una célula antes de trabajar con ella. Es necesario entender que la dirección de células requiere educación, trabajo y sacrificio por parte de los líderes.

\section{Quiẻnes dirigen la célula?}

1. Líderes nombrados por el Pastor

2. Líderes nombrados por el Primer Anciano

3. Líderes nombrados por el Director Misionero

4. Líderes nombrados por el Coordinador de Células

II. Quiénes conforman la célula?

1. Miembros de iglesia

2. Estudiantes de la Biblia

3. Familiares

4. Amistades

5. Compañeros de estudios

6. Compañeros de trabajo

7. Conocidos

III. Directiva de la célula (organización interna de la célula)

1. Líder, Pastor (de célula), Director

2. Secretario(a)

3. Tesorero)(a)

4. Director(a) misionero

5. Director(a) de cantos

6. Director(a) de niños

7. Director(a) de actividades sociales

8. Anfitrión(a) 
IV. Lugar de reunión de la célula
1.Un Hogar
2. Un salón
3. La iglesia
4. Cualquier lugar que convenga al grupo

\section{Programa a seguir en la célula}

1. Bienvenida y oración

2. Actividad para romper el hielo

3. Alabanzas

4. Testimonios y pedidos

5. Tiempo de orar

6. Lectura y estudio de la Palabra

7. Alabanza final

8. Oración final

9. Confraternización 
APÉNDICE E

RETIRO DE LÍDERES 


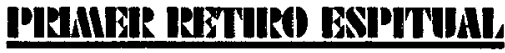

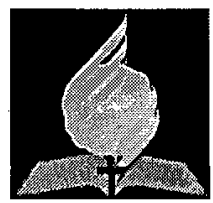

LÍDERES DE LAS IGLESIAS DE:

MARION OAX Y GAINSVILLE

"UNIDOS EN EL.SERVICIO"

\author{
' "NOS SALVÓ, NO POR OBRAS DE \\ JUSTICIA QUE NOSOTROS HUBIERAMOS \\ HECHO, SINO POR SU \\ MISERICORDIA, POR EL LAVAMIENTO DE LA \\ REGENERACIÓN Y POR LA RENOVACIÓN EN EL \\ ESPÍRITU SANTO" \\ Tito 3:5
}

CAMPAMENTO DE RETIRO PINE LAKE

2 - 4 DE NOVIEMBRE DE 2007 


\author{
2 - 4 de Noviembre del 2007 \\ "UNIDOS EN EL SERVICIO"
}

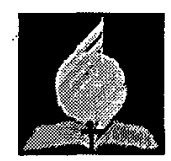

\section{PROGRAMA GENERAL}

VIERNES 21
REGISTRACIÓN Y UBICÁCIÓN ALABANZAS AL CREADOR MEDITACIÓN Y ORACIÓN

DULCES SUEÑOS

$$
\begin{array}{r}
\text { 6- - }: 30 \mathrm{PM} \\
\text { 7:30-8:00 PM } \\
8: 00-9: 00 \mathrm{PM} \\
\text { 10:00 PM }
\end{array}
$$

\section{SÁBADO 22}

DESAYUNO

DEVOCIONAL

"HECHOS II, LA CONTINUACIÓN"

RECESO

"CADA CREYENTE ES UN MINISTRO"

ALMUERZO

"EL EVANGELIO DE LA AMISTAD"

RECESO

"LA IGLESIA CELULAR"

CENA

SESIÓN DE ORACIÓN

DULCES SUEÑOS

$$
\begin{array}{r}
\text { 8:00-9:00 AM } \\
\text { 9:30- 10:00 AM } \\
\text { 10:00- 11:20 AM } \\
11: 20-1130 \mathrm{AM} \\
11: 30-12: 30 \mathrm{AM} \\
1: 00 \mathrm{PM} \\
3: 00-4: 00 \mathrm{PM} \\
4: 00-410 \mathrm{PM} \\
4: 10-6: 00 \mathrm{PM} \\
6: 00 \mathrm{PM} \\
8: 00 \mathrm{PM} \\
10: 00 \mathrm{PM}
\end{array}
$$

\section{DOMINGO}

DEVOCIONAL

"REVOLUCIÓN EN LA IGLESIA"

BRUNCH 
APÉNDICE F

PROGRAMA DE SERVICIO CELULAR 
1. BIENVENIDA

5 MNUTOS

2. ACTIVIDAD PARA ROMPER ELHIELO

5 MINUTOS

3. ALABANZAS

10 MNUTOS

4. TESTIMONIOS Y PEDIDOS

10 MINUTOS

5. TIEMPO PARA ORAR

10 MINUTOS

6. LECTURA Y ESTUDIO DE LA PALABRA

25 MNUTOS

7. ALABANZA FINAL

3 MINUTOS

8. ORACIÓN FINAL

2 MINUTOS

9. TIEMPO DE CONFRATERNIZAR

10 MINUTOS

\section{SUGERENCIAS}

- LA BIENVENIDA DEBE SER HECHA CON ENTUSIASMO; SIN HABLAR DE TEMAS QUE NO SEAN DE "BIENVENIDA"

- LA ACTIVIDAD DE ROMPER EL HIELO PUEDE SER CON PREGUNTAS O CON ALGUNA ACTIVIDAD

- LAS ALABANZAS DEBEN REPETIRSE EN CADA REUNIÓN HASTA QUE LA CÉLULA LAS APRENDA DE MEMORIA

- EL TIEMPO DE LA ORACIÓN DEBE SER EL CORAZÓN DE LA REUNIÓN; PUEDEN ORAR SOLOS O EN GRUPOS DE DOS, TRES, ETC.

- SE DEBE PEDIR QUE LOS TESTIMONIOS SEAN VOLUNTARIOS

- LA LECTURA Y ESTUDIO DE LA BIBLIA DEBE CUMPLIR EL OBJETIVO DE NUTRIR Y ANIMAR

- LUEGO DEL MOMENTO DE CONFRATERNIZACIÓN, ES BUENO NO DETENERSE CONVERSANDO MUCHO PUES AL HACERSE MUY TARDE VA A DESANIMAR A QUE VUELVAN PARA LA SIGUIENTE REUNIÓN

- LOS LÍDERES DE LA CÉLULA DEBIERAN VISITAR O LLAMAR POR TELÉFONO A LOS MIEMBROS QUE FALTEN, Y ORAR EN ALGÚN MOMENTO DE LA SEMANA. 


\section{APÉNDICE G}

HOJA DE CONTROL DE CÉLULAS DE LA IGLESIA DE GAINESVILLE 
CÉlUla:

LEMA:

LÍDER:

ANFITRIÓN:
CANTO TEMA:

VERSÍCULO BÍBLICO:

TELÉFONO

DIRECCIÓN:

DIRECTOR(A): DE

CANTO: DIRECCIÓN:

TELÉFONO:

ORACIÓN: .DIRECCIÓN

TELÉFONO.

TESTIMONIO: DIRECCIÓN:

TELÉFONO.

OBRA MISIONERA:

DIRECCIÓN:

TELÉFONO:

NIÑOS:

DIRECCIÓN:

TELÉFONO:

ACTIVIDADES SOCIALES:

.DIRECCIÓN:

\section{TELÉFONO:}

TESORERO: DIRECCIÓN:

TELÉFONO: 
MIEMBROS DE CÉLULA

NOMBRE:

.DIRECCIÓN.

TELÉFONO.

NOMBRE:

DIRECCIÓN

TELÉFONO.

NOMBRE:

DIRECCIÓN.

TELÉFONO.

NOMBRE:

DIRECCIÓN.

TELÉFONO

NOMBRE:

..DIRECCIÓN

TELÉFONO

NOMBRE:

..DIRECCIÓN.

TELÉFONO

NOMBRE:

.DIRECCIÓN.

TELÉFONO

NOMBRE:

.DIRECCIÓN

TELÉFONO 


\section{BIBLIOGRAFÍA}

Anthony, Michael J. (Ed.). (2001). Evangelical dictionary of Christian education.Grand Rapids, MI: Baker Academic.

Baker, Warren. (1994). The complete word study Old Testament. Chatanoga, TN: AMG Publishers.

Barna, George. (1988). Marketing the church. Colorado Springs, CO: Navpress.

Baxter, Margaret. (1987). Jesus Christ: His life and His church. Philadelphia, PA. Westminster Press.

Beckmann, Chris, Judy Boucias. (1994). A history of Gainesville and its people. Gainesville, FL: Turner Publishing Company.

Beers, Ronald P. (2001). Gainesville alive with oportunity. Montgomery, AL: Community Communications.

Bell, Skip. (2003). A time to serve. Lincoln, NE. Adventsource.

Berry, George Ricker. (1976). The interlinear literal translation of the Greek New Testament. Grand Rapids, MI: Zondervan.

Blenkinsopp, Joseph. (1992). The Pentateuch. New York: Doubleday.

Brow, Robert. (1981). Go make learners. Wheaton, IL: Harold Shaw.

Brown, Raymon E. (1997). An introduction to the New Testament. New York: Doubleday.

Bruggen, Jakob van (1996). Jesus the Son of God. Grand Rapids, MI: Baker Books.

Buttrick, George A. (Ed.). (1990). The interpreter's dictionary of the Bible. Nashville, TN: Abingdon Press.

Centro: Informática y Biblia de la Abadía de Maredsous. (1993). Diccionario enciclopédico de la Biblia. Barcelona: Editorial Herder. 
Cullmann, Oscar. (1995). Prayer in the New Testament. Minneapolis, MN: Fortress Press.

Davis, Dale R. (2000). Judges. Tain, UK: Christian Focus Publications.

de Ausejo, Serafin (Ed.). (1981). Diccionario de la Biblia. Barcelona: Editorial Herder.

Denyer, C. P. (1983). Concordancia de las Sagradas Escrituras: Revisión de 1960 de la versión Reina Valera (10th ed.). Miami, FL: Editorial Caribe.

Dever, Mark. (2004). Nine marks of a healthy church. Wheaton, IL: Crossway Books.

Dibelius, Martin. (2004). The book of Acts. Minneapolis, MN: Fortrees Press

Dodd, Brian J. (1997). Praying Jesus' way. Downers Grove, IL: Intervarsity Press.

Dodd, C. H. (1970). The founder of Christianity. New York: Macmillan.

Donato, Thomas E. (Ed.). (2008). Demographics USA. Westport, CT: Trade Dimensions International.

Driver, Juan. (1994). La obra redentora de Cristo y la misión de la iglesia. Buenos Aires, Argentina: Nueva Creación.

Dupertuis, Atilio R. (1995). De Egipto a Canaán. Berrien Springs, MI: Pioneer Publications.

Elwell, W. A. (Ed.). (1996). Evangelical dictionary of biblical theology. Grand Rapids, MI: Baker Books.

Floyd, Susan S. (Ed.). (2005). Florida statistical abstract 2005.Gainesville, FL: University of Florida. . (Ed.). (2008). Florida statistical abstract 2008. Gainesville, FL: University of

\section{Florida.}

Flynn, Leslie B. (1995). The Master's plan of prayer. Grand Rapids, MI: Kregel.

Foss, Michael W. (2000). Power surge.Minneapolis, MN: Fortress Press.

Foulkes, Francis. (1989). The letter of Paul to the Ephesians. Grand Rapids, MI: Eerdmands.

Freedman, David N. (Ed.). (2000). Dictionary of the Bible. Grand Rapids, MI: Eerdmands. 
Galloway, Dale. (1999). Making church relevant. Kansas City, MO: Bacon Hill Press.

Goergen, Donald. (1986). The mission and ministry of Jesus. Wilmington, DE: Michael Glazier.

Guinan, Michael D. (1990). The Pentateuch. Collegeville, MN: The Liturgical Press.

Hamilton, Victor P. (2001). Handbook on the historical books. Grand Rapids, MI: Baker Academic.

Hamlin, E. John. (1990). Judges. Grand Rapids, MI: Eerdmans.

Hildreth, Charles H. y Merlin G. Cox. (1981). History of Gainesville, Florida 1854-1979. Gainesville, FL: Alachua County Historical Society.

Horn, Siegfried H. (1979). Seventh-day Adventist dictionary. Washington, DC: Review and Herald Publishing Association.

. (Ed.). (1995). Diccionario biblico adventista del séptimo día. (Trad. por $\mathrm{R}$. Itin, G. Clouzet, A. D. Orrego). Buenos Aires, Argentina: Asociación Casa Editora Sudamericana.

Hunter, Kent R. (1994). Foundations for church growth. Corunna, IN: Church Growth Center.

Johnson, Thomas, F. (1995). New international biblical commentary. Peabody, MA: Hendrickson.

Keck, Leander E. (1994). The new interpreter's Bible. Nashville, TN: Abingdon Press.

Kohlenberger III, John R. (1987). The interlinear NIV Hebrew-English Old Testament. (Vols. 1, 2). Grand Rapids MI: Zondervan.

Kohlenberger III, John R., Goodrick, E. W. y Swanson, J. A. (1997). The Greek English concordance to the New Testament. Grand Rapids MI: Zondervan.

Liefeld, Walter L. (1997). Ephesians. Downers Grove, IL: Intervarsity Press.

Mackenzie, Leslie, pub. (2008). Profiles of Florida. Millerton, NY. Grey House.

Malphurs, Aubrey. (1999). The Dynamics of church leadership. Grand Rapids, MI: Baker. . (2004). Value-driven leadership. Grand Rapids, MI: Baker. 
Mills, Watson E. (Ed.). (1990). Mercer dictionary of the Bible. Macon, GA: Mercer University Press.

Morris, Allen y Joan P. Morris. (2007). The Florida handbook 2007-2008. Tallahassee, FL: Peninsular Publishing.

Morris, William (Ed.). (1973). The American heritage dictionary of the English language. New York: American Heritage.

Nichol, Francis D. (Ed.). (1953-57, 1976-80). The Seventh-day Adventist Bible commentary. (Vols. 1-7). Washington, DC: Review and Herald.

. (1982-88). Comentario biblico adventista del séptimo día. (Trad. por V. E. Ampuero Matta). (Vols. 1-7). Mountain View, CA y Boise, ID: Pacific Press.

O'Mahony, Kieran J. (2003). Christian origins. New York: Sheffield Academic Press.

Oak, John H. (2003). Healthy Christians make a healthy church. Fearn Ross-shire, Scotland: Christian Focus Publication.

Opsahl, Paul D. (Ed.). (1978). The Holy Spirit in the life of the church. Minneapolis, MN: Augsburg.

Parker, Jorge G. (1982). Lexico-concordancia del Nuevo Testamento en Griego y Español. El Paso, TX: Editorial Mundo Hispano.

Percy, Harold. (2003). Your church can thrive. Nashville, TN: Abingdon Press.

Pick, Aaron. (1977). Dictionary of Old Testament words for English readers. Grand Rapids, MI: Kregel.

Rajtar, Steve. (2008). Historical photos of Gainesville. Nashville, TN: Turner.

Rea, John. (1990). The Holy Spirit in the Bible. Lake Mary, FL: Creation House.

Renn, Stephen D. (Ed.). (2005). Expository dictionary of Bible words. Peabody, MA: Hendrickson.

Schirrmacher, Thomas. (2003). Studies in church leadership. Bonn, Germany: Culture and Science Publications.

Schwarz, Christian A. y Schalk, Christoph. (1999). Un desarrollo natural de la iglesia. Terrassa, Barcelona: Editorial CLIE.

Shanks, Hershel (Ed.). (1992). Christianity and rabbinic Judaism. Washington, DC: Biblical Archeology Society. 
Simpson, A. B. (1996). The Spirit-filled church in action. Camp Hill, PA: Christian Publications.

Sopena, Ramón (Ed.). (1973). Aristos: Diccionario ilustrado de la lengua española. Barcelona, España: Editorial Sopena.

Spader, Dann y Mayes, Gary. (1991). Growing a healthy church. Chicago, IL: Moody Press.

Sperling, Bert y Sander, Peter. (2007). Cities ranked \& rated. Hoboken, NJ: Wiley.

Tamez, Elsa y Foulkes, Irene W. (1978). Diccionario conciso griego-español del Nuevo Testamento. Stuttgart: West Germany: Biblia Druck.

Thomson, Marianne M. (1992). The IVP New Testament commentary series: 1-3 John. (Edit. Por Grant R. Osborne). Downers Grove, IL: Intervarsity Press.

Turner, Max. (1996). The Holy Spirit and spiritual gifts. Peabody, MA: Hendrickson. van Gemeren, W. A. (Ed.). (1997). New international dictionary of Old Testament Theology and Exegesis. (Vol. 2, 5). Grand Rapids, MI: Zondervan.

Vila, Samuel. y Escuain, S. (1986). Nuevo diccionario bíblico ilustrado. Barcelona, España: CLIE.

Vos, Howard F. (1982). Genesis. Chicago, MI: Moody Bible Institute.

Wagner, C. Peter. (1987). Strategies for church growth. Ventura, CA: Regal Books. . (1990). Your spiritual gifts.Bromley, UK: MARC. . (1996). The healthy church. Ventura, CA: Regal Books. . (1997). Plantando iglesias para una mayor cosecha. Miami, FL: Editorial Unilit.

Wansbrough, Henry (Ed.). (1985). The New Jerusalem Bible. Garden City, NY: Doubleday.

Warren, Rick. (1995). Una iglesia con propósito. Miami, FL: Editorial Vida.

Wescott, Brooke F. \& Hort, Fenton J. A. (1936) The New Testament in the original Greek. New York: Macmillan.

White, Elena G. (1959). Servicio cristiano. Mountain View, CA: Publicaciones Interamericanas. 
. (1966). Mensajes selectos t.1. Mountain View, CA: Publicaciones Interamericanas.

. (1968). El Deseado de todas las gentes. Mountain View, CA: Publicaciones Interamericanas.

. (1975). El evangelismo. Buenos Aires, Argentina: Asociación Casa Editora Sudamericana.

. (1976). El evangelismo. Buenos Aires, Argentina: Asociación Casa Editora Sudamericana.

. (1984). Mensajes selectos t. 3. Miami, FL: Asociación Publicadora Interamericana.

White, Leland J. (1985). Christ and the Christian movement. Staten Island, NY: Alba House.

Wigram, George W. (1997). The Englishman's Hebrew concordance of the Old Testament. Peabody, MA: Hendrickson.

Winsberg, Morton D. (2006). Atlas of race, ancestry, and religion in $21^{\text {st }}$-Century Florida. Gainesville, FL: University Press of Florida.

Wood, Leon. (1975). Distressing days of the judges. Grand Rapids, MI: Zondervan.

Wright, John H. (1974). A theology of Christian prayer. New York. Pueblo.

Youngblood, Ronald F. (1983). Exodus. Chicago, MI: Moody Bible Institute. 


\section{CURRÍCULUM VÍTAE}

\section{DATOS PERSONALES}

Nombre: Byron A. Rivera Galarza

Fecha de nacimiento: 5 de Mayo, 1955

Lugar de nacimiento: Quito, Ecuador

Esposa: Ximena Rivera

Hijos: Elías (1986), Byron Jr. (1988)

\section{EDUCACIÓN}

2010 D.Min. Andrews University

1998 Equivalencia M.A. Andrews University

1983 Bachiller en Teología, Universidad Unión Incaica, Lima-Perú.

19773 años de Psicología Clínica, Universidad Central, Quito, Ecuador.

1973 Bachiller en ciencias de la Educación, Quito, Ecuador.

\section{EXPERIENCIA PROFESIONAL}

2007- $\quad$ Pastor, Gainesville, Marion Oaks, Citrus, FL (Florida Conference)

1997-2007 Pastor, Winter Springs, Pine Hills, Orlando Sur, FL (Florida Conference)

1993-1997 Pastor, Melbourne, FL'(Florida Conference)

1990-1991 Pastor Asociado, Melbourne, FL (Florida Conference)

1986-1990 Pastor, Distrito “C”, Quito, Ecuador

1983-1986 Pastor, Distrito “C”, Guayaquil, Ecuador

1981-1982 Preceptor Asociado, Universidad Unión Incaica, Lima, Perú

1973-1977 Profesor, Colegio "Theodore W. Anderson", Quito, Ecuador 